\author{
UNIVERSIDADE DE BRASÍLIA \\ DEPARTAMENTO DE ECONOMIA
}

\title{
Ensaios sobre Gasto Público
}

Tese de Doutorado apresentada ao Departamento de Economia da Universidade de Brasília, como parte dos requisitos necessários à obtenção do título de Doutor em Economia.

\section{Carlos Renato de Melo Castro}

Orientador: Maria Eduarda Tannuri-Pianto

Co-orientador: Geraldo da Silva e Souza

\section{Brasília/DF}




\author{
UNIVERSIDADE DE BRASÍLIA \\ DEPARTAMENTO DE ECONOMIA
}

\title{
Ensaios sobre Gasto Público
}

\author{
Carlos Renato de Melo Castro
}

Tese de Doutorado apresentada ao Departamento de Economia da Universidade de Brasília, como parte dos requisitos necessários à obtenção do título de Doutor em Economia.

\section{Aprovada por:}

Profa. Dr. ${ }^{\mathrm{a}}$ Maria Eduarda Tannuri-Pianto - UnB (Orientador)

Profo Dr. Geraldo da Silva e Souza - UnB/Embrapa (Co-orientador)

Prof ${ }^{a}$ Dr. $^{a}$ Fabiana Fontes Rocha - USP (Membro Externo)

Prof $^{\circ}$ Dr. Michael Christian Lehmann - UnB (Membro Interno)

Prof ${ }^{\mathrm{a}}$ Dr. ${ }^{\text {a }}$ Ana Carolina Pereira Zoghbi - UnB (Membro Interno)

Profo $^{\circ}$ Dr. Rafael Terra de Menezes - UnB (Membro Interno)

Brasília, 2 de dezembro de 2014 
Ficha catalográfica elaborada pela Biblioteca Central da Universidade de Brasília. Acervo 1018958.

Castro, Carlos Renato de Melo.

C355e Ensaios sobre gasto público / Carlos Renato de Melo Castro. - 2014.

$150 \mathrm{f}$. : il. ; $30 \mathrm{~cm}$.

Tese (doutorado) - Universidade de Brasília, Departamento de Economia, 2014.

Orientação: Maria Eduarda Tannuri-Pianto ; Coorientação:

Geraldo da Silva e Souza.

Inclui bibliografia.

1. Despesa pública. 2. Despesa pública - Política governamental. 3. Ensino fundamental. 4. Ensino superior. I. Tannuri-Pianto, Maria Eduarda. II. Souza, Geraldo da Silva e. III. Título.

CDU 336.5 
À minha esposa, filha, pais e irmãos. 
Fraternidade, simplicidade, trabalho. 
À espiritualidade, que habita a minha vida através de um amor fraterno e incondicional.

À minha filha Mariana, que me ensina cada dia um pouco mais do sentido da existência.

À minha esposa Polyana, pelo amor e cuidado com minha vida, tornando-a muito mais feliz.

Aos meus pais Castro (in memorian) e Sônia, por terem solidificado em mim, através de seus exemplos, os valores do trabalho e da honestidade.

Aos meus irmãos Surama e Alexandre, que me dão o apoio e o carinho fundamentais na luta diária.

Aos meus sobrinhos Juliana e Mateus, que enchem minha vida de alegria.

Aos professores Maria Eduarda, Geraldo e Christian, que me orientaram e incentivaram com extrema dedicação e profissionalismo.

Aos professores Rafael Terra, Ana Carolina Zoghbi e Fabiana Rocha que aceitaram avaliar este trabalho.

À Secretaria do Tesouro Nacional, nas pessoas dos colegas Marcus Aucélio e Hailton Madureira, que autorizaram o afastamento temporário das minhas funções para elaboração desta tese.

Aos colegas do Tesouro Nacional, pela amizade e apoio constantes, em especial, meus amigos Luis Felipe e Helano.

Ao meu compadre e irmão Hordônio, por ser um companheiro nesta jornada.

À minha amiga Maria do Carmo, por cuidar com muito esmero do cotidiano em meu lar, para que eu pudesse realizar boa parte deste trabalho no ambiente familiar. 


\section{SUMÁRIO}

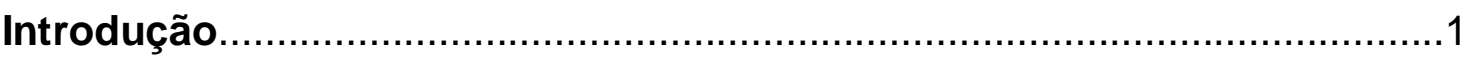

Capítulo 1 - Aplicando a Forma Flexível de Fourier para estimar a função custo em sistemas educativos: 0 caso brasileiro...................................... 4

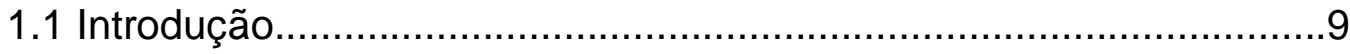

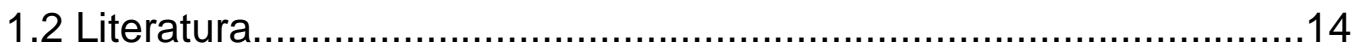

1.3 O Modelo Base

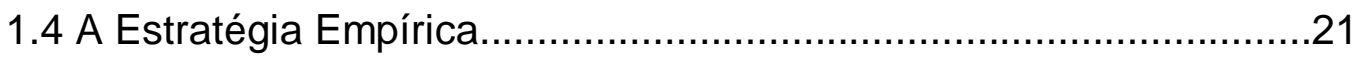

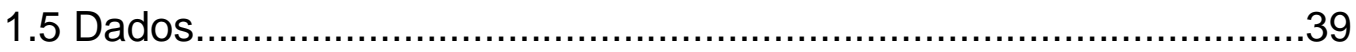

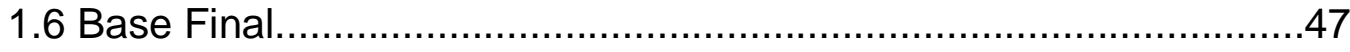

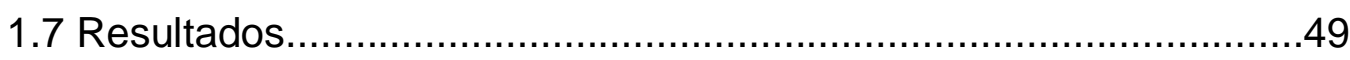

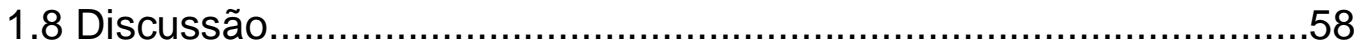

Capítulo 2 - Gasto Público e Organização Legislativa: Evidências da Lei

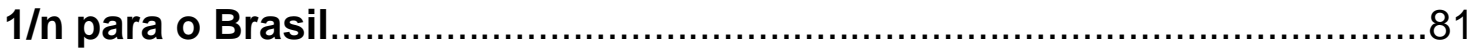

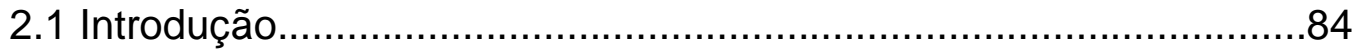

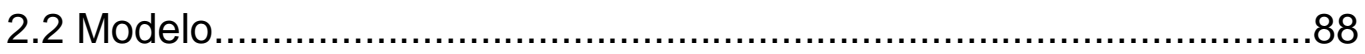

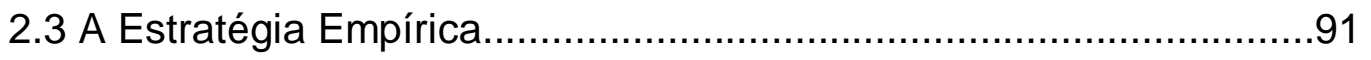

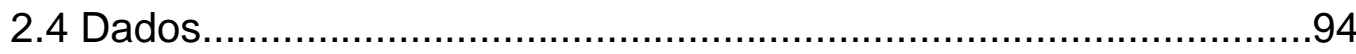

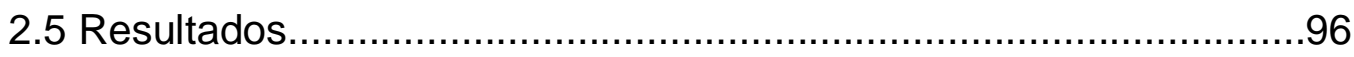

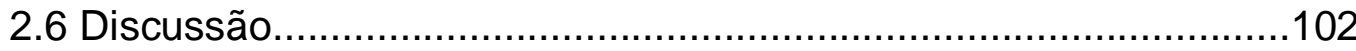

Capítulo 3 - Equidade de Renda na Educação Superior Pública..............113

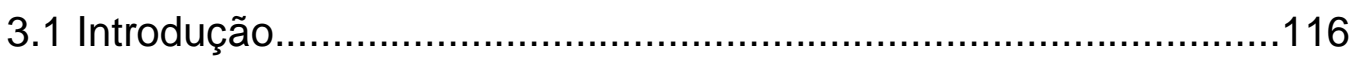

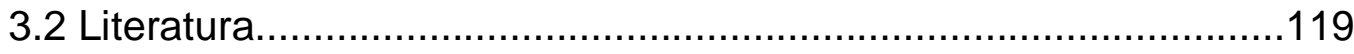

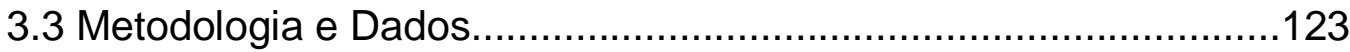

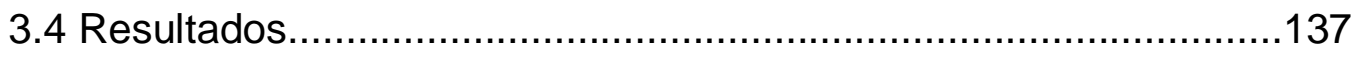

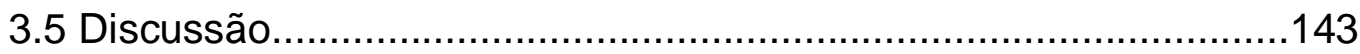

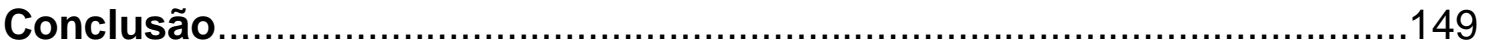




\section{Introdução}

Este trabalho aborda alguns dos aspectos usuais à temática "Qualidade do Gasto Público". Os resultados fiscais brasileiros recentes reforçam a importância de tais estudos, já que as principais estatísticas relacionadas apresentam trajetórias cada vez mais deficitárias. De 2011 a 2013, o resultado primário do governo central passou de 3,1\% para $1,9 \%$ do PIB, por exemplo. Paralelamente, a sociedade vem exigindo mais investimentos em alguns setores dados os baixos níveis dos serviços públicos. Adicione-se ainda, a este cenário, a pequena flexibilidade existente na elaboração e gestão do orçamento brasileiro. Os gastos mínimos constitucionais em educação e saúde aliados aos gastos com pessoal, previdência, assistência social, juros da dívida e políticas do trabalho (seguro-desemprego e abono), entre outros, engessam o orçamento público brasileiro.

Neste sentido, trabalhos que discutam aspectos de eficiência, equidade e que tentem mapear fatores preponderantes tornam-se importantes. Assim, os três capítulos que compõem esta tese abordam alguns destes aspectos em contextos relativamente distintos.

O primeiro contexto é o do ensino fundamental brasileiro. Nele, temos exatamente a coexistência de uma perspectiva de aportes significativos de novos recursos e de resultados até então não muito substantivos. Tenta-se entender como funciona a estrutura de gastos em educação básica no Brasil. Qual é a relação existente, no caso brasileiro, entre o gasto e a performance dos estudantes? Quais são as variáveis que têm mais impacto na estrutura de gastos do Brasil e quais são seus efeitos sobre o resultado do processo educativo? Onde há mais ineficiência na gestão dos recursos? Há realmente relação po- 
sitiva entre gasto e performance? Para isso, estima-se uma função custo para o ensino fundamental público municipal brasileiro, através da metodologia de fronteira estocástica. Concluímos que, na estrutura atual, não parece ser possível alcançar a proficiência de todos os estudantes do ensino fundamental municipal brasileiro, mesmo com gastos da ordem de 10\% do PIB. Entre vários outros aspectos, é fundamental combinar políticas que trabalhem com metas para variáveis adequadas (carga-horária, alunos por turma, por exemplo) com possíveis focalizações (municípios com piores indicadores socioeconômicos) na alocação dos novos recursos e aprimorando a gestão nos mais ineficientes . Isso poderia conduzir a uma elevação significativa da proficiência média dos estudantes.

O segundo capítulo inclui-se na literatura de economia política. Mais especificamente, discutimos a chamada Lei $1 / \mathrm{n}$ para o caso brasileiro. O resultado principal da literatura indica que a escala de projetos públicos cresce à medida que há uma maior fragmentação na elaboração do orçamento. Olhando para o gasto público municipal, avaliamos se o tamanho das câmaras de vereadores dos municípios brasileiros implicam em mais gastos per capita. Alguns resultados da literatura apontam neste sentido e estariam relacionados ao fato de que o legislador internalizaria por completo o benefício do gasto (para o seu distrito, por exemplo) e dividiria com toda a sociedade o custo. Tal estimativa torna-se importante, por exemplo, pela recorrente discussão sobre criação de municípios no Brasil e os resultados reforçam a importância de não se ampliar o número de municípios brasileiros.

O terceiro capítulo tem como pano de fundo novamente a educação, mas agora no contexto da educação superior. Discutimos aspectos de equidade de renda na aplicação de recursos direcionados à educação superior. Como que a oferta de educação superior pública no Brasil está distribuída pelas 
diversas classes de renda. Assim como em outros países, a percepção usual é de que as universidades públicas brasileiras são bens públicos usufruídos principalmente pelas classes de maior rendimento e portanto os mais pobres estariam financiando os mais ricos. Considerando um benefício líquido, que aloca também um custo para cada beneficiário, observamos que tal senso comum não se confirma. Os dois últimos decis de renda financiariam a educação superior pública do restante da população, com concentração de benefícios líquidos do $4^{\mathrm{o}}$ ao $7^{\circ}$ decil de renda. Conclui-se pela necessidade de uma focalização maior ainda nos três primeiros decis de renda. 
CAPÍTULO 1

\section{APLICANDO A FORMA FLEXÍVEL DE FOURIER PARA ESTIMAR A FUNÇÃO CUSTO EM SISTEMAS EDUCATIVOS: O CASO BRASILEIRO}


1 Aplicando a Forma Flexível de Fourier para estimar a função custo em sistemas educativos: o caso brasileiro 4 1.1 Introdução . . . . . . . . . . . . . . . . . . . . . 9

1.2 Literatura . . . . . . . . . . . . . . . . . . . . . . . 14

1.3 O Modelo Base . . . . . . . . . . . . . . . . . . . 18

$1.4 \quad$ A Estratégia Empírica $\ldots \ldots \ldots \ldots \ldots \ldots \ldots$

1.5 Dados . . . . . . . . . . . . . . . . . . . . . . . . . 39

1.6 Base Final $\ldots \ldots \ldots \ldots \ldots \ldots \ldots$

1.7 Resultados . . . . . . . . . . . . . . . . . . 50

1.8 Discussão $\ldots \ldots \ldots \ldots \ldots$

\begin{tabular}{|ll}
\hline A Rotina Fortran Multi-Índices & 68
\end{tabular}

\begin{tabular}{ll}
\hline B Coeficientes & 71
\end{tabular}

\begin{tabular}{ll}
\hline C Forma Flexível de Fourier & 73
\end{tabular} 


\section{LISTA DE FIGURAS}

1.1 Gasto Público Total em Educação . . . . . . . . . . . . . . . . . . 10

1.2 Gasto Público em Educação . . . . . . . . . . . . . . . . . . . 11

1.3 Frequência dos Municípios por Estado $\ldots \ldots \ldots \ldots$. . . . . 48

1.4 Ineficiência Média por UF $\ldots \ldots \ldots \ldots \ldots$. . . . . . 58 
LISTA DE TABELAS

1.1 Gasto Público Direto . . . . . . . . . . . . . . . . . . . . . . . . 12

$1.2 \quad \mathrm{~N}^{\mathbf{0}}$ de Parâmetros . . . . . . . . . . . . . . . . . . . . . . . 29

1.3 Matrículas . . . . . . . . . . . . . . . . . . . . . . 40

1.4 Gasto por Aluno no Ensino Fundamental (R\$) . . . . . . . . . . 40

1.5 Preço Anual do Trabalho (R\$) . . . . . . . . . . . . . . . . . 41

1.6 Preço Anual Custeio (R\$) $\ldots \ldots \ldots$. . . . . . . . . . . . . . . 42

1.7 Preço Anual do Capital (R\$) . . . . . . . . . . . . . . . . . . 42

1.8 Percentual de Alunos Proficientes (\%) $\ldots \ldots \ldots$. . . . . . . . . . . 43

1.9 Matrículas por turma $\ldots \ldots \ldots \ldots$. . . . . . . . . . . 44

1.10 Carga Horária Diária . . . . . . . . . . . . . . . . . . . . 45

1.11 Percentual de Professores com Ensino Superior (\%) . . . . . . . 45

1.12 Taxa de Analfabetismo - 15 anos ou mais (\%) . . . . . . . . . . . 45

1.13 Renda Domiciliar Mensal Per Capita (R\$) . . . . . . . . . . . . . 46

1.14 Índice de Gini . . . . . . . . . . . . . . . . . . . . . 46

1.15 Taxa de Urbanização (\%) . . . . . . . . . . . . . . . . 46

1.16 Infraestrutura da Casa . . . . . . . . . . . . . . . 47

1.17 Participação dos Pais (\%) . . . . . . . . . . . . . . . . 47

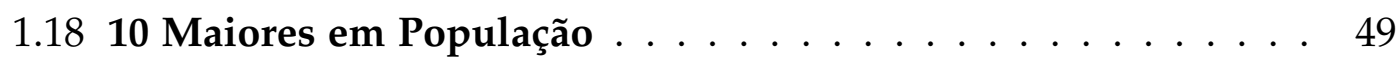

1.1910 Maiores em PIB $\ldots \ldots \ldots$. . . . . . . . . . . . . . . . . . . . 49

1.20 Elasticidades - Preços e Produto . . . . . . . . . . . . . . . . . 50

1.21 Elasticidades - Ambiente . . . . . . . . . . . . . 51 
1.22 População, Custo e Proficiência dos 30 menos ineficientes . . . 54

1.23 Qualif. do Prof., Carga Hor. e Alunos por Turma do 30 menos ineficientes $\ldots \ldots \ldots \ldots \ldots \ldots \ldots \ldots$

1.24 População, Custo e Proficiência dos $\mathbf{3 0}$ mais ineficientes . . . . 56

1.25 Qualif. do Prof., Carga Hor. e Alunos por Turma do 30 mais

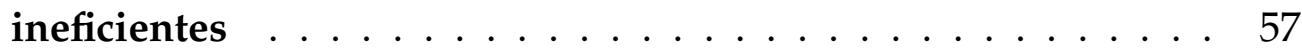

1.26 Ineficiência $\ldots \ldots \ldots \ldots \ldots \ldots \ldots \ldots$

B.1 Núcleo Principal da Função $\ldots \ldots \ldots \ldots \ldots \ldots$

B.2 Coeficientes do Termo de Ineficiência. . . . . . . . . . . . . 72 


\subsection{Introdução}

O crescimento significativo da oferta de bens públicos em educação ocorrido no passado recente e aquele que se projeta para o Brasil justificam a discussão acerca da estrutura econômica subjacente a tal oferta. Questões alocativas e de eficiência são fundamentais para que as políticas impliquem nos retornos esperados. O gasto por aluno da educação básica no Brasil mais que dobrou em termos reais de 2005 a 2011 e os resultados dos alunos brasileiros, na principal avaliação internacional de rendimento, não aumentou sequer $10 \%$.

Por ocasião da elaboração e votação do Plano Nacional de Educação, que estabelece metas para a educação brasileira para os próximos dez anos, muito se discute sobre o atual perfil do gasto brasileiro em educação. O ponto mais debatido estabelece que tal montante deve alcançar $10 \%$ do PIB, no $10^{\circ}$ ano. $\mathrm{O}$ argumento principal é que o Brasil precisa investir mais recursos para alcançar, entre outras metas, a qualidade do ensino. No entanto, não se fundamenta tal argumento explicitando uma efetiva relação entre gasto e performance no caso brasileiro.

Segundo o INEP, o gasto total em educação saltou de 4,5\% em 2005 para 6,1\% do PIB em 2011 (fig. 1.1). Este período caracterizou-se por um forte crescimento da arrecadação tributária no Brasil e como há uma vinculação destas com o gasto em educação, observamos também um crescimento das despesas nesta área superior ao do PIB. 
Figura 1.1: Gasto Público Total em Educação

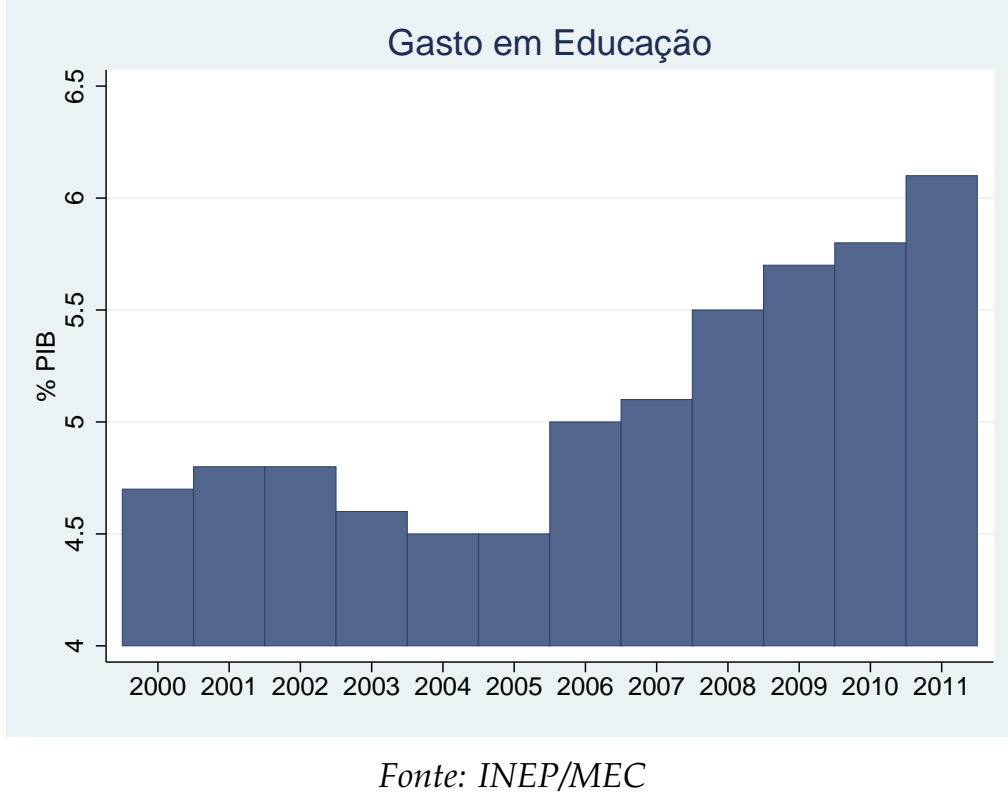

Segundo a OCDE, o gasto público do Brasil com educação (5,6\%), em proporção do PIB, foi superior à média dos países que pertencem àquela organização (5,4\%), em 2010 (fig. 1.2). Foi igual ao da Áustria, superior ao dos Estados Unidos, e comparável ao da França e ao da Grã-Bretanha e, de fato, bastante distante dos primeiros colocados: Dinamarca $(7,6 \%)$, Noruega $(7,5 \%)$ e Islândia $(7 \%)$. 
Figura 1.2: Gasto Público em Educação

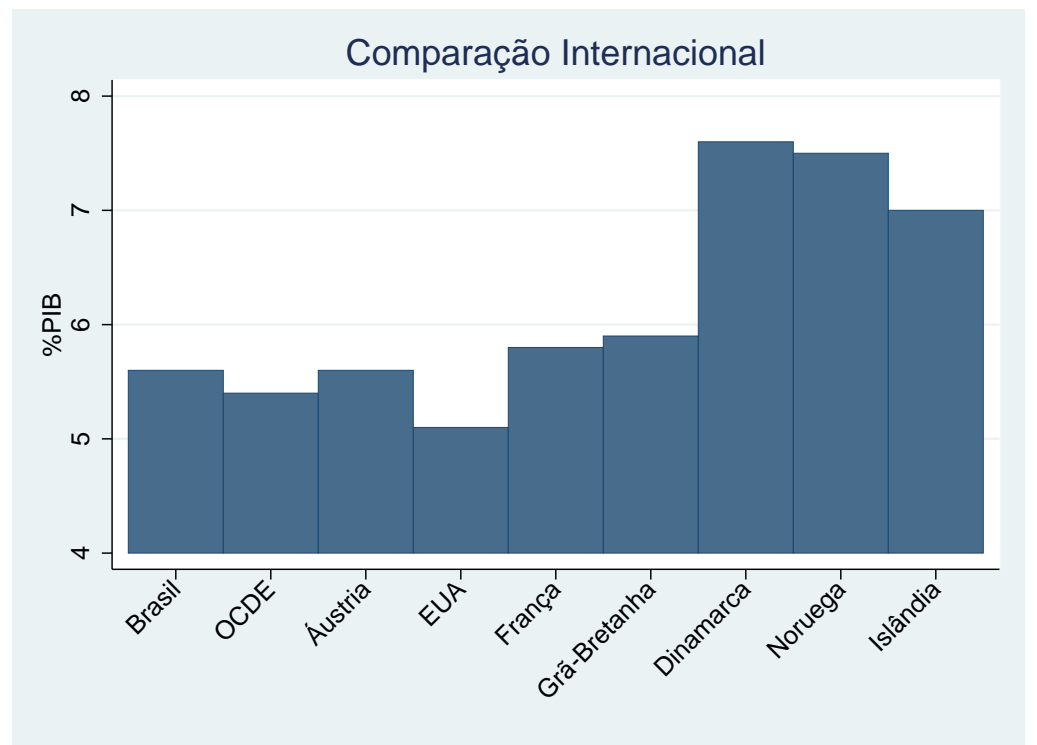

Fonte: Education at Glance - 2013 / OCDE

Uma das principais diferenças do perfil do gasto brasileiro está na distribuição dos recursos entre os níveis de ensino (tabela 1.1). Enquanto na média da OCDE, o gasto por aluno do ensino superior é apenas 35\% superior ao gasto por aluno da educação básica, no Brasil este percentual é superior a 380\%. 
Tabela 1.1: Gasto Público Direto

\begin{tabular}{c|c|c|c|c}
\hline \hline ano & Todos os Níveis & Educação Básica & Educação Superior & Superior / Básica \\
\hline 2000 & 1.962 & 1.633 & 18.050 & 11.1 \\
\hline 2001 & 2.031 & 1.693 & 17.839 & 10.5 \\
\hline 2002 & 2.026 & 1.678 & 16.912 & 10.1 \\
\hline 2003 & 2.029 & 1.704 & 14.818 & 8.7 \\
\hline 2004 & 2.147 & 1.822 & 15.001 & 8.2 \\
\hline 2005 & 2.282 & 1.933 & 15.255 & 7.9 \\
\hline 2006 & 2.657 & 2.307 & 15.385 & 6.7 \\
\hline 2007 & 3.074 & 2.695 & 16.309 & 6.1 \\
\hline 2008 & 3.524 & 3.097 & 17.370 & 5.6 \\
\hline 2009 & 3.814 & 3.353 & 17.576 & 5.2 \\
\hline 2010 & 4.353 & 3.813 & 19.141 & 5.0 \\
\hline 2011 & 4.916 & 4.267 & 20.690 & 4.8 \\
\hline \hline
\end{tabular}

Fonte: INEP/MEC

Quando comparamos em valores absolutos, o gasto público por aluno no Brasil, apesar de ter avançado significativamente nos últimos anos, ainda está bastante aquém da média dos países da OCDE. Em 2010, a média da OCDE era de US\$ 8.382, enquanto o Brasil gastava US\$2.964. De 2005 a 2011, o gasto médio por aluno no Brasil subiu 115\%, o que reflete, entre outros aspectos, uma priorização de gastos nesta área. De fato, o alcance dos patamares de gastos por aluno da ordem de US\$ 8.000 depende naturalmente também do crescimento da renda do país.

Destaque-se, portanto, que, apesar de em percentual do PIB estarmos próximos da média dos países da OCDE, em valores absolutos ainda estamos bem longe da média. Naturalmente isto é decorrente dos níveis de renda do Brasil.

Como uma das alternativas para aplicação de mais recursos, apresenta-se a proposta de direcionar $75 \%$ dos royalties decorrentes da exploração do pe- 
tróleo da camada pré-sal para a educação pública brasileira. Estimativas do MEC apontam para um volume de recursos superior a R 300 bilhões, em 30 anos.

Neste contexto, algumas questões naturais surgem, na medida que ampliaremos o volume de recursos aplicados. Qual é a relação existente no caso brasileiro entre o gasto e a performance dos estudantes? Quais são as variáveis que têm mais impacto na estrutura de gastos do Brasil e quais são seus efeitos sobre o resultado do processo educativo? Onde há mais ineficiência na gestão dos recursos? Há realmente relação positiva entre gasto e performance?

Nesta linha, pretende-se colaborar com a análise de como funciona a estrutura do gasto em educação no Brasil, através da tentativa de estimar uma função custo para o setor. Em termos metodológicos, utilizamos a técnica de fronteira estocástica considerando uma forma flexível de Fourier para a função custo, onde as firmas seriam os municípios brasileiros. Incluímos preços para trabalho, capital e custeio e consideramos o percentual de alunos proficientes como produto da firma. Adicionalmente acrescentamos covariáveis relacionadas ao ambiente familiar do aluno e ao ambiente escolar e municipal que tipicamente são consideradas nestes estudos. Desta forma, temos como estimar quanto custa elevar a performance dos estudantes brasileiros, como comparar a infuência de diversas variáveis sobre o nível de gastos e discutir questões de eficiência.

Os resultados indicam que, na estrutura atual, o alcance da proficiência dos alunos implicariam em um gasto por aluno 163\% superior. Isto indicaria que, tudo mais constante, a elevação de gasto de 6\% para $10 \%$ do PIB não seria suficiente para alcançar a proficiência de todos os alunos brasileiros. Ainda analisando a relação entre custo e produto, observamos que estamos em uma região de economias de escala. Ao comparar variáveis, concluímos a importância 
das variáveis carga-horária diária e alunos por turma, como instrumentos importantes para racionalização na utilização de recursos. Constatamos que os municípios mais eficientes apresentam piores indicadores socioeconômicos e gasto por aluno inferior. De onde inferimos a necessidade de focalização na alocação de recursos para que não haja desperdício e de aprimoramento na gestão para elevação dos níveis de eficiência.

Na sequência, apresentamos a literatura relacionada e o modelo que tenta adaptar os pressupostos da teoria da firma ao contexto de provisão de bens públicos educacionais. A estratégia empírica é abordada amplamente na seção seguinte que inclui a discussão acerca das formas flexíveis locais e globais. Aqui será apresentada a forma flexível de Fourier e a especificação final do estudo. A seção 1.5 apresenta a estatística descritiva dos dados e as proxies utilizadas para as variáveis consideradas na função custo a ser estimada. Com isso, é possível apresentar a amplitude da base de dados com a qual se trabalhou, detalhando aqueles municípios que ficaram de fora do escopo deste estudo. Por fim, apresentam-se os resultados obtidos e são discutidas as principais perguntas da pesquisa.

\subsection{Literatura}

Este trabalho insere-se em uma linha de pesquisa da Economia da Educação que, segundo a classificação de Blaug (1992), preocupa-se em investigar aspectos econômicos dos sistemas educativos. Segundo Waltenberg (2006), o instrumental de análise de um sistema educativo seria mais microeconômico e microeconométrico. Entre os temas tratados, nesta abordagem, está a análise de eficiência na alocação de recursos via funções de produção e funções custos. Ou seja, busca-se mobilizar o ferramental da teoria da firma para que seja 
possível encontrar a fronteira de possibilidades de produção e assim desenhar políticas. Nesta linha, observa-se um grande número de estudos realizados a partir da publicação do trabalho pioneiro de Coleman et al. (1966) entre os quais se destaca a meta-análise realizada por Hanushek (1997).

Não encontramos estudos para o contexto brasileiro que estimasse efetivamente uma função custo nos moldes próximos ao da teoria da firma. Avaliamos que a dificuldade com proxies para os preços seria uma das razões para tal escassez. Naturalmente, a dualidade existente entre funções de produção e funções custo nos permitem gerar inferências equivalentes. No entanto, destacamos que, com o objetivo também de discutir eficiência, a função custo nos permite tratar de uma eficiência econômica que engloba aspectos técnicos e alocativos. Em geral, nos modelos de eficiência estocástica, a função custo nos permite avaliar eficiência econômica na presença de outputs múltiplos. Intuitivamente nos parece mais natural considerar nossa variável resposta como uma proxy de um construto agregando outputs múltiplos do que determinante do modelo de produção. Por fim, a ausência de tais estudos nos motiva a esta tentativa.

Não obstante, dentro desta linha de pesquisa, Machado et al. (2008) analisou os determinantes do desempenho de alunos em escolas públicas estaduais mineiras. Menezes Filho et al. (2009) estudou a relação entre gastos e o desempenho educacional de municípios brasileiros. Com o objetivo de medir a qualidade das escolas brasileiras, Curi and Souza (2012) modelou a relação entre o desempenho dos alunos e características das escolas, dos alunos e outras. Considerando municípios goianos, Rosano-Peña et al. (2012) analisou eficiência dos gastos públicos em educação através de modelos de análise envoltória dos dados (DEA). Machado and Gonzaga (2007) analisou o impacto dos fatores familiares sobre a defasagem idade-série para as crianças brasileiras. Com um painel de dados de 1998 a 2005, Soares and Sátyro (2008) concluiu que os insumos 
escolares têm impacto significativo sobre a taxa de distorção série-idade. CarvaIho (2012) aplicou um modelo de DEA em três estágios e conclui que, mesmo desconsiderando os fatores ambientais e aleatórios, ainda persistem problemas de gestão nas escolas urbanas das regiões Nordeste e Sudeste brasileiras. Rocha et al. (2013) conclui, através de um modelo de DEA, que os recursos municipais seriam suficientes para alcançar metas do IDEB em 2021 dado o alto nível de desperdício apresentado pelo modelo.

Com isso, buscamos estudos que tentaram modelar uma função custo para sistemas educativos fora do contexto brasileiro. Com o objetivo de estudar economias de escala, Duncombe et al. (1995) estimou uma função custo para os distritos escolares de Nova Iorque e Tao (2005), para escolas públicas de Taipei em Taiwan. Considerando um painel de escolas do ensino médio de Nova Iorque, Stiefel et al. (2009) comparou os custos de diversos tipos de organizações escolares. Ajustando uma fronteira estocástica para função custo na forma translog, Gronberg et al. (2012) mostrou que as escolas charters geram os mesmos resultados a custos inferiores. Duncombe and Yinger (2005) estimou o custo adicional que os distritos escolares têm com alunos em desvantagem (baixa renda, baixo rendimento, etc.). Uma análise de meta-regressão com base em estudos que estimam função custo é feita por Colegrave and Giles (2008). Como estudos correlacionados destacamos:Burnell (1991) que estudou o impacto da fragmentação dos distritos escolares sobre o gastos, Afonso and St Aubyn (2006) que analisou a eficiência na provisão de educação secundária em 25 países e Thompson (2011) que estimou funções custo para avaliar o efeito da privatização do serviço de transporte escolar.

Tais estudos indicaram uma diversidade de formas funcionais utilizadas na estimação, tendo como principais as formas lineares e a translog. A unidade de produção considerada, em sua maioria, são os distritos escolares. Os problemas 
mais abordados são o tamanho ótimo e os índices de custo. O produto predominante são os resultados dos alunos em provas padronizadas. O preço mais comum é o do trabalho (salário dos professores) dado que a atividade seria intensiva em mão de obra. Por fim, há bastante diversidade no tipo de gasto utilizado como custo e normalmente são consideradas variáveis ambientais do processo produtivo.

Observa-se que aspectos metodológicos diversos surgem na discussão da tecnologia da produção educacional. Uma delas é a destacada por Figlio (1999) acerca das formas funcionais das funções de produção ou de custo utilizadas nestes estudos. Sobre estes, destacam-se os aspectos relacionados às formas funcionais do tipo Translog. Segundo Gallant (1981) há dois métodos frequentemente utilizados em aplicações que buscam aproximar funções de produção: aproximações por séries de Taylor e por séries de Fourier. O trabalho com formas funcionais flexíveis tem utilizado principalmente expansões em Taylor como mecanismo de aproximação. Destaque-se que o teorema de Taylor só se aplica localmente.A aplicabilidade local da aproximação basta para traduzir proposições da teoria da demanda em restrições sobre os parâmetros do sistema orçamentário aproximado. Contudo, o teorema de Taylor falha na compreensão do comportamento estatístico das estimativas dos parâmetros bem como nos testes relacionados. White (1980) apresentou a fundamentação dessas críticas. Em função deste problema é que métodos de regressão estatística, segundo Gallant (1981) e Elbadawi et al. (1983) devem essencialmente expandir a função verdadeira em uma série de Fourier geral e não em uma série de Taylor. A forma de Fourier possui uma propriedade de flexibilidade global: ela pode aproximar assintoticamente qualquer função contínua, no sentido da norma de Sobolev. Ela permite inclusive testar a forma translog, que faz parte da sua especificação. Gallant (1982) discutiu os detalhes da utilização da forma de 
Fourier na estimação de funções custo. E principalmente com base nesse estudo, Chalfant (1984) comparou a utilização da forma de Fourier à forma Box-Cox generalizada, dentro do contexto da agricultura americana.

Com isso, utilizamos neste trabalho a forma flexível de Fourier para estimar a função custo do ensino fundamental público ofertado pelos municípios brasileiros que serão as nossas unidades produtivas. Com base em Kumbhakar and Lovell (2003) e Coelli et al. (2005) estimamos fronteiras estocásticas assim como em Huang and Wang (2004) para realizarmos análises de eficiência.

\subsection{O Modelo Base}

O modelo de produção educacional utilizado neste trabalho está baseado principalmente em Duncombe et al. (1995). Nesta linha, propõe-se algumas adaptações à teoria geral da produção, considerando que trata-se de provisão de serviços públicos, no caso, educação. Em princípio, o processo de produção em uma escola, distrito escolar ou município poderia ser modelado com uma função de produção do tipo:

$$
G=f(L, K, T)
$$

onde $L$ representaria a força de trabalho (professores e outros), $K$, o capital, e T os outros insumos de custeio da firma.

Entre as referidas adaptações, destaque-se a importante discussão acerca do produto e do ambiente no caso de serviços públicos. Como medir produtos que representem quantidade de atividades de qualidade equivalentes? A entrega de uma hora-aula em um dado contexto pode ter qualidade completamente 
distinta se ocorrese em outra situação. Surge assim a distinção entre serviços diretamente produzidos e aquilo que é de interesse primário do cidadão consumidor. Conforme destacado por Bradford et al. (1969), quando o cidadão vota em um orçamento de segurança pública, por exemplo, ele não está interessado em avaliar se há 10 ou 15 viaturas de polícia, a sua utilidade é afetada principalmente pelo grau de segurança na sua comunidade. De fato, simplificadamente, teríamos:

$$
U=U(S, Z)
$$

onde $\mathrm{Z}$ representa o nível de provisão de outros bens públicos e dos bens privados e

$$
S=h(G, E)
$$

é obtido pela função $h$ que indica o grau de satisfação do cidadão consumidor com os serviços diretamente produzidos, $G$, no ambiente $E$.

Como se observa em grande número de estudos no âmbito educacional, a abordagem em linha com Bradford et al. (1969) é de se medir o produto da escola em termos do desempenho dos alunos em testes padronizados. Este seria um dos interesses primários de quem usufrui do serviço.

Como discutido anteriormente, essa linha de pesquisa tem em Hanushek (1979) e seus trabalhos posteriores uma importante referência em termos da discussão acerca da função de produção para o caso educacional. Segundo Duncombe et al. (1995), entre os fatores ambientais normalmente apontados na literatura (Hanushek (1997)), destacam-se os fatores físicos $(P)$, o background familiar $(F)$ e as características dos estudantes (ST). Ou seja,

$$
E=g(P, F, S T) .
$$


Substituindo (1.1) e (1.4) em (1.3) obtemos a função de produção adaptada, que é a base para gerar a nossa função custo:

$$
S=h(G, g(P, F, S T))
$$

Na teoria da produção, a função de produção padrão (1.1) pode ser resolvida de modo a gerar a função de custo implícita, onde $W$ são os preços:

$$
T C=c(G, W)
$$

Especificamente, ao resolvermos a equação (1.5) para G e substituirmos em (1.6), obtemos a função custo modificada:

$$
T C=c\left(h^{-1}(S, g(P, F, S T)), W\right)
$$

A equação (1.7) nos dá uma forma adaptada onde agregam-se resultados educacionais, variáveis ambientais e preços em uma análise de produção pública.

\subsubsection{As Variáveis}

As variáveis utilizadas neste estudo e que comporão a função custo modelada conforme (1.7) estão descritas em detalhes na seção 1.5 . De fato, além das variáveis de preços (trabalho, capital e custeio), buscamos variáveis ambientais para o caso brasileiro que retratassem o que é observado na literatura. Relativamente aos fatores físicos, incluímos a variável que informa a quantidade de alunos por turma. Quanto ao background familiar, consideramos a infraestrutura da 
casa do aluno, a participação dos pais na vida escolar e a escolaridade dos pais. Acrescentamos ainda as variáveis carga-horária diária dos alunos e escolaridade dos docentes, pois estão diretamente relacionadas à gestão educacional do município e têm impacto significativo sobre o custo. Por fim, acrescentamos variáveis que tentam retratar o ambiente socio-econômico do município: coeficiente de Gini, taxa de urbanização e taxa de analfabetismo. Não encontramos variáveis proxies para a variável ST, que reflete a existência de estudantes em condições especiais (aprendizagem, necessidades especiais ou outras).

Destacamos que a unidade produtiva escolhida neste estudo é o município. A disponibilidade de dados foi um dos fatores fundamentais nesta escolha.

\subsection{A Estratégia Empírica}

\subsubsection{Formas Flexíveis}

A literatura econômica tem utilizado de formas funcionais diversas ao tentar aplicar a teoria neoclássica do comportamento do consumidor e/ou do produtor a um conjunto de dados (Beccacece (1994)). Neste contexto, temos as chamadas formas funcionais flexíveis, que não impõem, a priori, restrições para que se estabeleçam algumas propriedades esperadas de tais funções. Segundo Chalfant (1983), a escolha de uma forma funcional bastante geral permitiria ao pesquisador testar empiricamente um amplo espectro de relações técnicas tais como possibilidades de substituições, complementaridades e retornos de escala.

Conforme destacado por Grifiin (1987), diferentes definições técnicas de flexibilidade surgem neste contexto e, por ser um conceito multidimensional, uma 
dada definição pode não ser adequada em todos as situações.

\subsubsection{Flexibilidade Local}

Um dos conceitos mais discutidos e utilizados é o de fexibilidade local, normalmente conhecido como "Diewert flexibility". Neste conceito temos convergência em torno de um ponto para a função e suas duas primeiras derivadas. Portanto, nenhuma restrição é imposta sobre a função ou sobre suas primeira e segunda derivadas neste ponto. Destaca-se a flexibilidade quanto aos valores das elasticidades de oferta e de demanda, que nos leva, por exemplo, a uma generalização das funções Cobb-Douglas e CES (Constant Elasticity of Substitution) no aspecto da flexibilização da elasticidade de substituição constante.

Suponha $f$ ser uma função de produção ou de custo tal que $y=f\left(x_{1}, \ldots, x_{n}\right)$. Segundo Diewert, $f$ é uma forma flexível (local) se possui parâmetros suficientes para que possa aproximar uma função arbitrária com derivadas contínuas de segunda ordem $f^{*}$, em um ponto $x^{*}$ no domínio de definição de $f$ e de $f^{*}$. Assim, $f$ deve ter parâmetros suficientes para satisfazer as seguintes equações:

$$
\begin{gathered}
f\left(x^{*}\right)=f^{*}\left(x^{*}\right) \\
\nabla f\left(x^{*}\right)=\nabla f^{*}\left(x^{*}\right) \\
\nabla^{2} f\left(x^{*}\right)=\nabla^{2} f^{*}\left(x^{*}\right)
\end{gathered}
$$

Como assumimos que $f$ e $f^{*}$ possuem derivadas de segunda ordem contínuas, não temos que satisfazer todas as $N^{2}$ equações que são decorrentes de 1.10 
pois temos, pelo Teorema de Young, que, para todo $i$ e $j$ :

$$
\frac{\partial^{2} f\left(x^{*}\right)}{\partial x_{i} \partial x_{j}}=\frac{\partial^{2} f\left(x^{*}\right)}{\partial x_{j} \partial x_{i}}
$$

$\mathrm{e}$

$$
\frac{\partial^{2} f^{*}\left(x^{*}\right)}{\partial x_{i} \partial x_{j}}=\frac{\partial^{2} f^{*}\left(x^{*}\right)}{\partial x_{j} \partial x_{i}}
$$

Com isto, garantindo que a diagonal principal e os termos superiores das matrizes $\nabla^{2} f\left(x^{*}\right)$ e $\nabla^{2} f^{*}\left(x^{*}\right)$ sejam iguais, já temos garantida, pelo Teorema de Young, a igualdade completa entre as matrizes. Portanto, uma forma funcional flexível geral deveria ter parâmetros lívres suficientes para garantir a igualdade entre as funções, igualdade entre as derivadas e a igualdade entre as segundas derivadas. Ou seja, no mínimo $1+N+\frac{N(N+1)}{2}$ parâmetros livres.

Segundo Diewert, a forma mais simples uma forma funcional flexível (local) é uma função quadrática:

$$
f(x)=a_{0}+a^{T} x+\frac{1}{2} x^{T} A x
$$

onde $a_{0}$ é um parâmetro escalar, $a^{T}=\left[a_{1}, \ldots, a_{N}\right]$ é um vetor de parâmetros e $A=\left[a_{i j}\right]$ é uma matriz simétrica de parâmetros. Assim a forma $f$ definida por (1.11) tem $1+N+\frac{N(N+1)}{2}$ parâmetros. Para mostrar que ela é flexível, precisamos escolher $a_{0}, a$ e $A$ para satisfazer as equações (1.8) - (1.10). Observando que $\nabla f(x)=a+A x$ e $\nabla^{2} f(x)=A x$, as equações (1.8) - (1.10) transformam-se em:

$$
a_{0}+a^{T} x^{*}+\frac{1}{2} x^{* T} A x^{*}=f^{*}\left(x^{*}\right)
$$

$$
a+A x^{*}=\nabla f^{*}\left(x^{*}\right)
$$




$$
A=\nabla^{2} f^{*}\left(x^{*}\right)
$$

Para satisfazer essas equações, escolha $A=\nabla^{2} f^{*}\left(x^{*}\right)$ ( e A será simétrica pela hipóteses de ser continuamente diferenciável até segunda ordem), $a=$ $\nabla f^{*}\left(x^{*}\right)-A x^{*}$ e finalmente, escolha $a_{0}=f^{*}\left(x^{*}\right)-\left[a^{T} x^{*}+\frac{1}{2} x^{* T} A x^{*}\right]$.

Segundo Chalfant (1983), Barnett (1983) mostrou a equivalência entre a definição de Diewert flexibilidade e a definição matemática padrão para aproximação local de $2^{\mathrm{a}}$ ordem, segundo a qual $g(x)$ é uma aproximação local de segunda ordem para $g^{*}(x)$ em $x_{0}$ se:

$$
\frac{g-g^{*}}{\left\|x-x_{0}\right\|} \rightarrow 0 \quad \text { quando } \quad x \rightarrow x_{0}
$$

Também no âmbito da flexibilidade local, surge a definição dada por Christensen et al. (1973). Este considera $G(y)$ uma aproximação de segunda ordem para $F(y)$ no ponto $y_{0}$ se:

$$
G\left(y_{0}\right)=F\left(y_{0}\right)
$$

$\mathrm{e}$

$$
|G(y)-F(y)| \leq \frac{k\left\|y-y_{0}\right\|^{3}}{\left\|y_{0}\right\|^{3}}
$$

para todo $y$ em uma vizinhança de $y_{0}$, onde $k$ é uma constante (para cada $y_{0}$ ), e ||.|| denota a norma utilizada.

Portanto, esta é uma aproximação mais forte que a dada pela definição de Diewert, conforme citado por Barnett (1983). Mas, Lau (1974) mostrou que qualquer aproximação por série de Taylor é flexível pela definição de flexibilidade usada por Christensen et al. (1973) e pela definição de Diewert. 


\subsubsection{Translog}

A função de produção transcendental logarítmica (Translog), introduzida por Christensen et al. (1973) é normalmente interpretada como uma aproximação a uma função arbitrária, $Y=F(x)$, por uma série de expansão de Taylor de segunda ordem de $\ln Y$ em potências de $\ln X_{i}$. Assim:

$$
\ln Y=a_{0}+\sum_{i=1}^{n} a_{i} \ln X_{i}+\frac{1}{2} \sum_{i=1}^{n} \sum_{j=1}^{n} a_{i j} \ln X_{i} \ln X_{j}
$$

onde $a_{0}$ é igual ao valor de $\ln F(a), a_{i}$ são as primeiras derivadas parciais de $\ln F$ com relação à variável $i$ e $a_{i j}$ são suas segundas derivadas parciais avaliadas no ponto de expansão $a$.

É uma das formas funcionais mais utilizadas quando se quer considerar flexibilidade local. Não impõe, a priori, separabilidade e homogeneidade como hipóteses pressupostas, permitindo, portanto, valores arbitrários para a elasticidade de substituição entre qualquer par de insumos. Ao impor determinadas restrições, ela pode ser usada para testar hipóteses como homogeneidade, separabilidade, mudanças tecnológicas e outras implicações da teoria da produção.

Dada a sua relativa generalidade, pode deixar de satisfazer a determinadas condições de regularidade, que produzem resultados econômicos naturais. Por exemplo, deixa de satisfazer, infelizmente, as condições de monotonicidade e concavidade em todo o quadrante positivo. Entretanto, como é uma aproximação local, faz-se necessário testá-la em regiões de interesse. 


\subsubsection{Estimação com formas flexíveis}

A utilização da forma funcional Translog para aproximar uma função desconhecida é um exemplo de uma abordagem denominada response-surface(Badawi (1983)). Como é típico em procedimentos de regressão, expressões polinomiais são usadas para ajustar os dados e o ajuste é considerado no sentido de que os valores preditos ficam próximos dos valores reais através da escolha dos parâmetros da polynomial response surface. Proximidade, neste caso, é definida simplesmente pelo quadrado da medida de distância euclideana da resposta observada para a resposta predita. Considerando o objetivo de minimizar esta medida, a regressão polinomial é uma abordagem plausível (Chalfant (1983)).

Segundo Gallant (1981), em análises de demanda, o objetivo é diferente. Em geral, nos estudos empíricos de demanda quer-se estimar elasticidades, que são obtidas como derivadas parciais da função desconhecida. Elas são transformações de derivadas parciais que expressam a curvatura da função desconhecida. E quando o interesse se extende às derivadas parciais, a medida euclideana de distância não é totalmente apropriada. A medida euclideana de distância incorpora apenas erros da função e não de suas derivadas.

White (1980) apresentou a questão, ilustrando os erros significativos que podem advir desta abordagem. Gallant (1981), Kumm (1981) e Simmons and Weiserbs (1979) também discutiram tal ponto. Na prática, obviamente, a função verdadeira é desconhecida. Esta é a razão do conjunto de equações na prova de Diewert não podem ser resolvidas como apresentado em (1.13) e (1.14). A prática padrão é usar mínimos quadrados para ajustar a função aproximante aos dados gerados pela função verdadeira. Os polinômios de segunda ordem geralmente usados têm uma uma interpretação que depende do teorema de 
Taylor, na qual os coeficientes de regressão são interpretados como os coeficentes da aproximação de Taylor de segunda ordem da função verdadeira. Isto é, contudo, inconsistente com a definição de Diewert de flexibilidade já que a regressão não produz os coeficientes de uma série de Taylor. (White (1980), Kumm (1981)).

Segundo White (1980), os coeficientes são corretamente interpretados como estimativas consistentes e não viesadas das derivadas da função verdadeira somente em casos especiais. Ou a função utilizada para aproximar é da forma da função verdadeira, ou os termos de ordem superior não são correlacionados com os termos lineares e quadráticos incluídos. Ele conclui afirmando que a hipótese de regressores ortogonais é "pouco confortável para os econometristas práticos". Como os polinômios de ordem superior em $x$ são variáveis omitidas na interpretação da aproximação por Taylor, as estimativas resultantes não podem ser consideradas ótimas em qualquer sentido aceito como aproximação local. A menos que a forma funcional possa ser considerada como verdadeira, qualquer teste estatístico não pode ser considerado como teste da hipótese de interesse. A rejeição pode ser devido à rejeição da forma funcional em vez da proposição econômica que está sendo testada. Gallant (1981) e Gallant (1982) apresentam a forma flexível de Fourier como uma solução para o problema, que passamos a descrever.

\subsubsection{Forma Flexível de Fourier}

Conforme descrito por Gallant (1982), para determinar se uma indústria exibe retornos constantes de escala, se a função de produção é homotética, ou se os insumos são separáveis, uma abordagem comum é especificar uma função custo, estimar os parâmetros usando dados tais como preços e quantidades de 
insumos e então testar as restrições paramétricas correspondentes a retornos constantes, a tecnologia homotética ou a separabilidade. Como vimos, as formas funcionais em linha com a Diewert flexibilidade não contornam este problema. É neste contexto que Gallant (1981) apresenta a forma flexível de Fourier (FFF). Com ela teríamos como construir testes estatísticos não-viesados. Estaríamos certos de que é a proposição econômica que está sendo testada e não algum erro de especificação devido à forma funcional utilizada na aproximação da função custo verdadeira. O desenvolvimento teórico destas ideias, extraídas de Gallant (1982), está exposto no apêndice C.

A FFF que garante a ausência de viés citada anteriormente têm como forma geral a expressão:

$g_{k}(x \mid \theta)=u_{0}+b^{\prime} x+\frac{1}{2} x^{\prime} C x+\sum_{\alpha=1}^{A}\left\{u_{0 \alpha}+2 \sum_{j=1}^{J}\left[u_{j \alpha} \cos \left(j \lambda k_{\alpha}^{\prime} x\right)-v_{j \alpha} \sin \left(j \lambda k_{\alpha}^{\prime} x\right)\right]\right\}$

O ponto inicial para a especificação é a definição do número de parâmetros a ser utilizado na FFF. Elbadawi et al. (1983) discute tal ponto e indica que os resultados assintóticos são obtidos fazendo o número de parâmetros depender do tamanho amostral. Chalfant and Gallant (1985), Eastwood and Gallant (1991), Mitchell and Onvural (1996) e Huang and Wang (2004) têm sugerido que o número de parâmetros a ser estimado, em um contexto de uma função custo na FFF, seja o número de observações elevado a dois-terços.

Considerando o conjunto de dados do presente estudo que soma 4.600 observações, teríamos que ter no máximo 277 parâmetros na forma. Por outro lado, ao observarmos a FFF descrita em (C.1), concluímos que ela possui $1+N+1+A(1+2 J)$ parâmetros. Dado que consideramos três tipos de pre- 
ços, temos $N=3$ e considerando os multi-índices elementares gerados pelo procedimento descrito no apêndice $C$ (e computado pela rotina apresentada no apêndice A) temos as seguintes possibilidades para $|k|$ e $J$ :

Tabela 1.2: $N^{o}$ de Parâmetros

\begin{tabular}{c|c|c|c}
\hline \hline$|\mathrm{k}|$ & $\mathrm{A}$ & $\mathrm{J}$ & $\mathrm{N}^{\mathrm{o}}$ de Parâmetros \\
\hline 3 & 56 & 1 & 173 \\
\hline 3 & 56 & 2 & 285 \\
\hline 4 & 305 & 1 & 920 \\
\hline \hline
\end{tabular}

Fonte: elaboração do autor

Portanto, tais possibilidades nos levaram então a decidir pelos seguintes valores $|k|=3$ e $J=1$, dado que temos que ter menos de 277 parâmetros na forma funcional.

Adicionalmente temos que considerar as restrições impostas por C.0.2. Com isso, chegamos à forma da nossa fff:

$$
y=g(\mathbf{1}, v)=f_{1}(\mathbf{1}, v)+f_{2}(\mathbf{1}, v)
$$

onde

$f_{1}(1, v)=b_{0}+b_{1} l_{1}+b_{2} l_{2}+b_{3} l_{3}+b_{4} v+c_{1} l_{1}^{2}+c_{2} l_{2}^{2}+c_{3} l_{3}^{2}+c_{4} v^{2}+c_{5} l_{1} l_{2}+c_{6} l_{1} l_{3}+$ $c_{7} l_{2} l_{3}+c_{8} l_{1} v+c_{9} l_{2} v+c_{10} l_{3} v$

com:

$$
l_{i}=\ln \left(p_{i}\right), v=\ln (u)
$$

onde:

$p_{1}$ : preço do trabalho 
$p_{2}$ : preço do capital

$p_{3}$ : preço do custeio

$u$ : output

e

$f_{2}(\mathbf{l}, v)=-v_{1} \sin (\lambda v)-v_{2} \sin \left(\lambda\left(l_{1}-l_{3}\right)\right)-v_{3} \sin \left(\lambda\left(l_{2}-l_{3}\right)\right)-v_{4} \sin \left(\lambda\left(l_{1}-\right.\right.$ $\left.\left.l_{2}\right)\right)-v_{5} \sin \left(\lambda\left(l_{2}-l_{3}+v\right)\right)-v_{6} \sin \left(\lambda\left(l_{1}-l_{2}+v\right)\right)-v_{7} \sin \left(\lambda\left(l_{1}-l_{3}+v\right)\right)-$ $v_{8} \sin \left(\lambda\left(l_{2}-l_{3}-v\right)\right)-v_{9} \sin \left(\lambda\left(l_{1}-l_{2}-v\right)\right)-v_{10} \sin \left(\lambda\left(l_{1}-l_{3}-v\right)\right)+u_{1} \cos (\lambda v)+$ $u_{2} \cos \left(\lambda\left(l_{1}-l_{3}\right)\right)+u_{3} \cos \left(\lambda\left(l_{2}-l_{3}\right)\right)+u_{4} \cos \left(\lambda\left(l_{1}-l_{2}\right)\right)+u_{5} \cos \left(\lambda\left(l_{2}-l_{3}+\right.\right.$ $v))+u_{6} \cos \left(\lambda\left(l_{1}-l_{2}+v\right)\right)+u_{7} \cos \left(\lambda\left(l_{1}-l_{3}+v\right)\right)+u_{8} \cos \left(\lambda\left(l_{2}-l_{3}-v\right)\right)+$ $u_{9} \cos \left(\lambda\left(l_{1}-l_{2}-v\right)\right)+u_{10} \cos \left(\lambda\left(l_{1}-l_{3}-v\right)\right)$

\subsubsection{Fronteira Estocástica}

A forma funcional (1.17) é estimada finalmente através da técnica de fronteira estocástica. Os modelos de fronteira estocástica foram introduzidos por Aigner et al. (1977) e Meeusen and Van den Broeck (1977) e Kumbhakar and Lovell (2003) apresenta uma boa revisão da metodologia.

Suponha que um produtor tem uma função de produção $f(z, \beta)$. Em um mundo sem erro ou ineficiência, a firma produzirá

$$
q=f(z, \beta)
$$

A análise de fronteira estocástica assume que cada firma produz potencialmente menos que ela poderia devido ao grau de ineficiência. Especificamente,

$$
q=f(z, \beta) \xi
$$


onde $\xi$ é o nível de eficiência da firma. $\xi$ deve estar no intervalo $(0,1]$. Se $\xi=1$, a firma atinge o produto ótimo com a tecnologia subjacente à função de produção $f(z, \beta)$. Se $\xi<1$, então a firma não está produzindo o máximo possível com a tecnologia disponível.

Assume-se que o produto esteja sujeito a choques aleatórios, implicando que

$$
q=f(z, \beta) \xi \exp (v)
$$

Tomando o logaritmo,

$$
\ln (q)=\ln f(z, \beta)+\ln (\xi)+v
$$

Assumindo que são $k$ insumos e que a função de produção é linear em logs e definindo $u=-\ln (\xi) \geq 0$, temos:

$$
\ln (q)=\beta_{0}+\sum_{j=1}^{k} \beta_{j} \ln \left(z_{j}\right)+v-u
$$

Como $u$ é subtraído de $\ln (q)$, restringindo $u \geq 0$ temos que $0<\xi \leq 1$, como especificado anteriormente.

Kumbhakar and Lovell (2003) apresenta uma versão detalhada da derivação anterior e mostra que há uma derivação análoga na qual o problema para a função custo dual permite uma especificação do tipo

$$
\ln (c)=\beta_{0}+\beta_{q} \ln (q)+\sum_{j=1}^{k} \beta_{j} \ln \left(p_{j}\right)+v+u
$$


onde $q$ é o produto, $c$ é o custo, e $p_{j}$ são os preços dos insumos. Naturalmente, o efeito de ineficiência gera um produto menor ou um gasto extra, dependendo da especificação.

Especificações diferentes de $u$ e de $v$ geram modelos distintos. Trabalhamos com as especificações disponíveis no comando frontier do software estatístico Stata, que nos parece bastante suficiente para o escopo deste trabalho. Estimamos os parâmetros para três modelos básicos nos quais assume-se que o componente do erro idiossincrático, $v$, possui distribuição normal $N\left(0, \sigma_{v}\right)$. Os modelos básicos diferem na especificação do termo de ineficiência, $u$, conforme a seguir:

1) exponencial: $u$ é distribuído exponencialmente e independentemente com variância $\sigma_{u}^{2}$

2) hnormal: $u$ é distribuído através de uma meia-normal, $N^{+}\left(0, \sigma_{u}^{2}\right)$, e independentemente com variância $\sigma_{u}^{2}$

2) tnormal: $u$ é distribuído através de uma normal truncada, $N^{+}\left(\mu, \sigma_{u}^{2}\right)$, e independentemente com ponto de truncação em 0 .

Para as distribbuições meia-normal ou exponencial, frontier ajusta modelos com erro heterocedástico, condicional a um conjunto de covariáveis. Para a distribuição normal truncada, frontier pode também ajustar um modelo de média condicional no qual a média é modelada como uma função linear de um conjunto de covariáveis.

\subsubsection{Testes}

Inicialmente utilizamos o C-teste de Davidson and MacKinnon (1981) para testar a significância da FFF quando comparada à forma Translog. Considerou- 
se a especificação dada pela FFF como hipótese nula e o teste corresponde simplesmente a ajustar a equação

$$
y_{t}-\widehat{f}=\alpha_{c}(\widehat{g}-\widehat{f})+e_{t}
$$

onde $\widehat{f}$ corresponde aos valores preditos da FFF e $\widehat{g}$, aos valores preditos da Translog. Os resultados apontaram na direção de não rejeitar a hipótese nula $(\mathrm{p}$-valor $=18 \%)$.

Considerando as covariáveis descritas na seção 1.3.1 e detalhadas em 1.5, ajustamos as três especificações (exponencial, meia-normal e normal truncada) para a nossa FFF. As covariáveis foram consideradas tanto no núcleo da função custo como parâmetros do termo de ineficiência ${ }^{1}$. Em seguida, utilizamos o "Critério de Informação de Akaike (AIC)"para escolher entre os três modelos. A especificação exponencial foi a mais bem ajustada segundo o AIC.

\subsubsection{Especificação final}

Temos a especificação final considerando o modelo exponencial para a ineficiência técnica e os respectivos valores encontrados para os parâmetros:

$$
y=g(\mathbf{l}, v, \mathbf{z})=f_{1}(\mathbf{1}, v)+f_{2}(\mathbf{l}, v)+h(\mathbf{z})+\mu+v
$$

onde $f_{1}$ corresponde à parte Translog da forma flexível de Fourier, $f_{2}$ contém os

\footnotetext{
${ }^{1}$ Não é de nosso conhecimento na literatura de restrições sobre a natureza das covariáveis nas componentes de produção e do termo de ineficiência. Aplicações típicas envolvem por exemplo o uso das mesmas variáveis indicadoras nas duas componentes. Exemplos de tal uso aparecem em Bos et al. (2009) e Alves et al. (2012)
} 
termos trigonométricos característicos da Fourier, $h$ é a combinação linear das covariáveis consideradas, $\mu$ é o erro idiossincrático e $v$ é o termo que caracteriza a ineficiência técnica do sistema produtivo. Destaque-se que y é o log do custo.

Mais especificamente, temos:

$$
h(\mathbf{z})=b_{0}+b_{1} z_{1}+b_{2} z_{2}+\ldots+b_{10} z_{10}
$$

onde:

$z_{1}: \ln ($ indicador de escolaridade dos docentes)

$z_{2}: \ln ($ indicador de carga horária diária dos alunos)

$z_{3}: \ln ($ indicador de número de alunos por turma)

$z_{4}: \ln ($ indicador de índice de Gini)

$z_{5}: \ln ($ indicador de taxa de urbanização)

$z_{6}: \ln ($ indicador de infraestrutura da casa do aluno)

$z_{7}: \ln ($ indicador de participação dos pais na vida escolar)

$z_{8}: \ln ($ indicador de escolaridade da mãe)

$z_{9}: \ln ($ indicador de escolaridade do pai)

$z_{10}: \ln ($ indicador de taxa de analfabetismo)

Ao estimar a função (1.17) através de uma fronteira estocástica ajustada para função custo, assumimos que:

$$
\mu \sim N(0, \sigma)
$$




$$
v \sim \operatorname{Exp}(\lambda)
$$

onde

$$
\operatorname{var}(v)=\left(\frac{1}{\lambda}\right)^{2}=\exp \left(a_{0}+a_{1} z_{1}+\ldots+a_{10} z_{10}\right)
$$

Com isso, as elasticidades do custo relativamente às covariáveis podem ser obtidas da seguinte forma:

$$
\frac{\partial E(y)}{\partial z_{j}}=b_{j}+\frac{1}{2}\left(\exp \left(a_{0}+a_{1} z_{1}+\ldots+a_{10} z_{10}\right)\right)^{-\frac{1}{2}} \exp \left(a_{0}+a_{1} z_{1}+\ldots+a_{10} z_{10}\right) a_{j}
$$

Isto porque

$$
\begin{gathered}
E(y)=f_{1}(\mathbf{1}, v)+f_{2}(\mathbf{1}, v)+h(\mathbf{z})+E(\mu)+E(v) \\
E(y)=f_{1}(\mathbf{1}, v)+f_{2}(\mathbf{1}, v)+h(\mathbf{z})+0+\frac{1}{\lambda} \\
E(y)=f_{1}(\mathbf{1}, v)+f_{2}(\mathbf{1}, v)+h(\mathbf{z})+0+(\operatorname{var}(v))^{\frac{1}{2}}
\end{gathered}
$$

E as elasticidades-preço do custo:

$$
\begin{aligned}
& \frac{\partial E(y)}{\partial l_{1}}=b_{1}+2 c_{1} l_{1}+c_{5} l_{2}+c_{6} l_{3}+c_{8} v-v_{2} \lambda \cos \left(\lambda\left(l_{1}-l_{3}\right)\right)-v_{4} \lambda \cos \left(\lambda\left(l_{1}-l_{2}\right)\right)- \\
& v_{6} \lambda \cos \left(\lambda\left(l_{1}-l_{2}+v\right)\right)-v_{7} \lambda \cos \left(\lambda\left(l_{1}-l_{3}+v\right)\right)-v_{9} \lambda \cos \left(\lambda\left(l_{1}-l_{2}-v\right)\right)-v_{10} \lambda \cos \left(\lambda \left(l_{1}-\right.\right. \\
& \left.\left.l_{3}-v\right)\right)-u_{2} \lambda \sin \left(\lambda\left(l_{1}-l_{3}\right)\right)-u_{4} \lambda \sin \left(\lambda\left(l_{1}-l_{2}\right)\right)-u_{6} \lambda \sin \left(\lambda\left(l_{1}-l_{2}+v\right)\right)-
\end{aligned}
$$


$u_{7} \lambda \sin \left(\lambda\left(l_{1}-l_{3}+v\right)\right)-u_{9} \lambda \sin \left(\lambda\left(l_{1}-l_{2}-v\right)\right)-u_{10} \lambda \sin \left(\lambda\left(l_{1}-l_{3}-v\right)\right)$

$\frac{\partial E(y)}{\partial l_{2}}=b_{2}+2 c_{2} l_{2}+c_{5} l_{1}+c_{7} l_{3}+c_{9} v-v_{3} \lambda \cos \left(\lambda\left(l_{2}-l_{3}\right)\right)+v_{4} \lambda \cos \left(\lambda\left(l_{1}-l_{2}\right)\right)-$ $v_{5} \lambda \cos \left(\lambda\left(l_{2}-l_{3}+v\right)\right)+v_{6} \lambda \cos \left(\lambda\left(l_{1}-l_{2}+v\right)\right)-v_{8} \lambda \cos \left(\lambda\left(l_{2}-l_{3}-v\right)\right)+v_{9} \lambda \cos \left(\lambda\left(l_{1}-\right.\right.$ $\left.\left.l_{2}-v\right)\right)-u_{3} \lambda \sin \left(\lambda\left(l_{2}-l_{3}\right)\right)+u_{4} \lambda \sin \left(\lambda\left(l_{1}-l_{2}\right)\right)-u_{5} \lambda \sin \left(\lambda\left(l_{2}-l_{3}+v\right)\right)+$ $u_{6} \lambda \sin \left(\lambda\left(l_{1}-l_{2}+v\right)\right)-u_{8} \lambda \sin \left(\lambda\left(l_{2}-l_{3}-v\right)\right)+u_{9} \lambda \sin \left(\lambda\left(l_{1}-l_{2}-v\right)\right)$

$\frac{\partial E(y)}{\partial l_{3}}=b_{3}+2 c_{3} l_{3}+c_{6} l_{1}+c_{7} l_{2}+c_{10} v+v_{2} \lambda \cos \left(\lambda\left(l_{1}-l_{3}\right)\right)+v_{3} \lambda \cos \left(\lambda\left(l_{2}-\right.\right.$ $\left.\left.l_{3}\right)\right)+v_{5} \lambda \cos \left(\lambda\left(l_{2}-l_{3}+v\right)\right)+v_{7} \lambda \cos \left(\lambda\left(l_{1}-l_{3}+v\right)\right)+v_{8} \lambda \cos \left(\lambda\left(l_{2}-l_{3}-v\right)\right)+$ $v_{10} \lambda \cos \left(\lambda\left(l_{1}-l_{3}-v\right)\right)+u_{2} \lambda \sin \left(\lambda\left(l_{1}-l_{3}\right)\right)+u_{3} \lambda \sin \left(\lambda\left(l_{2}-l_{3}\right)\right)+u_{5} \lambda \sin \left(\lambda\left(l_{2}-\right.\right.$ $\left.\left.l_{3}+v\right)\right)+u_{7} \lambda \sin \left(\lambda\left(l_{1}-l_{3}+v\right)\right)+u_{8} \lambda \sin \left(\lambda\left(l_{2}-l_{3}-v\right)\right)+u_{10} \lambda \sin \left(\lambda\left(l_{1}-l_{3}-\right.\right.$ v))

E por fim a elasticidade-produto do custo:

$$
\begin{aligned}
& \frac{\partial E(y)}{\partial l_{3}}=b_{4}+2 c_{4} v+c_{8} l_{1}+c_{9} l_{2}+c_{10} l_{3}-v_{1} \lambda \cos (\lambda v)-v_{5} \lambda \cos \left(\lambda\left(l_{2}-l_{3}+v\right)\right)- \\
& v_{6} \lambda \cos \left(\lambda\left(l_{1}-l_{2}+v\right)\right)-v_{7} \lambda \cos \left(\lambda\left(l_{1}-l_{3}+v\right)\right)+v_{8} \lambda \cos \left(\lambda\left(l_{2}-l_{3}-v\right)\right)+v_{9} \lambda \cos \left(\lambda \left(l_{1}-\right.\right. \\
& \left.\left.l_{2}-v\right)\right)+v_{10} \lambda \cos \left(\lambda\left(l_{1}-l_{3}-v\right)\right)-u_{1} \lambda \sin (\lambda v)-u_{5} \lambda \sin \left(\lambda\left(l_{2}-l_{3}+v\right)\right)-u_{6} \lambda \sin \left(\lambda \left(l_{1}-\right.\right. \\
& \left.\left.l_{2}+v\right)\right)-u_{7} \lambda \sin \left(\lambda\left(l_{1}-l_{3}+v\right)\right)+u_{8} \lambda \sin \left(\lambda\left(l_{2}-l_{3}-v\right)\right)+u_{9} \lambda \sin \left(\lambda \left(l_{1}-l_{2}-\right.\right. \\
& v))+u_{10} \lambda \sin \left(\lambda\left(l_{1}-l_{3}-v\right)\right)
\end{aligned}
$$

\subsubsection{Análise Fatorial e Indicadores}

Para finalizar a seção relativa à metodologia, apresentamos a técnica que utilizamos para construir três indicadores: o de capital físico das escolas do município, da infraestrutura média da casa das famílias dos alunos do município e da participação dos pais na vida escolar dos alunos. 
Para termos uma proxy para o preço de capital foi necessário construir um indicador de quantidade de capital presente nas escolas de cada município. O Censo Escolar da Educação Básica disponibiliza uma série de informações relacionadas à infraestrutura física de cada escola. Especificamente utilizamos informações relacionadas à existência de sala diretor, sala de professores, laboratório de informática, laboratório de ciências, sala de atendimento especializado, quadra de esporte, cozinha, biblioteca, sala de leitura, parque, berçário, sanitário fora da escola, sanitário dentro da escola, sanitário PNE, tv, vídeo, dvd, parabolica, copiadora, retro, impressora, computadores, internet e banda larga. Sendo cada uma dessas variáveis uma dummy para cada escola, geramos para cada município a mesma quantidade de variáveis no nível do município, sendo que esta representa a soma sobre todas as escolas. Por exemplo:

$$
t v_{m u n}=\sum_{e s c} t v_{e s c}
$$

A metodologia empregada para construção de tal indicador consiste basicamente da aplicação de uma análise fatorial sobre os ranks destas variáveis de modo a agregá-las em apenas um indicador. A utilização dos ranks, na linha de Conover and Conover (1980), permite retirar as eventuais diferenças de dimensão entre as variáveis tornando-as comparáveis. Desta forma, a cada município foi associado um rank para cada variável que representa a sua posição em termos da infraestrutura de capital presente em suas escolas

$$
r t v_{m u n}=\text { rank }_{\text {entre }} \text { os municipios }(t v)
$$

Tendo uma variável rank para cada um daqueles itens de capital citado anteriormente ( $t v$, sala do diretor, $\mathrm{dvd}$, etc), aplicamos então uma análise fatorial 
para construir enfim um índice unidimensional. Conforme descrito em Moreira et al. (2004), na análise fatorial, busca-se representar um conjunto de $p$ variáveis $X_{1}, X_{2}, \ldots, X_{p}$ em um número menor de fatores não diretamente observáveis. Especificamente o modelo fatorial postula que:

$$
X_{1}=a_{11} F_{1}+a_{12} F_{2}+\ldots+a_{1 m} F_{m}+e_{i}
$$

onde $a_{i 1}, a_{i 2}, \ldots, a_{i m}$ são as cargas fatoriais (pesos fatoriais) da variável $X_{i}$ nos fatores $F_{1}, F_{2}, \ldots, F_{m}$, respectivamente.

Supondo que as variáveis têm variância unitária obtém-se:

$$
a_{11}^{2} \operatorname{var}\left(F_{1}\right)+a_{12}^{2} \operatorname{var}\left(F_{2}\right)+\ldots+a_{1 m}^{2} \operatorname{var}\left(F_{m}\right)+\sigma_{1}^{2}=1
$$

e, portanto:

$$
1=a_{11}^{2}+a_{12}^{2}+\ldots+a_{1 m}^{2}+\sigma_{1}^{2}
$$

onde $h_{i}^{2}=a_{i 1}^{2}+a_{i 2}^{2}+\ldots+a_{i m}^{2}$ é um termo denominado comunalidade de $X_{i}$, que representa a parte da variância de $X_{i}$ associada aos fatores comuns ou explicada por estes. A comunalidade, portanto, é característica de cada variável. Se uma variável demonstra uma elevada comunalidade, isto significa que a variabilidade nela observada é fortemente explicada pelos fatores comuns.

No estudo em tela, utilizamos apenas um fator para agregar todas as variáveis de infraestrutura escolar do município, gerando assim o nosso indicador de quantidade de capital do município.

De maneira idêntica, geramos um indicador para retratar infraestrutura média 
da casa das famílias dos alunos do município e outro para medir o nível de participação dos pais na vida escolar dos alunos. Ambas foram consideradas variáveis ambientais importantes neste contexto. Para a primeira, agregamos informações relativas à presença de tv, radio, dvd,geladeira,freezer,máquina de lavar,computador e de outras facilidades ou bens da família tais como carro, quarto, banheiro dentro da casa. Para a segunda, consideramos informações constantes da Prova Brasil acerca da atuação dos pais no incentivo à execução das tarefas de casa, à leitura, a não faltar às aulas, além da participação em reuniões escolares.

\subsection{Dados}

Descrevemos, nesta secão, as variáveis que estarão presentes na função custo a ser estimada. A fonte dos dados e algumas estatísticas básicas são apresentadas. Definimos o universo do estudo e analisamos, por fim, a parcela de municípios ausentes da base final.

Importante ressaltar que este estudo tem como escopo o ensino fundamental ofertado pelas escolas públicas municípais e o município é a nossa "unidade produtiva".

\subsubsection{Matrículas}

O Censo Escolar de 2011 informa que há 16.557.341 matrículas de ensino fundamental na rede municipal. Isto considerando a base mais desagregada disponibilizada pelo INEP/MEC, que apresenta os dados no nível da matrícula 2 .

\footnotetext{
${ }^{2}$ Utizamos os códigos 4 a 11, 14 a 21 e 41 da variável FK COD ETAPA ENSINO para caracterizar o aluno do ensino fundamental
} 
Obtivemos 5.548 municípios com matrículas de ensino fundamental na rede municipal. Isto significa que há no Brasil 15 municípios cujos alunos do ensino fundamental são atendidos apenas pela rede estadual. A menor rede é a do município paulista de Santana da Ponte Pensa (10 matrículas) e a maior é a do município do Rio de Janeiro (539.214 matrículas).

Tabela 1.3: Matrículas

\begin{tabular}{c|c|c|c|c|c|c}
\hline \hline mínimo & $1^{\circ}$ quartil & média & mediana & $3^{\circ}$ quartil & máximo & desvio padrão \\
\hline 10 & 465 & 2.984 & 1.128 & 2.867 & 539.214 & 11.472 \\
\hline \hline
\end{tabular}

Fonte: elaboração do autor

\subsubsection{Custo: Despesa Empenhada no Ensino Fundamental}

O Ministério da Educação (MEC) através do Fundo Nacional de Desenvolvimento da Educação (FNDE) coleta informações referentes aos orçamentos de educação dos entes federados. Estes dados estão no Sistema de Informações sobre Orçamentos Públicos em Educação (SIOPE). Especificamente, utilizou-se a despesa paga por município na subfunção "Ensino Fundamental"como proxy para o custo. Obteve-se também a segregação da despesa por grupos de despesa, a saber: Pessoal, Outras Despesas Correntes (Custeio) e Investimento.

Tabela 1.4: Gasto por Aluno no Ensino Fundamental (R\$)

\begin{tabular}{c|c|c|c|c|c|c}
\hline \hline mínimo & $1^{\circ}$ quartil & média & mediana & $3^{\circ}$ quartil & máximo & desvio padrão \\
\hline $1.625,12$ & $3.542,00$ & $5.359,05$ & $4.782,71$ & $6.445,88$ & $32.694,57$ & $2.528,56$ \\
\hline \hline
\end{tabular}

Fonte: elaboração do autor 


\subsubsection{Preço do Trabalho: Salário Anual do Professor}

Construímos uma proxy para o preço do trabalho combinando dados da despesa com pessoal, obtidos no SIOPE, com os dados de funcionários presentes no Censo Escolar, que é realizado anualmente pelo Instituto Nacional de Estudos e Pesquisas Educacionais Anísio Teixeira (INEP/MEC). A razão entre a despesa municipal com pessoal na subfunção 'Ensino Fundamental' e a quantidade de funcionários das escolas municipais é o que consideramos como salário anual pago aos profissionais do ensino fundamental das redes municipais no Brasil. A menor remuneração foi registrada no município de Bujaru no Pará e a maior, no município de Porto Alegre.

Tabela 1.5: Preço Anual do Trabalho (R\$)

\begin{tabular}{c|c|c|c|c|c|c}
\hline \hline mínimo & $1^{\mathrm{o}}$ quartil & média & mediana & $3^{\circ}$ quartil & máximo & desvio padrão \\
\hline $2.841,69$ & $12.460,85$ & 15.872 .31 & $15.251,70$ & 18.487 .91 & $61.378,76$ & $5.246,09$ \\
\hline \hline
\end{tabular}

Fonte: elaboração do autor

\subsubsection{Preço do Custeio}

Observando que o custeio representa uma parcela signficativa da estrutura de custo em tela, foi imprescindível a inserção de uma proxy para seu preço. De maneira análoga ao preço de pessoal, consideramos as informações de gasto obtidas no SIOPE 3 . Como proxy para a variável de quantidade, utilizamos o número de salas de aula presentes nas escolas municipais, dado este retirado do Censo Escolar.

\footnotetext{
${ }^{3}$ Considerou-se a diferença entre o gasto total e a soma do gasto de pessoal com o gasto em investimento
} 
Tabela 1.6: Preço Anual Custeio (R\$)

\begin{tabular}{c|c|c|c|c|c|c}
\hline \hline mínimo & $1^{\circ}$ quartil & média & mediana & $3^{\circ}$ quartil & máximo & desvio padrão \\
\hline 0 & $28.738,24$ & 48.195 .34 & $41.356,07$ & $58.891,38$ & $831.239,30$ & $32.387,43$ \\
\hline \hline
\end{tabular}

Fonte: elaboração do autor

\subsubsection{Preço do Capital}

De maneira similar aos preços anteriores, construiu-se um preço para o capital através da razão entre o gasto com investimento (SIOPE) e um indicador de quantidade de capital. Tal indicador foi construído a partir de uma série de informações acerca da infraestrutura escolar conforme descrito na respectiva seção de metodologia.

Tabela 1.7: Preço Anual do Capital (R\$)

\begin{tabular}{c|c|c|c|c|c|c}
\hline \hline mínimo & $1^{\text {o }}$ quartil & média & mediana & $3^{\circ}$ quartil & máximo & desvio padrão \\
\hline 0,0006 & 1,35 & 8,71 & 4,24 & 9,67 & 700,61 & 19,47 \\
\hline \hline
\end{tabular}

Fonte: elaboração do autor

\subsubsection{Output - Percentual de alunos com nota superior}

A Prova Brasil é a fonte de dados para construção da variável que consideramos como output do processo produtivo na nossa função custo. A Prova Brasil é "uma avaliação censitária envolvendo os alunos da $4^{\mathrm{a}}$ série $/ 5^{\circ}$ ano e $8^{\mathrm{a}}$ série $/ 9^{\circ}$ ano do Ensino Fundamental das escolas públicas das redes municipais, estaduais e federal, com o objetivo de avaliar a qualidade do ensino ministrado nas escolas públicas. Participam desta avaliação as escolas que possuem, no mínimo, 20 alunos matriculados nas séries/anos avaliados, sendo os resultados disponibilizados por escola e por ente federativo"(INEP/MEC). 
Consideramos especificamente o desempenho na prova de Matemática dos alunos do $5^{\circ}$ e $9^{\circ}$ anos nas redes municipais.A rigor, a nossa variável final tenta expressar, por município, o percentual de alunos que atingiu um dado patamar de desempenho $4^{4}$. Em busca da referência do que seria este nível ideal de desempenho, adotamos os números apresentados pelo movimento "Todos pela Educação". Tal referência vem sendo utilizado pela sociedade em geral a cada divulgação dos dados da Prova Brasil. Especificamente considera que os alunos $5^{\circ}$ ano deveriam obter pelo menos 225 pontos e os do $9^{\circ}$ ano, 300 pontos na prova de Matemática. Com esta referência e utilizando os dados relativos a 5.147 redes municipais de ensino presentes na base de dados que contém a performance dos estudantes, observamos que as redes municipais apresentam resultados bastante insatisfatórios. Analisando o desempenho médio dos estados, observamos que o Maranhão apresenta a menor média $(7,7 \%)$ enquanto o Paraná, a maior (44,9\%). Apenas o município paulista de Tacaiu tem $100 \%$ dos alunos proficientes, segundo este parâmetro. No universo considerado, 58 municípios não apresentam nenhum dos alunos avaliados como proficientes. A seguir, mais algumas estatísticas gerais:

Tabela 1.8: Percentual de Alunos Proficientes (\%)

\begin{tabular}{c|c|c|c|c|c|c}
\hline \hline mínimo & $1^{\circ}$ quartil & média & mediana & $3^{\circ}$ quartil & máximo & desvio padrão \\
\hline 0 & 10,5 & 28,1 & 28,1 & 24,4 & 41,7 & 100 \\
\hline \hline
\end{tabular}

Fonte: elaboração do autor/MEC

\footnotetext{
${ }^{4}$ Golebiewski (Golebiewski) evidencia a utilização dessa proxy como output em estudos similares
} 


\subsubsection{Variáveis Ambientais - Gestão da Rede Municipal de En- sino}

Descreveremos agora as variáveis que não são as varáveis típicas de uma função custo (custo, preços e output), mas que impactam o processo produtivo por afetar o ambiente em que é realizado. Denominaremos estas variáveis de ambientais. Entedemos que uma parcela delas está sob a gestão da rede municipal de ensino e outro conjunto é completamente exógeno.

\section{Matrículas por turma}

As informações do número médio de matrículas por turma são disponibilizadas pelo INEP de forma agregada para cada rede municipal. A fonte primária desta variável é o Censo Escolar.

Tabela 1.9: Matrículas por turma

\begin{tabular}{c|c|c|c|c|c|c}
\hline \hline mínimo & $1^{\mathrm{o}}$ quartil & média & mediana & $3^{\circ}$ quartil & máximo & desvio padrão \\
\hline 4,5 & 17,8 & 20,5 & 20,6 & 23,2 & 36,5 & 4,1 \\
\hline \hline
\end{tabular}

\section{Carga Horária Diária}

De maneira similar, as informações da carga horária diária média a que os alunos estão expostos são disponibilizadas também de forma agregada para cada rede municipal pelo INEP. A fonte primária desta variável é novamente o Censo Escolar. 
Tabela 1.10: Carga Horária Diária

\begin{tabular}{c|c|c|c|c|c|c}
\hline \hline mínimo & $1^{\circ}$ quartil & média & mediana & $3^{\circ}$ quartil & máximo & desvio padrão \\
\hline 3,6 & 4,0 & 4,3 & 4,2 & 4,4 & 9,3 & 0,5 \\
\hline \hline
\end{tabular}

Fonte: INEP/MEC

\section{Percentual de Professores com Ensino Superior}

De maneira similar, obtivemos os dados referentes ao percentual de professores das redes municipais de ensino que possuem curso superior completo.

Tabela 1.11: Percentual de Professores com Ensino Superior (\%)

\begin{tabular}{c|c|c|c|c|c|c}
\hline \hline mínimo & $1^{\mathrm{o}}$ quartil & média & mediana & $3^{\circ}$ quartil & máximo & desvio padrão \\
\hline 0,0 & 67,6 & 77,7 & 84,7 & 94,1 & 100,0 & 21,2 \\
\hline \hline
\end{tabular}

Fonte: INEP/MEC

\section{Taxa de Analfabetismo - 15 anos ou mais}

Por fim, acrescentamos a variável Taxa de Analfabetismo (15 anos ou mais) cuja fonte primária é o Censo de 2010 realizado pelo Instituto Brasileiro de Geografia e Estatística (IBGE). Avaliamos inicialmente que tal variável pode influenciar o comportamento do gasto em educação do município.

Tabela 1.12: Taxa de Analfabetismo - 15 anos ou mais (\%)

\begin{tabular}{c|c|c|c|c|c|c}
\hline \hline mínimo & $1^{\circ}$ quartil & média & mediana & $3^{\circ}$ quartil & máximo & desvio padrão \\
\hline 0,9 & 7,6 & 15,6 & 12,6 & 23,7 & 47,1 & 9,8 \\
\hline \hline
\end{tabular}

Fonte: IBGE

Entedemos que as variáveis ambientais, a seguir, não estão sob a gestão das redes municipais de ensino. 


\subsubsection{Outras Variáveis Ambientais}

As variáveis Renda Domiciliar Per Capita, Índice de Gini e Taxa de Urbanização, que têm como fonte primária o Censo de 2010 (IBGE), estão disponíveis para todos os municípios. A seguir apresentamos as suas estatísticas:

\section{Renda Domiciliar Per Capita}

Tabela 1.13: Renda Domiciliar Mensal Per Capita (R\$)

\begin{tabular}{c|c|c|c|c|c|c}
\hline \hline mínimo & $1^{\text {o }}$ quartil & média & mediana & $3^{\circ}$ quartil & máximo & desvio padrão \\
\hline 95,59 & 109,40 & 488,32 & 463,68 & 644,35 & $2.008,98$ & 239,29 \\
\hline \hline
\end{tabular}

Fonte: IBGE

Índice de Gini

Tabela 1.14: Índice de Gini

\begin{tabular}{c|c|c|c|c|c|c}
\hline \hline mínimo & $1^{\mathrm{o}}$ quartil & média & mediana & $3^{\circ}$ quartil & máximo & desvio padrão \\
\hline 0,28 & 0,46 & 0,50 & 0,50 & 0,54 & 0,80 & 0,06 \\
\hline \hline
\end{tabular}

Fonte: IBGE

Taxa de Urbanização

Tabela 1.15: Taxa de Urbanização (\%)

\begin{tabular}{c|c|c|c|c|c|c}
\hline \hline mínimo & $1^{\mathrm{o}}$ quartil & média & mediana & $3^{\mathrm{o}}$ quartil & máximo & desvio padrão \\
\hline 17,9 & 49,0 & 65,6 & 67,0 & 83,8 & 100,0 & 21,6 \\
\hline \hline
\end{tabular}

Fonte: IBGE 
Além destas variáveis que tentam retratar o ambiente socioeconômico do município, consideramos também aquelas relacionadas ao ambiente familiar dos alunos do município. Para tanto, utilizamos informações dos questionários socioeconômicos aplicados aos alunos na Prova Brasil (INEP). Construímos indicadores que retratam o a infraestrutura física da residência do aluno, a participação dos pais na vida escolar dele e a escolaridade dos pais.

\section{Infraestrutura da Casa}

Conforme descrevemos na seção de metodologia, construímos um indicador que retrata a infraestrutura média da casa do aluno do município. Eis as estatísticas:

Tabela 1.16: Infraestrutura da Casa

\begin{tabular}{c|c|c|c|c|c|c}
\hline \hline mínimo & $1^{\circ}$ quartil & média & mediana & $3^{\circ}$ quartil & máximo & desvio padrão \\
\hline 454,37 & $1.770,98$ & $2.626,17$ & $2.665,74$ & $3.487,44$ & $4.749,79$ & 979,82 \\
\hline \hline
\end{tabular}

Fonte: elaboração do autor

\section{Participação dos Pais}

O indicador de participação dos pais foi construído de maneira análoga ao da infraestrutura da casa. Ele retrata a frequência com que os pais vão à reunião na escola, se eles incentivam os filhos a estudar, a fazer o dever de casa, a ler, a não faltar as aulas e se conversam sobre o que ocorre na escola.

Tabela 1.17: Participação dos Pais (\%)

\begin{tabular}{c|c|c|c|c|c|c}
\hline \hline mínimo & $1^{\circ}$ quartil & média & mediana & $3^{\circ}$ quartil & máximo & desvio padrão \\
\hline 39,33 & $1.439,66$ & $2.621,67$ & $2.683,07$ & $3.820,18$ & $5.141,05$ & $1.393,21$ \\
\hline \hline
\end{tabular}

Fonte: elaboração do autor 


\subsection{Base Final}

Agregamos as informações por município para todas essas variáveis e chegamos a informações consistentes para 4.600 municípios. Portanto, o nosso estudo terá como universo esta parcela da rede pública municipal brasileira que atua no Ensino Fundamental.

\section{Municípios Ausentes}

Há portanto 965 municípios ausentes no nosso estudo, representando portanto 17,3\% dos 5.565 existentes no país. Eles representam 5,95\% da população brasileira e 3,12\% da soma dos PIB Municipais do Brasil. Relativamente às matrículas, estamos deixando de fora do estudo cerca de $8,24 \%$ das matrículas de ensino fundamental da rede municipal do Brasil.

A seguir, apresentamos uma distribuição regional destes municípios e uma lista com os 10 municípios com os maiores valores de PIB e de população (fig.1.3. tabelas 1.18 e 1.19):

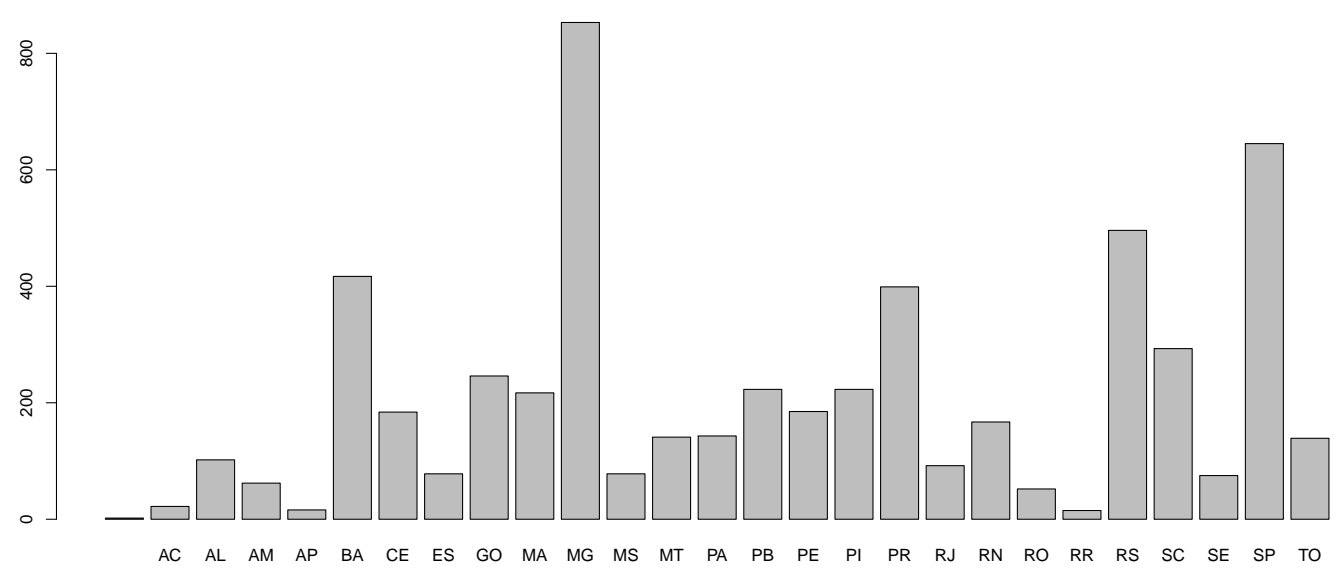

Figura 1.3: Frequência dos Municípios por Estado 
Tabela 1.18: 10 Maiores em População

\begin{tabular}{c|c|c}
\hline Município & UF & População \\
\hline Mauá & PA & 417.064 \\
\hline Itaboraí & PE & 218.008 \\
\hline Castanhal & GO & 173.149 \\
\hline Teresópolis & PR & 163.746 \\
\hline Teixeira de Freitas & PA & 138.341 \\
\hline Barbacena & SP & 126.284 \\
\hline Cametá & BA & 120.896 \\
\hline Santana de Parnaíba & BA & 108.813 \\
\hline Paço do Lumiar & TO & 105.121 \\
\hline Almirante Tamandaré & MT & 103.204 \\
\hline \hline
\end{tabular}

Fonte: elaboração do autor

Tabela 1.19: 10 Maiores em PIB

\begin{tabular}{c|c|c}
\hline \hline Município & UF & PIB \\
\hline Mauá & PR & 3.280 .497 \\
\hline Santana do Parnaíba & BA & 1.624 .707 \\
\hline Barcarena & TO & 1.584 .110 \\
\hline São João da Barra & SP & 1.554 .872 \\
\hline Aracruz & PA & 1.266 .119 \\
\hline Mariana & MT & 1.253 .023 \\
\hline Teresópolis & MG & 1.233 .351 \\
\hline Itaboraí & PR & 975.608 \\
\hline Araçariguama & BA & 670.133 \\
\hline Barbacena & PB & 669.069 \\
\hline \hline Fonte: elaboração do autor &
\end{tabular}




\subsection{Resultados}

Apresentamos, nesta seção, os principais resultados da função custo estimada 5 e as medidas de eficiência decorrentes do modelo de fronteira estocástica ajustado.

\subsubsection{Elasticidades}

Com o objetivo de avaliar o efeito marginal de cada um dos preços dos insumos e do produto no custo do processo produtivo, estimamos as elasticidades-preço e a elasticidade-produto da função custo, avaliadas na média de cada uma de suas variáveis (tabela 1.20 ). Todas mostraram-se significativas a 1\%:

Tabela 1.20: Elasticidades - Preços e Produto

\begin{tabular}{c|c|c}
\hline \hline elasticidade & coeficiente & erro-padrão \\
\hline trabalho & 0,167 & 0,011 \\
\hline capital & 0,011 & 0,003 \\
\hline custeio & 0,356 & 0,008 \\
\hline produto & 0,640 & 0,296 \\
\hline \hline
\end{tabular}

De maneira similar, obtivemos os efeitos marginais de cada uma das variáveis ambientais, que também mostraram-se muito signficativas (tabela 1.21):

\footnotetext{
${ }^{5}$ Os coeficientes do modelo 1.18 e 1.17 estão descritos no apêndice $B$
} 
Tabela 1.21: Elasticidades - Ambiente

\begin{tabular}{c|c|c}
\hline \hline elasticidade & coeficiente & erro-padrão \\
\hline carga horária diária & 0,360 & 0,033 \\
\hline alunos por turma & $-0,817$ & 0,016 \\
\hline coeficiente de Gini & $-0,141$ & 0,025 \\
\hline taxa de urbanização & 0,038 & 0,009 \\
\hline infraestrutura da casa do aluno & 0,227 & 0,012 \\
\hline participação dos pais & 0,061 & 0,005 \\
\hline escolaridade do pai & $-0,024$ & 0,005 \\
\hline escolaridade da mãe & $-0,013$ & 0,005 \\
\hline taxa de analfabetismo & $-0,047$ & 0,007 \\
\hline escolaridade dos docentes & 0,074 & 0,014 \\
\hline \hline
\end{tabular}

Fonte: elaboração do autor

Relativamente aos preços, os sinais estão de acordo com as expectativas de uma função custo.

A elasticidade-produto é coerente com o que se observa na realidade no que tange ao expressivo custo de se alterar o rendimento dos alunos na atual estrutura produtiva dos municípios brasileiros. Nesta realidade, para que os municípios alcançassem 100\% dos alunos com o nível de proficiência proposto, por exemplo, teríamos que ter um custo-aluno 163\% superior. Como a elasticidade é inferior à unidade, concluímos que, na média, estamos trabalhando em uma região da curva de custo que apresenta economia de escala. Há portanto outras combinações dos insumos cujo acréscimo de custo seria proporcionalmente inferior ao acréscimo decorrente no produto.

Ao avaliar o ambiente em que o município está inserido observa-se que os municípios mais urbanos, com menos desigualdade de renda e com menos analfabetos têm custo-aluno maior.

Com respeito ao ambiente familiar do aluno, pais mais participativos e com 
maior infraestrutura em casa implicam em maiores gastos pelo município. Na direção contrária, pais com maior escolaridade gerariam menor custoaluno.

Por fim, as variáveis que estão no âmbito da gestão educacional do município apresentaram sinais coerentes com a expectativa usual. Municípios com maior carga-horária diária, com menos alunos por turma e com maior escolaridade dos seus docentes implicam em maior custo-aluno. Neste ponto, destacam-se as magnitudes das elasticidades das variáveis "alunos por turma"e "carga horária diária". Por exemplo, podemos afirmar que aumentar a carga-horária média de 4,3 horas para 7 horas (mínimo da educação integral) implicaria em um aumento de $23 \%$ no custo. E considerando que a atual média de alunos por turma é de 20,5, obteríamos uma redução da ordem de 38\% no custo, se essa média fosse levada para 30 alunos por turma.

\subsubsection{Eficiência}

Os municípios têm um custo de ineficiência médio da ordem de 14,7\%. Considerando o gasto municipal no ensino fundamental em 2011, isto corresponderia a cerca de $\mathrm{R}$ \$ 8,9 bilhões. O destaque de eficiência é o município de Morpará na Bahia e o da ineficiência, Xavantina em Santa Catarina. A eliminação desta ineficiência poderia aumentar a proficiência média em 23\%. Tal resultado apresenta-se inferior ao obtido, por exemplo, por Rocha et al. (2013), que foi superior a $40 \%$ e por Rosano-Peña et al. (2012), superior a $60 \% 6$,

Apresentamos, a seguir, as características dos 30 mais eficientes (tabelas $1.22 \mathrm{e}$ 1.23) e dos 30 menos eficientes (tabelas 1.24 e 1.25). Além disso, comparamos as médias das ineficiências, considerando os 100 municípios menos eficientes

\footnotetext{
${ }^{6}$ Estes dois estudos utilizaram metodologia distinta: Análise Envoltória de Dados
} 
com os 100 mais eficientes (tabela 1.26). Observamos que, na média, os mais eficientes apresentam piores indicadores socioeconômicos e menor nível de proficiência. No entanto, o gasto por aluno é bastante inferior nestes, o que parece determinar uma menor ineficiência. Destaque-se ainda que os mais eficientes apresentam menor carga-horária diária, maior número de alunos por turma e menor escolaridade dos docentes.

Finalmente, uma análise por unidade da federação indica que, em geral, os Estados da região Nordeste destacam-se como menos ineficientes (fig 1.4). 
Tabela 1.22: População, Custo e Proficiência dos 30 menos ineficientes

\begin{tabular}{|c|c|c|c|c|}
\hline Município & População & Custo (R\$) & Proficientes $(\%)$ & Eficiência \\
\hline Morpará - BA & 8.280 & $4.077,71$ & 2,1 & 1,007 \\
\hline Jussiape - BA & 8.031 & $6.342,85$ & 17,9 & 1,007 \\
\hline Cícero Dantas - BA & 32.300 & $2.239,84$ & 7,0 & 1,010 \\
\hline Canápolis - BA & 9.410 & $3.191,44$ & 4,6 & 1,011 \\
\hline Itamari - BA & 7.903 & $3.378,39$ & 6,0 & 1,013 \\
\hline Lençóis - BA & 10.368 & $2.889,89$ & 6,3 & 1,014 \\
\hline Batalha - AL & 17.076 & $3.442,83$ & 10,6 & 1,018 \\
\hline Lizarda - TO & 3.725 & $4.305,12$ & 0,0 & 1,019 \\
\hline Ibateguara - AL & 15.149 & $2.681,82$ & 4,8 & 1,019 \\
\hline Atalaia do Norte - AM & 15.153 & $2.940,68$ & 21,4 & 1,019 \\
\hline São João do Carú - MA & 12.309 & $3.423,84$ & 9,4 & 1,020 \\
\hline Centro do Guilherme - MA & 12.565 & $3.371,22$ & 2,2 & 1,021 \\
\hline Nova Redenção - BA & 8.034 & $3.229,92$ & 8,7 & 1,021 \\
\hline Caatiba - BA & 11.420 & $3.128,04$ & 5,0 & 1,021 \\
\hline Mortugaba - BA & 12.477 & $2.538,30$ & 28,7 & 1,021 \\
\hline Saúde - BA & 11.845 & $3.696,87$ & 10,7 & 1,022 \\
\hline Teodoro Sampaio - BA & 7.895 & $2.709,90$ & 12,5 & 1,022 \\
\hline São Bento - MA & 40.736 & $2.435,35$ & 7,6 & 1,023 \\
\hline Andaraí - BA & 13.960 & $2.833,32$ & 10,8 & 1,023 \\
\hline Abaíra - BA & 8.316 & $4.825,38$ & 12,9 & 1,023 \\
\hline União - PI & 42.654 & 2864,05 & 3,5 & 1,023 \\
\hline Caraíbas - BA & 10.222 & 3003,18 & 8,3 & 1,023 \\
\hline Buriticupu - MA & 65.237 & $2.614,19$ & 5,9 & 1,024 \\
\hline Camamu - BA & 35.180 & $3.138,13$ & 5,2 & 1,024 \\
\hline Santa Teresinha - BA & 9.648 & $4.041,18$ & 16,3 & 1,025 \\
\hline Nova Canaã - BA & 16.713 & $3.015,03$ & 12,0 & 1,025 \\
\hline Brejo da Madre de Deus - PE & 45.180 & $3.281,21$ & 11,4 & 1,025 \\
\hline Ipecaetá - BA & 15.331 & $2.186,40$ & 4,9 & 1,025 \\
\hline Tabocas do Brejo Velho - BA & 11.431 & $3.425,07$ & 2,6 & 1,025 \\
\hline Caetanos - BA & 13.639 & $2.846,98$ & 10,5 & 1,026 \\
\hline
\end{tabular}

Fonte: elaboração do autor 
Tabela 1.23: Qualif. do Prof., Carga Hor. e Alunos por Turma do 30 menos ineficientes

\begin{tabular}{|c|c|c|c|}
\hline Município & \% Docentes Ens. Sup. & Carga Horária & Alunos por turma \\
\hline Morpará - BA & 0,0 & 4,1 & 18,0 \\
\hline Jussiape - BA & 0,0 & 4,1 & 16,7 \\
\hline Cícero Dantas - BA & 1,9 & 4,1 & 21,0 \\
\hline Canápolis - BA & 0,6 & 4,0 & 12,5 \\
\hline Itamari - BA & 3,8 & 4,1 & 28,3 \\
\hline Lençóis - BA & 3,3 & 4,1 & 19,0 \\
\hline Batalha - AL & 9,2 & 4,3 & 26,0 \\
\hline Lizarda - TO & 4,8 & 4,2 & 10,3 \\
\hline Ibateguara - AL & 11,7 & 4,2 & 28,6 \\
\hline Atalaia do Norte - AM & 14,0 & 4,0 & 23,9 \\
\hline São João do Carú - MA & 8,2 & 4,0 & 22,3 \\
\hline Centro do Guilherme - MA & 5,2 & 4,0 & 18,6 \\
\hline Nova Redenção - BA & 5,4 & 4,2 & 19,8 \\
\hline Caatiba - BA & 5,0 & 3,9 & 19,2 \\
\hline Mortugaba - BA & 5,5 & 4,3 & 20,3 \\
\hline Saúde - BA & 4,8 & 4,1 & 20,0 \\
\hline Teodoro Sampaio - BA & 10,0 & 4,1 & 20,7 \\
\hline São Bento - MA & 12,0 & 4,2 & 29,5 \\
\hline Andaraí - BA & 8,6 & 4,4 & 21,9 \\
\hline Abaíra - BA & 3,6 & 4,2 & 15,9 \\
\hline União - PI & 40,4 & 4,4 & 9,3 \\
\hline Caraíbas - BA & 7,3 & 4,0 & 21,0 \\
\hline Buriticupu - MA & 20,6 & 4,0 & 25,3 \\
\hline Camamu - BA & 11,0 & 4,0 & 24,3 \\
\hline Santa Teresinha - BA & 6,3 & 4,2 & 20,4 \\
\hline Nova Canaã - BA & 37,1 & 3,9 & 8,0 \\
\hline Brejo da Madre de Deus - PE & 42,7 & 4,4 & 25,8 \\
\hline Ipecaetá - BA & 7,8 & 4,0 & 11,2 \\
\hline Tabocas do Brejo Velho - BA & 4,9 & 4,0 & 15,8 \\
\hline Caetanos - BA & 21,8 & 4,0 & 19,5 \\
\hline
\end{tabular}

Fonte: elaboração do autor 
Tabela 1.24: População, Custo e Proficiência dos 30 mais ineficientes

\begin{tabular}{|c|c|c|c|c|}
\hline Município & População & Custo & Proficientes & Eficiência \\
\hline Xavantina - SC & 4.142 & $24.591,20$ & 21,6 & 3,32 \\
\hline Ariranha do Ivaí - PR & 2.453 & $18.428,71$ & 50,0 & 2,71 \\
\hline Jateí - MS & 4.011 & $32.694,57$ & 5,2 & 2,63 \\
\hline Campo Bonito - PR & 4.407 & $13.801,31$ & 40,0 & 2,57 \\
\hline Candiota - RS & 8.771 & $21.250,47$ & 0,0 & 2,39 \\
\hline Tocantinópolis - TO & 22.619 & $12.526,08$ & 15,7 & 2,36 \\
\hline Muitos Capões - RS & 2.988 & $21.576,40$ & 26,3 & 2,35 \\
\hline Tigrinhos - SC & 1.757 & $13.452,61$ & 45,4 & 2,32 \\
\hline Itambé - PR & 5.979 & $9.634,63$ & 50,6 & 2,28 \\
\hline Macaé - RJ & 206.728 & $15.470,06$ & 35,8 & 2,28 \\
\hline Esperança Nova - PR & 1.970 & $12.191,12$ & 17,5 & 2,26 \\
\hline Cutias - AP & 4.696 & $9.110,09$ & 5,7 & 2,23 \\
\hline Nova Canaã Paulista - SP & 2.114 & $14.190,07$ & 60,8 & 2,23 \\
\hline Itutinga - MG & 3.913 & $19.426,39$ & 50,0 & 2,23 \\
\hline São João de Iracema - SP & 1.780 & $16.278,72$ & 60,7 & 2,22 \\
\hline São Domingos - SC & 9.491 & $14.073,30$ & 60,0 & 2,22 \\
\hline Barra do Chapéu - SP & 5.244 & $14.587,93$ & 15,9 & 2,20 \\
\hline Casa Branca - SP & 28.307 & $12.731,00$ & 33,3 & 2,19 \\
\hline Gameleiras - MG & 5.139 & $8.708,08$ & 4,3 & 2,16 \\
\hline Guamaré - RN & 12.404 & $11.943,94$ & 8,9 & 2,14 \\
\hline Dona Emma - SC & 3.721 & $18.273,42$ & 70,8 & 2,09 \\
\hline Sebastianópolis do Sul - SP & 3.031 & $28.272,82$ & 66,6 & 2,08 \\
\hline Iporá - GO & 31.274 & $9.143,72$ & 7,5 & 2,01 \\
\hline Governador Celso Ramos - SC & 12.999 & $8.996,71$ & 21,7 & 1,98 \\
\hline Abdon Batista - SC & 2.653 & $13.419,95$ & 45,9 & 1,95 \\
\hline Presidente Epitácio - SP & 41.318 & $9.912,34$ & 33,7 & 1,95 \\
\hline Nova Aliança do Ivaí - PR & 1.431 & $15.582,13$ & 54,1 & 1,94 \\
\hline Santa Cecília do Pavão - PR & 3.646 & $8.262,63$ & 35,7 & 1,93 \\
\hline Brunópolis - SC & 2.850 & $17.681,62$ & 34,6 & 1,93 \\
\hline Água Doce - SC & 6.961 & $7.977,63$ & 42,8 & 1,93 \\
\hline
\end{tabular}

Fonte: elaboração do autor 
Tabela 1.25: Qualif. do Prof., Carga Hor. e Alunos por Turma do 30 mais ineficientes

\begin{tabular}{|c|c|c|c|}
\hline Município & \% Docentes Ens. Sup. & Carga Horária & Alunos por turma \\
\hline Xavantina - SC & 70,0 & 4,0 & 11,1 \\
\hline Ariranha do Ivaí - PR & 100,0 & 4,0 & 17,8 \\
\hline Jateí - MS & 83,3 & 4,5 & 17,3 \\
\hline Campo Bonito - PR & 100,0 & 4,1 & 18,5 \\
\hline Candiota - RS & 100,0 & 4,0 & 16,3 \\
\hline Tocantinópolis - TO & 85,4 & 4,3 & 15,0 \\
\hline Muitos Capões - RS & 100,0 & 4,0 & 20,7 \\
\hline Tigrinhos - SC & 100,0 & 4,0 & 15,0 \\
\hline Itambé - PR & 100,0 & 4,0 & 19,7 \\
\hline Macaé - RJ & 77,8 & 4,7 & 25,4 \\
\hline Esperança Nova - PR & 100,0 & 4,0 & 20,3 \\
\hline Cutias - AP & 73,7 & 4,0 & 10,0 \\
\hline Nova Canaã Paulista - SP & 100,0 & 5,0 & 18,0 \\
\hline Itutinga - MG & 69,2 & 4,3 & 16,9 \\
\hline São João de Iracema - SP & 75,0 & 9,0 & 19,6 \\
\hline São Domingos - SC & 83,3 & 4,0 & 20,6 \\
\hline Barra do Chapéu - SP & 90,0 & 5,0 & 19,4 \\
\hline Casa Branca - SP & 87,5 & 8,9 & 20,9 \\
\hline Gameleiras - MG & 95,0 & 4,3 & 11,2 \\
\hline Guamaré - RN & 96,7 & 4,5 & 23,6 \\
\hline Dona Emma - SC & 100,0 & 4,0 & 12,0 \\
\hline Sebastianópolis do Sul - SP & 100,0 & 5,3 & 15,9 \\
\hline Iporá - GO & 100,0 & 4,4 & 20,4 \\
\hline Governador Celso Ramos - SC & 83,0 & 4,0 & 20,6 \\
\hline Abdon Batista - SC & 100,0 & 4,0 & 19,2 \\
\hline Presidente Epitácio - SP & 91,5 & 4,8 & 23,2 \\
\hline Nova Aliança do Ivaí - PR & 90,0 & 4,2 & 21,0 \\
\hline Santa Cecília do Pavão - PR & 96,0 & 4,2 & 22,8 \\
\hline Brunópolis - SC & 76,9 & 4,0 & 10,0 \\
\hline Água Doce - SC & 94,7 & 4,0 & 24,8 \\
\hline
\end{tabular}

Fonte: elaboração do autor 
Tabela 1.26: Ineficiência

\begin{tabular}{c|c|c}
\hline \hline Variável & 100 menos ineficientes & 100 mais ineficientes \\
\hline PIB & $139,803.00$ & $353,710.70$ \\
\hline população & $28,396.00$ & $22,610.00$ \\
\hline gasto aluno & $3,101.29$ & $12,537.29$ \\
\hline esc doc & 24.29 & 88.37 \\
\hline ch & 4.12 & 4.54 \\
\hline al turm & 20.76 & 18.84 \\
\hline gini & 0.55 & 0.48 \\
\hline tx urb & 0.54 & 0.63 \\
\hline infra casa & $1,760.33$ & $3,238.64$ \\
\hline part pais & $1,333.16$ & $3,265.40$ \\
\hline esc pai & $1,476.08$ & $3,355.97$ \\
\hline esc mãe & $1,464.20$ & $3,484.42$ \\
\hline tx analf & 25.35 & 10.46 \\
\hline produto & 0.13 & 0.38 \\
\hline \hline
\end{tabular}

Fonte: elaboração do autor

Figura 1.4: Ineficiência Média por UF

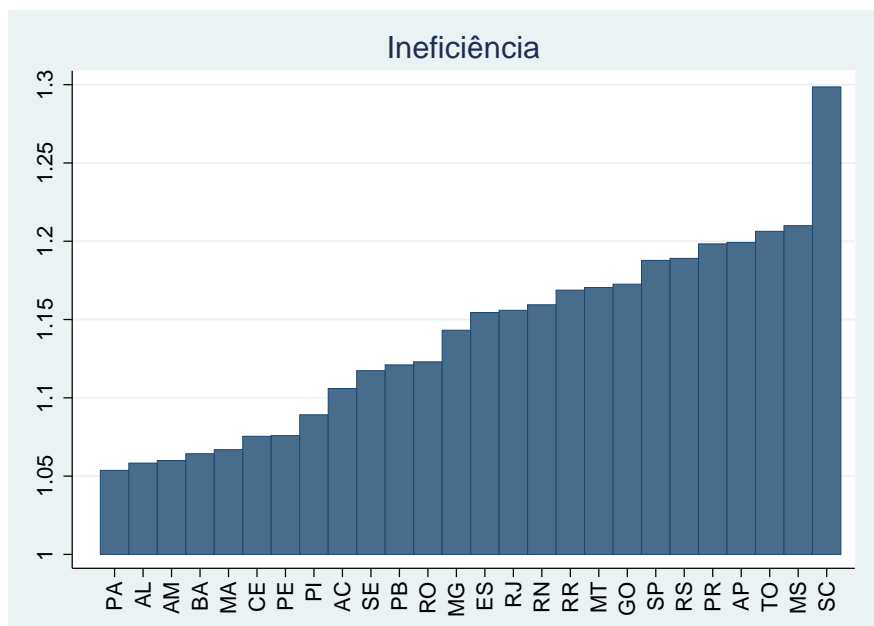

Fonte: elaboração do autor 


\subsection{Discussão}

O modelo construído para estimar uma função custo para o ensino fundamental municipal no Brasil permite comparar o impacto dos preços dos diversos insumos, do produto e das covariáveis no custo-aluno e discutir questões de eficiência. Com isto, alguns direcionamentos de políticas podem ser levantados, considerando os aspectos de custo, resultados e eficiência estudados.

Neste sentido, as elasticidades-preço mostram que o preço do custeio ordinário têm aproximadamente o dobro do impacto do preço do trabalho e que o preço do capital tem um efeito bastante inferior aos anteriores, considerando as proxies construídas para eles. Uma das políticas mais debatidas em educação atualmente refere-se à necessidade de valorização do salário dos professores, razão porque, desde 2009, vigora o piso salarial nacional dos professores. Segundo os nossos resultados, o acréscimo de 1\% nos salário dos professores e funcionários implicaria em um aumento de 0,16\% no custo-aluno.

Quando avaliamos a elasticidade-produto, observamos que, para alcançar 100\% dos alunos com a performance mínima, segundo a definição utilizada neste estudo, o custo teria que ser $163 \%$ superior. Tal relação nos parece bastante coerente e, combinada com outras ações, permite traçar uma trajetória de crescimento da performance do estudante brasileiro. Considerando que o Plano Nacional de Educação prevê uma trajetória de gasto que sairá de 6 para 10\% do PIB, concluímos que tal expansão deve ser combinada com redução das ineficiências e outras ações pois, senão, não alcançaremos o nível desejado de proficiência. Nesta linha, dada a presença de economias de escala, devemos buscar outras combinações de insumos cujo acréscimo de custo seria proporcionalmente inferior ao acréscimo decorrente no produto. Cumpre, então, discutir 
políticas que nos oriente neste sentido.

Consideremos então os resultados obtidos para as variáveis que estão sob a gestão educacional do município. Eles estão entre os que mais podem subsidiar políticas no sentido de alterar a relação entre custo e performance. Por exemplo, podemos afirmar que aumentar a carga-horária média diária de 4,3 horas para 7 horas implicaria em um aumento de 23\% no custo. Tal acréscimo de carga horária nos faria alcançar a chamada educação integral e todas as suas externalidades positivas para a performance dos alunos. Por outro lado, a elevação da média de alunos por turma de 20,5 (atual) para 30 provocaria uma redução significativa de 38\% no custo, por exemplo.

As elasticidades das variáveis do ambiente socioeconômico do município apresentaram resultados que indicam talvez maiores exigências de gastos nos municípios mais urbanos, com menos desigualdade de renda e com menos analfabetos. Infelizmente, isso não parece estar acompanhado de mais eficiência. Tais características também foram observadas ao avaliar os municípios mais ineficientes. A ineficiência média observada de $14,7 \%$ pode não parecer muito grande, mas concluímos que ela está presente principalmente nos municípios com melhores indicadores socioeconômicos. Estes apresentam melhores resultados educacionais porém com custo-aluno muito alto. Observemos, por exemplo, que os municípios da região Nordeste aparecem como menos ineficientes, indicando que parece haver uma relação inversa entre desenvolvimento socioeconômico e eficiência. Tal informação pode ser importante para focalização na alocação de novos recursos.

Desta forma, concluímos que, na estrutura atual, não parece ser possível alcançar a proficiência de todos os estudantes do ensino fundamental municipal brasileiro, mesmo com gastos da ordem de 10\% do PIB. Entre vários outros 
aspectos, é fundamental combinar políticas que trabalhem com metas para variáveis adequadas (carga-horária, alunos por turma, por exemplo) com possíveis focalizações (municípios com piores indicadores socioeconômicos) na alocação dos novos recursos e aprimorando a gestão nos mais ineficientes . Isso poderia conduzir a uma elevação significativa da proficiência média dos estudantes. Ratifica-se, por fim, o senso comum de que maiores níveis de gastos sem o respectivo endereçamento dos problemas de eficiência e de gestão das variáveis adequadas implicaria em desperdício óbvio de recursos públicos. 


\section{REFERÊNCIAS BIBLIOGRÁFICAS}

Afonso, A. and M. St Aubyn (2006). Cross-country efficiency of secondary education provision: A semi-parametric analysis with non-discretionary inputs. Economic modelling 23(3), 476-491.

Aigner, D., C. A. Lovell, and P. Schmidt (1977). Formulation and estimation of stochastic frontier production function models. Journal of econometrics 6(1), $21-37$.

Alves, E., G. d. S. Souza, E. G. Gomes, E. Magalhães, D. d. P. Rocha, et al. (2012). Um modelo de produção para a agricultura brasileira ea importância da pesquisa da embrapa. Revista de Política Agrícola 21(4), 35-59.

Badawi, I. E. (1983). Semi-Nonparametric Analysis of Consumer Demand Systems. Ph. D. thesis, North Carolina State University.

Barnett, W. A. (1983). New indices of money supply and the flexible laurent demand system. Journal of Business and Economic Statistics 1(1), 7-23.

Beccacece, F. (1994). On the flexible functional forms. Rivista di matematica per le scienze economiche e sociali 17(1), 11-18.

Blaug, M. (1992). The methodology of economics: Or, how economists explain. Cambridge University Press.

Bos, J. W., M. Koetter, J. W. Kolari, and C. J. Kool (2009). Effects of heterogeneity 
on bank efficiency scores. European Journal of Operational Research 195(1), 251-261.

Bradford, D. F., R. A. Malt, and W. E. Oates (1969). The rising cost of local public services: some evidence and reflections. National Tax Journal, 185-202.

Burnell, B. S. (1991). The effect of school district structure on education spending. Public Choice 69(3), 253-264.

Carvalho, L. D. B. d. (2012). Eficiência das escolas públicas urbanas das regiões nordeste e sudeste do brasil: uma abordagem em três estágios.

Chalfant, J. A. (1983). Choosing among flexible functional forms: an application of the generalized Box-Cox and the Fourier Flexible Forms to U.S. agriculture. Ph. D. thesis, North Carolina State University.

Chalfant, J. A. (1984). Comparison of alternative functional forms with application to agricultural input data. American Journal of Agricultural Economics 66(2), $216-220$.

Chalfant, J. A. and A. R. Gallant (1985). Estimating substitution elasticities with the fourier cost function: Some monte carlo results. Journal of Econometrics 28(2), 205-222.

Christensen, L. R., D. W. Jorgenson, and L. J. Lau (1973). Transcendental logarithmic production frontiers. Review of economics and statistics 55(1), 28-45.

Coelli, T. J., D. S. P. Rao, C. J. O’Donnell, and G. E. Battese (2005). An introduction to efficiency and productivity analysis. Springer.

Colegrave, A. D. and M. J. Giles (2008). School cost functions: A meta-regression analysis. Economics of Education Review 27(6), 688-696. 
Coleman, J. S., E. Q. Campbell, C. J. Hobson, J. McPartland, A. M. Mood, F. D. Weinfeld, and R. York (1966). Equality of educational opportunity. Washington, dc.

Conover, W. J. and W. Conover (1980). Practical nonparametric statistics.

Curi, A. Z. and A. P. Souza (2012). Medindo a qualidade das escolas: Evidências para o brasil. XL Encontro Nacional de Economia (Anpec). Salvador.

Davidson, R. and J. G. MacKinnon (1981). Several tests for model specification in the presence of alternative hypotheses. Econometrica: Journal of the Econometric Society, 781-793.

Duncombe, W., J. Miner, and J. Ruggiero (1995). Potential cost savings from school district consolidation: A case study of new york. Economics of Education Review 14(3), 265-284.

Duncombe, W. and J. Yinger (2005). How much more does a disadvantaged student cost? Economics of Education Review 24(5), 513-532.

Eastwood, B. J. and A. R. Gallant (1991). Adaptive rules for seminonparametric estimators that achieve asymptotic normality. Econometric Theory 7(03), 307340.

Edmunds, D. E. and V. B. Moscatelli (1977). Fourier approximation and embeddings of Sobolev spaces, Volume 145. Państwowe Wydawn. Naukove.

Elbadawi, I., A. R. Gallant, and G. Souza (1983). An elasticity can be estimated consistently without a priori knowledge of functional form. Econometrica: Journal of the Econometric Society, 1731-1751.

Figlio, D. N. (1999). Functional form and the estimated effects of school resources. Economics of Education Review 18(2), 241-252. 
Gallant, A. R. (1981). On the bias in flexible functional forms and an essentially unbiased form: the fourier flexible form. Journal of Econometrics 15(2), 211-245.

Gallant, A. R. (1982). Unbiased determination of production technologies. Journal of Econometrics 20(2), 285-323.

Golebiewski, J. A. The literature on education cost functions: An overview.

Grifiin, R. C. (1987). Selecting functional form in production function analysis. Western Journal of Agricultural Economics 12(2), 216-227.

Gronberg, T. J., D. W. Jansen, and L. L. Taylor (2012). The relative efficiency of charter schools: A cost frontier approach. Economics of Education Review 31(2), 302-317.

Guilkey, D. K., C. K. Lovell, and R. C. Sickles (1983). A comparison of the performance of three flexible functional forms. International Economic Review, 591-616.

Hanushek, E. A. (1979). Conceptual and empirical issues in the estimation of educational production functions. Journal of human Resources 14(3).

Hanushek, E. A. (1997). Assessing the effects of school resources on student performance: An update. Educational evaluation and policy analysis 19(2), 141-164.

Huang, T.-h. and M.-h. Wang (2004). Comparisons of economic inefficiency between output and input measures of technical inefficiency using the fourier flexible cost function. Journal of Productivity Analysis 22(1-2), 123-142.

Kumbhakar, S. C. and C. K. Lovell (2003). Stochastic frontier analysis. Cambridge University Press. 
Kumm, M. (1981). Comparison of the Generalized Box-Cox and Fourier Functional Forms for Analysis of Time-of-Use Electricity Pricing Experiments. Ph. D. thesis, Duke University.

Lau, L. J. (1974). Comments on Applications of Duality Theory, Chapter 3. Frontiers of Quantitative Economics. North-Holland Publishing Company.

Machado, A. F., S. Moro, L. Martins, and J. Rios (2008). Qualidade do ensino em matemática: determinantes do desempenho de alunos em escolas públicas estaduais mineiras. Revista da Anpec 9(1).

Machado, D. C. and G. Gonzaga (2007). O impacto dos fatores familiares sobre a defasagem idade-série de crianças no brasil. Revista Brasileira de Economia 61(4), 449-476.

Meeusen, W. and J. Van den Broeck (1977). Efficiency estimation from cobbdouglas production functions with composed error. International economic review, 435-444.

Menezes Filho, N. A., L. F. L. E. Amaral, et al. (2009). A relação entre gastos educacionais e desempenho escolar. Technical report, Insper Working Paper, Insper Instituto de Ensino e Pesquisa.

Mitchell, K. and N. M. Onvural (1996). Economies of scale and scope at large commercial banks: Evidence from the fourier flexible functional form. Journal of Money, Credit and Banking, 178-199.

Moreira, T. B. S., M. d. P. Pinto, and G. d. S. Souza (2004). Uma metodologia alternativa para mensuração de pressão sobre o mercado de câmbio. Estudos Econômicos 34(1), 73-100. 
Rocha, F., J. Duarte, et al. (2013). E possível atingir as metas para educação sem aumentar os gastos? uma análise para os municípios brasileiros. Technical report, Textos para Discussão, Secretaria do Tesouro Nacional/MF.

Rosano-Peña, C., P. H. M. Albuquerque, and C. J. Marcio (2012). A eficiência dos gastos públicos em educação: evidências georreferenciadas nos municípios goianos. Economia Aplicada 16(3), 421-443.

Simmons, P. and D. Weiserbs (1979). Translog flexible functional forms and associated demand systems. American Economic Review 69(5), 892-901.

Soares, S. and N. Sátyro (2008). O impacto de infra-estrutura escolar na taxa de distorção idade-série das escolas brasileiras de ensino fundamental: 1998 a 2005. Technical report, Texto para Discussão, Instituto de Pesquisa Econômica Aplicada (IPEA).

Stiefel, L., A. E. Schwartz, P. Iatarola, and C. C. Chellman (2009). Mission matters: The cost of small high schools revisited. Economics of Education Review 28(5), 585-599.

Tao, Hung-Lin e Yuan, M.-C. (2005). Optimal scale of a public elementary school with commuting costs:a case study of taipei county. Economics of Education Review 24(4), 407-416.

Thompson, O. (2011). The estimated cost impact of privatizing student transportation in minnesota school districts. Public Choice 146(3-4), 319-339.

Waltenberg, F. D. (2006). Teorias econômicas de oferta de educação: evolução. Educação e Pesquisa 32(1), 117-136.

White, H. (1980). Using least squares to approximate unknown regression functions. International Economic Review, 149-170. 
APÊNDICE A

ROTINA FORTRAN MULTI-ÍNDICES 


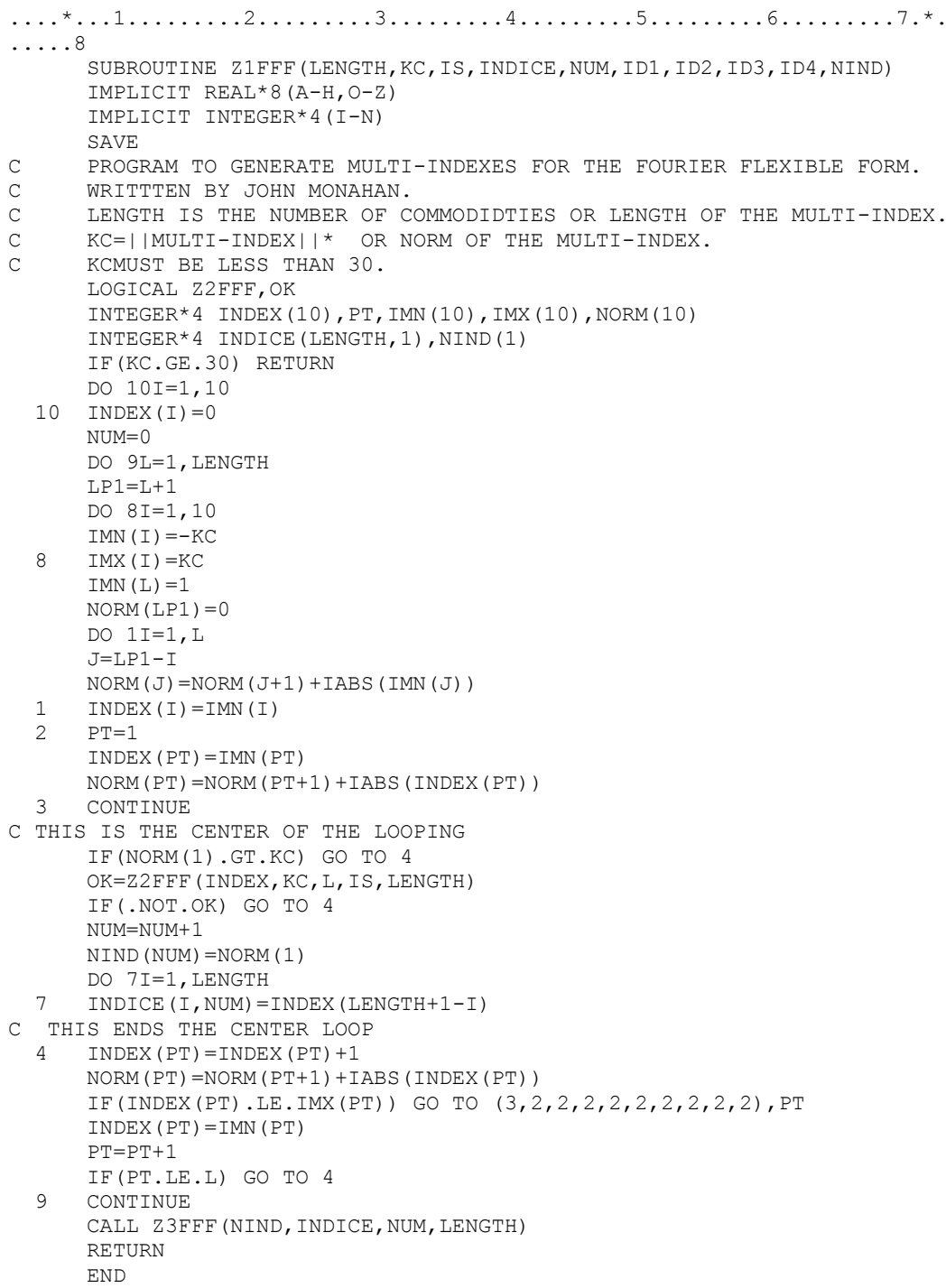




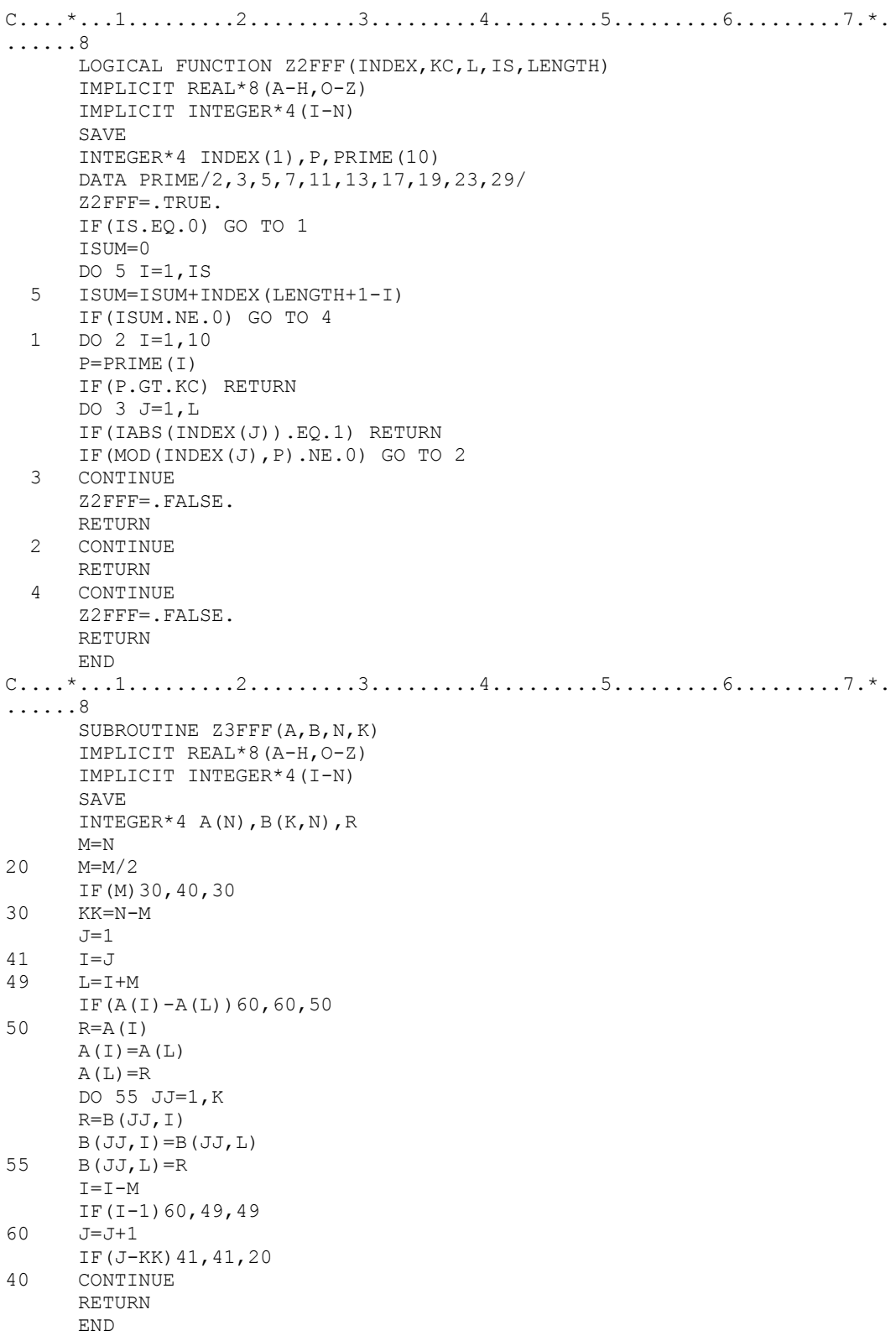




\section{APÊNDICE B}

\section{COEFICIENTES}

Tabela B.1: Núcleo Principal da Função

\begin{tabular}{c|c||c|c}
\hline \hline variável & Coeficiente & variável & Coeficiente \\
\hline 11 & -6.84 & esc-doc & $-0,0009$ \\
\hline 12 & $-2,65$ & ch & 0,29 \\
\hline 13 & 10,49 & gini & $-0,11$ \\
\hline v & 19,85 & tx-urb & 0,04 \\
\hline 11 sq & $-0,08$ & infra-casa & 0,20 \\
\hline 12 sq & $-0,001$ & part pais & $-0,04$ \\
\hline $13 s q$ & $-0,06$ & esc-pai & $-0,02$ \\
\hline vsq & $-0,26$ & esc-mae & $-0,01$ \\
\hline 1112 & $-0,002$ & tx-analf & $-0,03$ \\
\hline 1113 & 0,20 & constante & $-34,41$ \\
\hline 1213 & 0.004 & - & - \\
\hline $11 v$ & 2,89 & - & - \\
\hline $12 \mathrm{v}$ & 1,13 & - & - \\
\hline $13 \mathrm{v}$ & $-4,71$ & - & - \\
\hline v2 & 18,99 & - & - \\
\hline v3 & $-42,43$ & - & - \\
\hline v4 & 0,48 & - & - \\
\hline v5 & $-18,26$ & - & - \\
\hline v6 & $-3,39$ & - & - \\
\hline v7 & $-15,67$ & - & - \\
\hline v8 & 42,06 & - & - \\
\hline v9 & 2,47 & - & - \\
\hline v10 & $-19,78$ & - & - \\
\hline v12 & 1,82 & - & - \\
\hline v13 & $-69,71$ & - & - \\
\hline v14 & $-4,91$ & - & - \\
\hline v15 & 35,17 & - & - \\
\hline \hline
\end{tabular}

Fonte: elaboração do autor 
Tabela B.2: Coeficientes do Termo de Ineficiência

\begin{tabular}{|c|c|c|}
\hline Variável & Coeficiente & Erro-Padrão \\
\hline esc doc & 1,28 & 0,31 \\
\hline ch & 1,06 & 0,53 \\
\hline al turm & $-1,90$ & 0,28 \\
\hline gini & $-0,46$ & 0,49 \\
\hline tx urb & $-0,10$ & 0,17 \\
\hline infra casa & 0,35 & 0,26 \\
\hline part pais & $-0,04$ & 0,10 \\
\hline esc pai & $-0,006$ & 0,11 \\
\hline esc mae & 0,11 & 0,11 \\
\hline tx analf & $-0,15$ & 0,14 \\
\hline cons & $-8,92$ & 2,83 \\
\hline
\end{tabular}




\section{APÊNDICE C}

\section{FORMA FLEXÍVEL DE FOURIER}

Seja $c(p, u)$ a função custo que dá o custo mínimo de produzir o produto $u$ durante um dado período de tempo usando os insumos $q=\left(q_{1}, q_{2}, \ldots, q_{N}\right)^{\prime}$ aos preços $p=\left(p_{1}, p_{2}, \ldots, p_{N}\right)^{\prime}$. Por conveniência matemática assumiremos que a função custo tem derIvadas parciais de terceira ordem contínuas, no mínimo.

A teoria da firma implica em restrições sobre a forma funcional da função custo, entre as quais destacamos:

R0. Homogeneidade linear positiva: $c(p, u)$ é uma função positiva definida sobre o quadrante positivo e é homogênea de grau 1 em $p$, ou seja, $\lambda c(p, u)=c(\lambda p, u)$

R1. Retornos constantes de escala: $c(p, u)=u c(p, 1)=u c(p)$

R2. Tecnologia de Produção Homotética: $c(p, u)=b(u) c(p)$

Denotaremos o conjunto de funções custo que satisfazem R0 por M0, M02 contém aquelas que satisfazem R0 e R2 e assim por diante. Para simplificar a notação trabalharemos com o problema colocado em termos de logaritimos, assim:

$$
\begin{aligned}
l_{i} & =\ln p_{i}+\ln a_{i}, \quad i=1,2, \ldots, N \\
v & =\ln u+\ln a_{N+1}
\end{aligned}
$$


$\mathrm{e}$

$$
g(l, v)=\ln c\left(\frac{e^{l_{1}}}{a_{1}}, \frac{e^{l_{2}}}{a_{2}}, \ldots, \frac{e^{l_{N}}}{a_{N}}, \frac{e^{l_{N+1}}}{a_{N+1}}\right)
$$

onde $l=\left(l_{1}, l_{2}, \ldots, l_{N}\right)^{\prime}$ e os $\ln a_{i}$ são parâmetros de locação que serão determinados posteriormente.

Nesta notação, a abordagem descrita nas seções anteriores seria equivalente a aplicar uma expansão quadrática nos preços transformados:

$$
c(p, u)=f\left(b^{\prime} z+\frac{1}{2} z^{\prime} B z, u\right)
$$

onde

$$
z=\left(\mathcal{O}\left(p_{1}\right), \ldots, \mathcal{O}\left(p_{N}\right)\right)^{\prime}
$$

e algumas das transformações são as já citadas Translog $\left(\mathcal{O}\left(p_{i}\right)=\ln \left(p_{i}\right)\right)$, Leontief generalizada $\left(\mathcal{O}\left(p_{i}\right)=\sqrt{p_{i}}\right)$ e $\operatorname{Box}-\operatorname{Cox}\left(\mathcal{O}\left(p_{i}\right)=\left(p_{i}^{\lambda}-1\right) / \lambda\right)$.

O resultado dessa abordagem tem sido gerar uma coleção finita de funções custo que têm sido usadas:

$$
\mathcal{M}_{0}^{*}=\left\{g_{1}, g_{2}, \ldots, g_{L}\right\}
$$

Cada função custo de $\mathcal{M}_{0}^{*}$ tem performado bem em algum sentido em algumas aplicações. Contudo, se assumimos que, digamos, $g_{1} \mathrm{em} \mathcal{M}_{0}^{*}$ seja a função custo verdadeira, então todas as funções custo em $\mathcal{M}_{0}^{*}$ que não geram $g_{1}$ como um caso especial gerará inferências viesadas em algum sentido (Guilkey et al. (1983)), conforme vimos anteriormente. O problema é que encontrar $\mathcal{M}_{0}$ observando $s=(\partial / \partial l) g(l, v)$ é estatisticamente intratável pois $\mathcal{M}_{0}$ é uma classe de modelos muito extensa. $\mathrm{O}$ que se precisa então é reduzir $\mathcal{M}_{0}$ a um tamanho tratável.

Eis um método de reduzir $\mathcal{M}_{0}$ a uma classe tratável de modelos. Primeiro, determine quais erros de aproximação são importantes e quais podem ser negligenciados. Para isso é preciso definir uma norma $\|e\|$ que seja sensível aos erros de aproxima- 
ção importantes $e=g^{*}-g$. Segundo, encontre uma forma funcional $g_{k}(l, v \mid \theta)$ com um número variável $p_{k}$ de parâmetros $\theta=\left(\theta_{1}, \theta_{2}, \ldots, \theta_{p_{k}}\right)^{\prime}$ tal que $g_{k}$ pertença a $\mathcal{M}_{0}$ para todo $\theta \in \Theta \mathrm{e}$

$$
\lim _{K \rightarrow \infty} \min _{\Theta}\left\|g-g_{k}\right\|=0
$$

para todo $g \in \mathcal{M}_{0}$. Equivalentemente, isto corresponderia a encontrar um subconjunto denso de $\mathcal{M}_{0}$ indexado convenientemente:

$$
\mathcal{M}_{0}^{\prime}=\left\{g_{k}(l, v \mid \theta): \theta \in \Theta \subset R^{p_{k}} ; k=1,2, \ldots\right\} \subset \mathcal{M}_{0}
$$

Matematicamente, a menor classe $\mathcal{M}_{0}^{\prime}$ pode ser considerada equivalente a $\mathcal{M}_{0}$ já que seu fecho contém $\mathcal{M}_{0}$. Estatisticamente, o problema muda de encontrar uma $g \in \mathcal{M}_{0}$ para determinar um valor adequado de $k$, que é um problema estatístico muito mais tratável.

Serão suficientes as aproximações feitas sobre um retângulo do quadrante positivo. Consideremos que os llimites para este retângulo sejam:

$$
0<p_{i}^{L}<p_{i}^{H}<\infty, \quad i=1,2, \ldots, N
$$

e

$$
0<u^{L}<u^{H}<\infty
$$

Essas escolhas são arbitrárias, no entanto, todos os dados e os valores para os quais pretende-se fazer aproximações devem estar neste retângulo. Devemos escolher o os parâmetros de locação $a_{1}, a_{2}, \ldots, a_{N+1}$ da transformação:

$$
\begin{gathered}
l_{i}=\ln p_{i}+\ln a_{i} \quad i=1,2, \ldots, N \\
v=\ln u+\ln a_{N+1}
\end{gathered}
$$


tal que

$$
\begin{gathered}
l_{i}^{L}=\ln p_{i}+\ln a_{i} \quad i=1,2, \ldots, N \\
v^{L}=\ln u+\ln a_{N+1}
\end{gathered}
$$

Se $x=\left(l^{\prime}, v\right)^{\prime}$, então a região de aproximação é

$$
\aleph=\left\{x=\left(l^{\prime}, v\right)^{\prime}: l_{i}^{L}<l_{i}<l_{i}^{H}, v^{L}<v<v^{H}\right\}
$$

que é um retângulo aberto no quadrante positivo de $R^{N+1}$. O fecho $\bar{\aleph}$ é também um subconjunto próprio do quadrante positivo.

Agora definiremos uma medida de distância, a norma de Sobolev, que é sensível aos erros de aproximação relevantes (função e suas primeira e segunda derivadas) sobre $\aleph$. Antes definamos uma notação importante.

Um multi-índice é um vetor de ordem $N+1$ com componentes inteiros. O comprimento do multi-índice é definido como

$$
|k|^{*}=\sum_{i=1}^{N+1}\left|k_{i}\right|
$$

Seja $\lambda$ um multi-índice com componentes não negativos, a derivada parcial de uma função $g(x)$ é denotada por:

$$
D^{\lambda} g(x)=\frac{\partial^{|\lambda|^{*}}}{\partial x_{1}^{\lambda_{1}} \partial x_{2}^{\lambda_{2}} \ldots \partial x_{N+1}^{\lambda_{N+1}}} g(x)
$$

Assumimos que a função $D^{\lambda} g(x)$ é uma função contínua de $x$ quando esta notação é usada. Seja $\mu(x)$ uma função de distribuição contínua que dá a frequência com que os valores da variável independente $x_{t}$ ocorre à medida que o tamanho amostral $N$ tende ao infinito. Usamos esta notação para definir a norma de Sobolev.Com $1 \leq p<\infty$ a norma de Sobolev de uma função $g(x)$ com respeito à distribuição de probabilidade $\mu$ é: 


$$
\|g\|_{m, p, \mu}=\left(\sum_{|\lambda|^{*} \leq m} \int_{\aleph}\left|D^{\lambda} g(x)\right|^{p} d \mu(x)\right)^{1 / p}
$$

Denotamos por $W^{m, p}(\aleph)$ o espaço linear normado de funções complexas $g(x)$ com norma de Sobolev finita de ordem $m$ e do tipo $p$.

$$
W^{m, p}(\aleph)=\left\{g(x):\|g\|_{m, p, \mu}<\infty\right\}
$$

Vemos da definição que a norma de Sobolev é noção de distância que queremos, já que aproxima as derivadas. Agora discutiremos como construir subconjuntos densos de $\mathcal{M}_{0}$ com respeito a essa norma. A construção é com base em uma modificação de um resultado devido a Edmunds and Moscatelli (1977).

A construção de $\mathcal{M}_{0}^{\prime}$ é baseada em uma sequencia de multi-índices elementares:

$$
\mathcal{K}_{N+1}^{\prime}=\left\{k_{\alpha}: \alpha=1,2, \ldots A\right\},
$$

que passamos a construir. Dado

$$
\mathcal{K}_{N+1}=\left\{k:|k|^{*} \leq K\right\}
$$

primeiro delete dele o vetor nulo e todos aqueles com primeiro elemento não-nulo negativo. Segundo, delete todos aqueles que cujos elementos têm um divisor inteiro comum. Terceiro, arranje os $k$ que permanecem na sequência

$$
\mathcal{K}_{N+1}^{\prime}=\left\{k_{\alpha}: \alpha=1,2, \ldots A\right\}
$$

de forma que $k_{1}, k_{2}, \ldots, k_{N+1}$ são os vetores elementares e $\left|k_{\alpha}\right|^{*}$ seja não-decrescente 
em $\alpha$. Defina $J$ como sendo menor inteiro positivo tal que

$$
\mathcal{K}_{N+1}^{\prime} \subset\left\{j k_{\alpha}: \alpha=1,2, \ldots, A ; j=0, \pm 1, \pm 2, \ldots, \pm J\right\}
$$

A FFF pode ser utilizada para gerar subconjuntos densos de um espaço de Sobolev, confome apresentado por Gallant (1981). Considere uma função que toma valores reais $g \in W^{m, p}(\aleph)$, onde

$$
g_{k}(x \mid \theta)=a_{0}+b^{\prime} x+\frac{1}{2} x^{\prime} C x+\sum_{\alpha=1}^{A} \sum_{j=-J}^{J} a_{j \alpha} e^{i j \lambda k_{\alpha}^{\prime} x}
$$

onde

$$
a_{j \alpha}=\bar{a}_{-j \alpha}, \quad C=-\sum_{\alpha=1}^{A} a_{0 \alpha} \lambda^{2} k_{\alpha} k_{\alpha}^{\prime}
$$

e $a_{0}, a_{0 \alpha}$, e $b$ são números reais. A barra denota a conjugação complexa e $i=\sqrt{-1}$. O fator de escala $\lambda$ é calculado como:

$$
\lambda=\frac{2 \pi-\epsilon}{\max \left\{x_{i}^{H}: i=1,2, \ldots, N+1\right\}},
$$

para algum $\epsilon \operatorname{com} 0<\epsilon<2 \pi, x_{i}^{H}$ denota $l_{i}^{H}$ para $i \leq N$ e $v_{i}^{H}$ para $i=N+1$. Uma escolha razoável é $2 \pi-\epsilon=6$.

O fator $\lambda$ faz com que $\lambda \aleph=\{\lambda x: x \in \aleph\}$ seja um retângulo com lado não superior a $2 \pi$. Este é um ponto crucial da construção. A locação de $\aleph$ no quadrante positivo através da escolha de $a_{i}$ é apenas para conveniência das aplicações. O que é essencial é que $\lambda \aleph$ não tenha nenhum lado superior a $2 \pi$.

Embora as representações exponenciais complexas sejam mais convenientes na discussão, nas aplicações, as representações em termos de senos e cossenos são 
mais fáceis de trabalhar. Escrevendo:

$$
\begin{aligned}
a_{0 \alpha} & =u_{0 \alpha}, \quad \alpha=1,2, \ldots, A \\
a_{j \alpha} & =u_{j \alpha}+i v_{j \alpha}, \quad \alpha=1,2, \ldots, A \quad j=1,2, \ldots, J \\
a_{-j \alpha} & =u_{j \alpha}-i v_{j \alpha}, \quad \alpha=1,2, \ldots, A \quad j=1,2, \ldots, J
\end{aligned}
$$

e usando

$$
e^{i j \lambda k_{\alpha}^{\prime} x}=\cos \left(j \lambda k_{\alpha}^{\prime} x\right)+i \sin \left(j \lambda k_{\alpha}^{\prime} x\right)
$$

temos que:

$$
g_{k}(x \mid \theta)=u_{0}+b^{\prime} x+\frac{1}{2} x^{\prime} C x+\sum_{\alpha=1}^{A}\left\{u_{0 \alpha}+2 \sum_{j=1}^{J}\left[u_{j \alpha} \cos \left(j \lambda k_{\alpha}^{\prime} x\right)-v_{j \alpha} \sin \left(j \lambda k_{\alpha}^{\prime} x\right)\right]\right\}
$$

Se $\theta_{(0)}=b=\left(c^{\prime}, b_{N+1}\right)^{\prime}$ e $\theta_{(\alpha)}=\left(u_{0 \alpha}, u_{1 \alpha}, v_{1 \alpha}, \ldots, u_{J \alpha}, v_{J \alpha}\right)^{\prime}$, então os parâmetros de $g_{k}(x \mid \theta)$ são $\theta=\left(u_{0}, \theta_{(0)}^{\prime}, \theta_{(1)}^{\prime}, \ldots, \theta_{(A)}^{\prime}\right)^{\prime}$.

Uma verificação de que a FFF pode ser usada para construir um subconjunto denso de $\mathcal{M}_{0}$ decorre do seguinte resultado:

Theorem C.0.1 Edmunds and Moscatelli (1977, corolário1) Seja g(x) uma função real continuamente diferenciável, no mínimo em uma ordem $m$, em um conjunto aberto que contém o fecho de $\aleph$. Então é possível escolher um vetor de coeficientes $\bar{\theta}_{1}, \bar{\theta}_{2}, \ldots, \bar{\theta}_{k}, \ldots$ tal que para todo $p$ com $1 \leq p \leq \infty$, todo $l$ com $0 \leq l<m$ e todo $\epsilon>0$,

$$
\left\|g-g_{k}\left(\bar{\theta}_{k}\right)\right\|_{l, p, \mu}=o\left(k^{-m+l+\epsilon}\right) \quad \text { quando } \quad k \rightarrow \infty
$$

A construção de $\mathcal{M}_{0}^{\prime}$ é dada pelo seguinte teorema. Ele estabelece que uma função custo que satisfaz $R 0$ pode ser aproximada por uma FFF com todos os termos com $\sum_{i=1}^{N} k_{i \alpha} \neq 0$ deletados e a restrição $\sum_{i=1}^{N} b_{i}=1$ imposta.

Theorem C.0.2 Seja $g(x)$ uma função real continuamente diferenciável, no mínimo em 
uma ordem m, em um conjunto aberto que contém o fecho de ` e que satisfaz R0. Seja

$$
g_{k}(l, v \mid \theta)=a_{0}+b^{\prime} x+\frac{1}{2} x^{\prime} C x+\sum_{\alpha=1}^{A} \sum_{j=-J}^{J} a_{j \alpha} e^{i j \lambda k_{\alpha}^{\prime} x}
$$

onde $x=\left(l^{\prime}, v\right)^{\prime}$ está sujeito às seguintes restrições paramétricas:

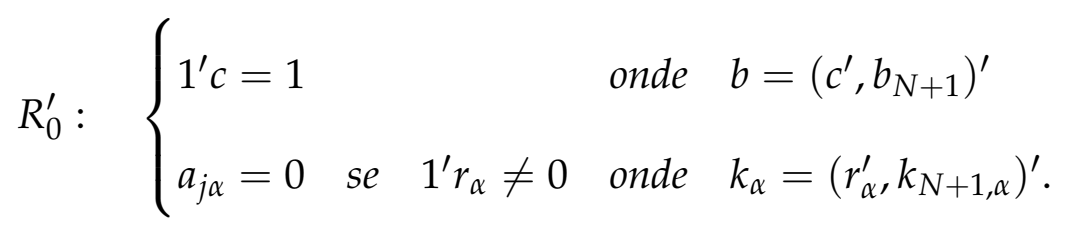

Então $g_{k}(l, v \mid \theta)$ satisfaz $R_{0}$ e é possível escolher um vetor de coeficientes $\bar{\theta}_{1}, \bar{\theta}_{2}, \ldots, \bar{\theta}_{k}, \ldots$ tal que para todo $p$ com $1 \leq p \leq \infty$, todo $l$ com $0 \leq l<m$ e todo $\epsilon>0$,

$$
\left\|g-g_{k}\left(\bar{\theta}_{k}\right)\right\|_{l, p, \mu}=o\left(k^{-m+l+\epsilon}\right) \quad \text { quando } \quad k \rightarrow \infty
$$

Observe que $a_{j \alpha}=\bar{a}_{-j \alpha}$ e que $C=-\sum_{\alpha=1}^{A} a_{0 \alpha} \lambda^{2} k_{\alpha} k_{\alpha}^{\prime}$, e que $a_{0}, a_{0 \alpha}$ e b são valores reais. 
CAPÍTULO 2

GASTO PÚBLICO E ORGANIZAÇÃO LEGISLATIVA: EVIDÊNCIAS DA LEI 1/N PARA O BRASIL 
2 Gasto Público e Organização Legislativa: Evidências da Lei 1/n para o Brasil $\quad 81$

2.1 Introdução . . . . . . . . . . . . . . . . . . . . . 84

2.2 Modelo . . . . . . . . . . . . . . . . . . . . . . . 88

2.3 Estratégia Empírica . . . . . . . . . . . . . . . . . . . 91

2.4 Dados . . . . . . . . . . . . . . . . . . . . . 94

2.5 Resultados . . . . . . . . . . . . . . . . . . . . 96

2.6 Discussão . . . . . . . . . . . . . . . . . . 102

\begin{tabular}{|ll}
\hline A Regra $\mathrm{N}^{0}$ de Vereadores & 108
\end{tabular}

\begin{tabular}{ll}
\hline B Estatística Descritiva & 109
\end{tabular}

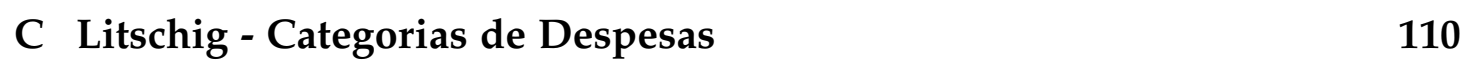

\begin{tabular}{ll}
\hline D Metodologia Litschig & 112
\end{tabular} 
LISTA DE TABELAS

2.1 Estatística Descritiva . . . . . . . . . . . . . . . . . . . 94

2.2 Impacto do Tamanho do Legislativo - Sem covariáveis* . . . . . 96

2.3 Impacto do Tamanho do Legislativo - Com covariáveis* . . . . . 97

$2.4 \quad$ Impacto do Tamanho do Legislativo - Despesa Total . . . . . . . 98

2.5 Receitas Próprias / Receita Total (\%) . . . . . . . . . . . . . . . 99

2.6 Impacto do Tamanho do Legislativo - Despesa Total ${ }^{*}$. . . . . . 100

2.7 Votos Eleição (\%) . . . . . . . . . . . . . . . . . . . . . . . . 101

2.8 Impacto do Tamanho do Legislativo - Despesa Total ${ }^{*}$. . . . . . 101

A.1 População $\times \mathbf{N}^{\mathbf{0}}$ de Vereadores . . . . . . . . . . . . . . . 108

B.1 Estatística Descritiva - Funções da Despesa (em milhares) . . . 109

C.1 Impacto do Tamanho do Legislativo - Categorias de Despesa* ${ }^{*} 111$ 


\subsection{Introdução}

Um dos temas centrais da Nova Economia Política é o desenvolvimento de implicações teóricas e empíricas de arranjos institucionais alternativos para as escolhas políticas (Besley (2007)). Entre outros aspectos, busca-se avaliar como uma instituição influencia atores econômicos e políticos e quais são os efeitos sobre a performance econômica subjacente. Conforme apresentado em Persson and Tabellini (2005), uma literatura de estudos teóricos e empíricos desenvolveuse buscando comparar instituições e indicadores econômicos regionalmente distintos. O presente trabalho insere-se nesta literatura ao tentar avaliar o efeito do tamanho das casas legislativas sobre o gasto per capita dos municípios brasileiros, avaliando o impacto das políticas distributivas.

Segundo Baqir (2002), uma das questões centrais da literatura relacionada à economia política dos gastos governamentais é o papel proeminente das políticas distributivas. Em especial, as políticas que produzem benefícios concentrados em um grupo particular de pessoas e custos que são distribuídos por toda a população. Utilizaremos a expressão common-pool problem ou Lei 1/n, presentes na literatura, para nos referir a tal fenômeno.

O fenômeno da descentralização da administração pública ocorrido a partir da Constituição de 1988 reforça a importância do estudo em tela para o Brasil. Segundo Magalhães (2007), de 1984 a 2000 foram instalados 1.405 municípios no país, sendo as regiões Sul e Nordeste as que mais contribuíram em termos absolutos para esta expansão. Como a imensa maioria dos novos municípios criados possuía população abaixo de 20 mil habitantes e os municípios divididos permaneciam na mesma faixa de definição do tamanho das casas legislativas, observamos portanto uma expansão do número de vereadores no Brasil durante 
esse período.

No caso brasileiro, um dos principais instrumentos que evidenciam o commonpool problem são as emendas orçamentárias. Segundo Santana (2011), as emendas parlamentares, por características inerentes ao seu processo de inserção no orçamento, são consideradas o recurso público mais territorializado. É justamente essa característica das emendas individuais ao orçamento que faz com que esse recurso seja considerado como do tipo pork barrel - cuja característica central é segmentar os benefícios difundido os custos pela sociedade. Samuels (2002) destaca a importância das emendas no caso do Brasil, não pelos motivos clientelistas normalmente ressaltados pela literatura, e sim por representarem um mecanismo de obter recursos de financiamento de campanha. A importância política e ecconômica das emendas orçamentárias, destacadas também por Pereira and Mueller (2002) e Alston and Mueller (2006), por exemplo, justificam também o presente estudo.

A literatura que trata do chamado common-pool problem é ampla e tem como artigo seminal Weingast et al. (1981). O resultado principal indica que a escala de projetos públicos cresce à medida que o governo é mais subdividido. A ideia é que os legisladores se beneficiam completamente do gasto público realizado em seus distritos enquanto internalizam só uma fração dos custos tributários. Um tema comum nesta literatura é que instituições que centralizam o poder de decisão estão associadas a menores déficits fiscais. A abordagem geral examina como índices construídos da fragmentação do processo orçamentário afetam os resultados fiscais.

Neste sentido, muitos trabalhos utilizam a organização do legislativo e, em especial, o seu tamanho, como uma proxy para a subdivisão do país, estado ou município em distritos. DelRossi and Inman (1999) estimou uma relação nega- 
tiva entre a demanda por projetos locais de saneamento nos Estados Unidos e o custo tributário local. Primo and Snyder Jr (2005) argumenta que a função payoff assumida para os legisladores na literatura está incorreta, no mínimo para os bens públicos puros. Ao usar uma forma funcional mais geral, eles mostram uma fragilidade da"Lei 1/n". Utilizando uma amostra de 38 países, Bradbury and Crain (2001) encontrou evidência da relação em questão, com efeitos menores para os que apresentam bicameralismo quando comparados àqueles cujo legislativo é formado por apenas uma casa. Com dados para as cidades americanas, Baqir (2002) confirma que, quanto mais distritos apresenta uma cidade, maior é a sua atividade governamental. Obtem que, ao contrário de resultados anteriores, sistemas eleitorais majoritários não quebram essa relação. E, por fim, corrobora resultados anteriores que não evidenciam a "Lei 1/n"nas cidades que concentram poderes no Executivo local. Pettersson-Lidbom (2008) aborda a questão dos possíveis problemas de endogeneidade ao se relacionar o tamanho do legislativo e os gastos governamentais. Aplica, neste sentido, técnicas de regressão descontínua para estimar tal relação considerando dados de cidades suecas e finlandesas. Obtém relação negativa entre o tamanho do legislativo e o tamanho do governo. Schaltegger and Feld (2004) investiga duas variantes do grau de fragmentação do governo com base em um painel de 26 estados suíços: o tamanho do ministério do governo e o tamanho de coalizões. Os resultados indicam que o número de ministérios é negativamente associado com a disciplina fiscal e os referendos fiscais não restringem efetivamente o common-pool problem. Ao contrário, Egger and Koethenbuerger (2010) apresenta evidência de um efeito positivo entre o tamanho dos conselhos municipais e os gastos governamentais utilizando dados de 2056 municípios do estado alemão da Bavaria, considerando um período de 21 anos. Caracteriza o resultado como robusto, já que considera vários aspectos da técnica de regressão 
descontínua.

Destaca-se o trabalho de Persson, Roland and Tabelllini $(1997,1998,2000)$ para avaliar conjuntamente o common-pool problem. Eles desenvolveram um significativo estudo na linha relacionar instituições políticas e resultados fiscais. Seu trabalho mostra que gastos excessivos são mais comuns em sistemas parlamentaristas. Isto porque os membros da coalizão do governo seriam mais propensos a ter poder de veto sobre a legislação orçamentária. Do mesmo modo, espera-se que, em sistemas presidencialistas, observe-se gastos menores já que contam com uma maior separação de poderes e um poder executivo mais independente.

Na sequência do trabalho, apresenta-se o modelo teórico subjacente que contrasta o resultado decorrente de uma tributação lump-sum teórica com a utilização de uma tributação que divide o custo do bem público igualmente por todos os indivíduos. Os problemas de endogeneidades usuais neste tipo de estudo bem como a proposta de se utilizar a Regressão Descontínua são apresentadas na seção "Estratégia Empírica". As estatísticas dos dados relativos à composição das câmaras de vereadores dos municípios brasileiros, bem como sua população, despesas e variáveis socio-econômicas são descritas na sequência. Os resultados que apresentam indícios da veracidade da Lei $1 / \mathrm{n}$ no caso brasileiro estão na última seção. Assim como a ausência de robustez advinda de resultados não significativos ao variar itens da metodologia como bandwidths e polinômios. Por fim, discute-se alguns aspectos institucionais presentes no caso brasileiro que podem explicar a falta de robustez dos resultados. 


\subsection{Modelo}

Esta seção, extraída de Persson and Tabellini (2002), apresenta o modelo básico do presente estudo. Considere uma sociedade com J grupos distintos de indivíduos idênticos. Cada grupo $J$ tem tamanho $N^{J}$, de modo que $\sum_{J} N^{J}=N$, onde $N$ é o tamanho da população. Os indivíduos do grupo $J$ têm preferências quasilineares:

$$
w^{J}=c^{J}+H\left(g^{J}\right)
$$

onde $c^{J}$ denota o consumo de bens privados (que é o mesmo para todos os membros do grupo) e $g^{J}$ é a oferta per capita do bem público. A função côncava e crescente $H$, com $H(0)=0$, é definida sobre um bem que beneficia apenas o grupo $J$ e que deve ser ofertado em igual quantidade per capita. A renda individual é igual em todos os grupos: $y_{J}=y$. Uma unidade de renda (consumo privado) pode ser convertida sem custo em uma unidade de qualquer um dos $\mathrm{J}$ bens provisionados publicamente. Tais grupos podem ser definidos por suas preferências, ocupação, idade, atributos pessoais ou localização geográfica.

Como benchmark normativo, considere o ótimo utilitarista, obtido maximizando a função de bem-estar Benthamita:

$$
\sum_{J} \frac{N^{J}}{N} w^{J}
$$

sujeita à restrição orçamentária

$$
\sum_{J} N^{J}\left(g^{J}+c^{J}\right)=N y
$$

A alocação resultante é relativamente óbvia, seria aquela em que o vetor $g \equiv\left(g^{J}\right)$ 
faz com que o benefício marginal em cada grupo seria igual ao custo social marginal unitário.

$$
H_{g}\left(g^{*}\right)-1=0
$$

Para referência futura, denotaremos o gasto agregado associado a essa alocação como

$$
G^{*}=N g^{*}
$$

Esta alocação poderia ser facilmente implementada se tributos lump sum específicos por grupo, $\tau^{J}$, financiassem cada um dos bens públicos daquele grupo, de modo que:

$$
c^{J}=y-\tau^{J}=y-g^{J} .
$$

Se essa completa descentralização de gasto e financiamento fosse possível, este seria o arranjo institucional ótimo. Os incentivos daqueles que elaboram as políticas não seriam distorcidos e a política ótima socialmente emergiria como um equilíbrio. No mundo real, contudo, é muito difícil desenhar um sistema tributário onde aqueles que financiam o bem público de um grupo específico coincide com o beneficiário do mesmo bem público.

Neste contexto, podemos explorar os incentivos que surgem quando o financiamento é centralizado e como diferentes instituições políticas mudam esses incentivos e as alocações resultantes. Assumiremos a hipótese simplficadora que todos os bens públicos são financiados por uma fonte comum de receitas tributárias, com contribuições iguais de cada grupo.

Com esta estrutura, indivíduos têm incentivos distorcivos, e há um desacordo evidente na política, já que os grupos compartilham o custo de financiar o bem público. Assim, beneficiários de um bem público particular tenderiam 
a gastar excessivamente com este bem já que seu custo seria compartilhado com todos. De outro lado, todo grupo deseja reduzir o gasto com os bens públicos dos quais não se beneficiam, já que eles não internalizam nenhum benefício e compartilham o custo de sua provisão. É exatamente o contexto do Common-Pool Problem.

\subsubsection{Common-Pool Problem}

Para ilustrar os problemas de incentivos que surgem do financiamento centralizado, apresentamos um procedimento de decisão simples. Cada grupo decide livremente sobre a oferta de cada bem público e o tributo é definido residualmente, A utilidade do indivíduo do grupo J pode ser escrita como:

$$
W^{J}(g)=y-\tau+H\left(g^{J}\right)=y-\sum_{I} g^{I} \frac{N^{I}}{N}+H\left(g^{J}\right)
$$

Um equilíbrio é um vetor $g^{D}$ tal que cada grupo J maximixa $W^{J}(g)$ com respeito a $g^{J}$, considerando os gastos de equilíbrio de todos os outros grupos como dados. É direto verificar que os gastos de equilíbrios satisfazem:

$$
H_{g}\left(g^{J, D}\right)-1=\frac{N^{J}}{N}-1
$$

Como o lado direito de (2.8) é negativo, todos os grupos apresentam gastos excessivos quando comparados ao ótimo social definido por (2.4): $g^{J, D}>G^{*}$ para todo J. Evidenciando assim o "common-pool problem": cada grupo internaliza completamente o benefício de seu próprio bem público, mas internaliza apenas a fração $\frac{N^{J}}{N}$ do custo marginal social de altos tributos. O problema aqui está no procedimento de escolha coletiva, no qual a tributação é residualmente determinada já que todas as decisões de gasto são feitas de forma 
descentralizada.

Este problema surge em muitas situações. Por exemplo, decisões de gastos podem estar descentralizadas em governos locais, agências governamentais ou empresas públicas, enquanto o financiamento continua centralizado. Além disso, o problema do incentivo não desaparece mesmo sobre decisões centralizadas do gasto se cada grupo ainda busca influenciar o governo central a satisfazer seus interesses. As instituições políticas e orçamentárias são portanto decisivas, conforme já ressaltamos anteriormente.

\subsection{Estratégia Empírica}

Estudos empíricos diversos que buscam avaliar o impacto do tamanho do legislativo sobre as despesas governamentais não endereçam a questão de possíveis endogeneidades nas equações estimadas. Conforme destacado por Egger and Koethenbuerger (2010), o principal problema é que o tamanho do legislativo pode estar correlacionado com outras varáveis omitidas que determinam o gasto do governo. Por exemplo, o tamanho do conselho pode refletir a preferência dos eleitores por uma maior rede de representação no legislativo. Ao mesmo tempo, os eleitores podem querer ver maiores níveis de gastos públicos 1 . Segundo Pettersson-Lidbom (2008), a causalidade reversa é também uma preocupação já que o tamanho do governo pode pode influenciar o tamanho do legislativo, na medida em que um setor público maior pode requerer um número maior de legisladores dada a maior complexidade do orçamento. No Brasil, como em outros países, o tamanho dos conselhos municipais é função do tamanho populacional, conforme tabela A. Portanto, despesas maiores observadas em

\footnotetext{
${ }^{1}$ Ver Acemoglu (2005) para uma discussão geral de problemas de endogeneidade em análises empíricas de economia política
} 
cidades com maiores conselhos podem refletir uma maior demanda de serviços públicos decorrentes do tamanho da população. Uma maior concentração populacional aumentaria o gasto per capita devido, por exemplo, ao crescente crowding no consumo de serviços públicos.

Na nossa análise empírica, assim como em Pettersson-Lidbom (2008) e Egger and Koethenbuerger (2010), endereçamos tais questões utilizando a técnica quasi-experimental denominada regressão descontínua (Regression-Discontinuity Design - RDD). Com a relação descontínua entre população e tamanho das camâras de vereadores presente nos municípios brasileiros, a aplicação de um RDD no desenho sharp mostra-se adequada.

Como sabemos, tal técnica tenta construir um experimento natural onde indivíduos são associados a grupos de tratamento e controle de forma aleatória e seus resultados são comparados. Temos que assumir que há uma relação contínua entre os determinantes do resultado de interesse e uma dada variável que chamaremos de $Z$ e uma relação descontínua entre a participação no tratamento e Z. Com esta hipótese, qualquer descontinuidade que ocorra na função que relaciona $Y$ a $Z$ pode ser atribuída ao salto que ocorre na participação do tratamento em determinado valor de $Z$ e o tamanho deste salto pode ser interpretado como o efeito médio local do tratamento.

Uma forma direta de estimar o efeito médio do tratamento seria usar um modelo de regressão que combina os modelos em ambos os lados do ponto de corte:

$$
Y_{i}=\alpha_{l}+\tau T_{i}+\beta_{l} \cdot\left(Z_{i}-c\right)+\gamma T_{i} \cdot\left(Z_{i}-c\right)+\epsilon_{i}, \quad \text { se } c-h \leq Z<c+h
$$

Dado uma vizinhança h, é fácil estimar o modelo de regressão representado 
pela equação (2.9). Mas para estimar esta regressão, precisamos escolher o h. Se escolhermos um h muito grande, iremos usar um número maior de observações na estimação, o que aumenta a precisão das estimativas. No entanto, quanto maior o $\mathrm{h}$, maior a chance da especificação linear não ser a correta para estimar a relação entre $\mathrm{Y}$ e $\mathrm{Z}$ estarmos considerando indivíduos com características muitos distintas e desta forma podemos aumentar o viés do efeito médio do tratamento. Estes dois pontos importantes da estratégia empírica, a definição do polinômio de aproximação e do tamanho do intervalo em torno do ponto de corte ("bandwith"), foram bem explorados na seção de robustez.

O nosso resultado principal utiliza o comando "rd"do pacote estatístico Stata. A nossa variável $Y_{i}$ é a despesa per capita do município $i$ em um dado ano e a variável $Z_{i}$ é a variável que expressa a distância em relação ao limiar de definição da regra populacional. Portanto, se $N_{i}$ representa a população do município $i$, então $\tilde{N}_{i} \equiv N_{i} / N_{d}$ expressa a sua distância ao limiar. Conforme vimos na tabela A, a regra de definição do número de vagas possui vários limiares, exigindo assim que associemos cada município a um limiar específico para podermos calcular $\tilde{N}_{i}$. Separamos os limiares através do ponto médio dos seus respectivos intervalos. Utilizamos apenas os três primeiros limiares da tabela A, o que faz com mais de $92 \%$ dos municípios brasileiros estejam presentes na base de dados utilizada.

Para reforçar a viabilidade de aplicação desta metodologia aos dados em tela, realizamos ainda o teste de McCrary (2008), que avalia manipulações na variável de alocação de tratamento. Segundo Monasterio (2013), o objetivo do autor é fornecer um teste para verificar se os objetos dos experimentos, por conhecerem quais são os critérios de alocação entre controle e tratamento, se esforçaram para ficar aquém ou além do ponto de descontinuidade. O procedimento proposto por McCrary (2008) testa a hipótese nula de continuidade da densidade da 
variável de alocação contra a hipótese de quebra no ponto de corte. Encontramos um p-valor de $36,12 \% 2^{2}$, indicando assim que não podemos rejeitar a hipótese nula de continuidade da variável de alocação, que, no nosso caso, é a população. Assim, a ausência de indícios de manipulação da variável reforça a adequação da aplicação de um RDD no presente contexto.

\subsection{Dados}

Os dados da tabela 2.1, a seguir, têm como referência principal os anos de 2004 e 2008. Tais períodos foram escolhidos pois permitem a definição clara da regra populacional que estabelece o número de vereadores em cada município do Brasil.

Tabela 2.1: Estatística Descritiva

\begin{tabular}{c|c|c|c|c|c|c|c}
\hline \hline variável & mínimo & $1^{\mathrm{O}}$ quartil & média & mediana & $3^{\circ}$ quartil & máximo & desv. pad. \\
\hline população & 804 & 5.052 & 18.202 & 10.371 & 20.735 & 164.803 & 22.782 \\
\hline desp. p capita & 159 & 832 & 1.310 & 1.140 & 1.563 & 10.045 & 736 \\
\hline esc. média & 0,81 & 3,01 & 3,99 & 4,05 & 4,86 & 8,74 & 1,21 \\
\hline coef. de Gini & 0,29 & 0,50 & 0,55 & 0,55 & 0,59 & 0,87 & 0,06 \\
\hline IDH & 0,46 & 0,47 & 0,69 & 0,71 & 0,76 & 0,91 & 0,08 \\
\hline mort. infantil & 5,37 & 18,54 & 33,99 & 29,34 & 46,05 & 109,66 & 18,50 \\
\hline renda p capita & 42,81 & 170,09 & 331,79 & 304,34 & 455,66 & $3.468,20$ & 189,91 \\
\hline taxa urb. & 0,00 & 0,40 & 0,58 & 0,59 & 0,77 & 100,00 & 0,22 \\
\hline taxa analf. & 0,80 & 11,00 & 20,88 & 17,40 & 30,70 & 62,60 & 12,10 \\
\hline pobreza & 0,49 & 8,38 & 24,83 & 20,06 & 40,54 & 81,65 & 18,08 \\
\hline situação & 0 & 0 & 0,5 & 0,5 & 1 & 1 & 0,5 \\
\hline \hline
\end{tabular}

A primeira Constituição a citar a questão do número de vereadores foi a de 1967 que estabelecia um máximo de 21 e previa a proporcionalidade com a população do Município. Em 1982, estabeleceu-se que nos municípios com mais de 1 milhão de habitantes a câmara de vereadores possuiria 33 cadeiras.

\footnotetext{
${ }^{2}$ Utilizamos o comando DCdensity do pacote rdd do software estatístico R.
} 
A Constituição de 1988 define 3 limiares e mantém o conceito de proporcionalidade, o que na prática implica em números de vereadores diferentes para municípios similares. Isto porque havia interpretações distintas para a proporcionalidade, dependendo do Estado a que pertencia o Município. Em 2004, o TSE aprovou resolução $\mathrm{n}^{\mathrm{o}}$ 21.702/2004 com definição de limites compatíveis com a "proporcionalidade"e com os limites constitucionais. Esta regra, apresentada na tabela A, vigorou nas eleições de 2004 e 2008 e foram a base para o presente estudo. Por fim, em 2009, a Emenda Constitucional no 58 estabeleceu novos limites e a expressão proporcional deixa de existir. Esta regra vigorou na eleição de 2012 e não foi incluído na base deste estudo pois os dados de despesa não estavam ainda disponíveis.

Naturalmente o número de vagas definido em 2004 é associado à despesa per capita do ano de 2005 e o de 2008 à despesa de 2009. Destaque-se que cada município brasileiro aparece duas vezes em nossa base de dados, uma para os dados de 2004/2005 e outra para 2008/2009. Assim, nossa base de dados, que possui 10.308 observações, é composta pelas seguintes variáveis: população, despesa per capita, escolaridade média, coeficiente de Gini, IDH, mortalidade infantil, renda per capita, taxa de urbanização, taxa de analfabetismo, indicador de pobreza ${ }^{3}$, indicador de se o partido do prefeito é da base do governo federal ou não.

Destaque-se que quando nos referimos à despesa per capita, consideramos tanto o orçamento total como diversas categorias do gasto obtidas através da classificação funcional da despesa presente no orçamento brasileiro. A estatística descritiva de tais categorias de despesa estão sumarizadas no apêndice

\footnotetext{
${ }^{3}$ Percentual de pessoas com renda domiciliar per capita inferior a 1/4 do salário mínimo vigente.
} 


\subsection{Resultados}

A tabela 2.2. a seguir, contém o resultado base do nosso estudo onde estimamos o impacto do tamanho do legislativo na despesas 4 do município . Nestas estimativas, utilizamos o kernel retangular e bandwidths variando de $3 \%$ a $10 \%$ 5

Tabela 2.2: Impacto do Tamanho do Legislativo - Sem covariáveis*

\begin{tabular}{c|c|c|c|c|c|c|c|c}
\hline \hline despesa & $\mathbf{3 \%}$ & $\mathbf{4} \%$ & $\mathbf{5 \%}$ & $\mathbf{6 \%}$ & $\mathbf{7 \%}$ & $\mathbf{8 \%}$ & $\mathbf{9 \%}$ & $\mathbf{1 0 \%}$ \\
\hline total & 325.2 & $431.7^{* *}$ & $410.8^{* *}$ & $404.5^{* *}$ & $469.4^{* * *}$ & $382.3^{* * *}$ & $297.1^{* *}$ & $290.0^{* *}$ \\
& $(211.8)$ & $(210.4)$ & $(171.4)$ & $(159.9)$ & $(148.5)$ & $(138.2)$ & $(130.0)$ & $(124.6)$ \\
\hline adm. & 88.22 & $93.78^{*}$ & $80.69^{*}$ & $74.40^{*}$ & $90.11^{* *}$ & $80.85^{* *}$ & $64.43^{*}$ & $64.73^{*}$ \\
& $(57.95)$ & $(56.43)$ & $(45.30)$ & $(42.36)$ & $(40.24)$ & $(37.30)$ & $(35.32)$ & $(33.73)$ \\
\hline assistência & $19.09^{* *}$ & $20.07^{* * *}$ & $19.68^{* * *}$ & $19.19^{* * *}$ & $19.85^{* * *}$ & $16.41^{* * *}$ & $12.43^{* * *}$ & $11.75^{* *}$ \\
social & $(7.48)$ & $(6.87)$ & $(6.13)$ & $(5.73)$ & $(5.29)$ & $(4.92)$ & $(4.73)$ & $(4.61)$ \\
\hline educação & 33.86 & 86.21 & $83.24^{*}$ & $80.47^{*}$ & $76.64^{* *}$ & $63.64^{*}$ & 42.93 & 40.51 \\
& $(55.26)$ & $(53.98)$ & $(44.78)$ & $(41.38)$ & $(37.76)$ & $(34.94)$ & $(33.15)$ & $(31.83)$ \\
\hline urbanismo & 51.86 & 55.83 & $54.51^{*}$ & $48.56^{*}$ & $53.84^{* *}$ & $39.51^{*}$ & $39.12^{*}$ & $39.10^{* *}$ \\
& $(38.31)$ & $(37.11)$ & $(28.55)$ & $(25.97)$ & $(23.96)$ & $(22.71)$ & $(20.94)$ & $(19.79)$ \\
\hline desporto & 3.613 & $8.189^{*}$ & $7.200^{* *}$ & $7.079^{* *}$ & $8.511^{* * *}$ & $5.968^{* *}$ & $4.379^{*}$ & $4.431^{*}$ \\
& $(3.37)$ & $(4.56)$ & $(3.01)$ & $(2.82)$ & $(2.75)$ & $(2.87)$ & $(2.59)$ & $(2.46)$ \\
\hline n obs & 127 & 167 & 213 & 247 & 296 & 341 & 387 & 430 \\
\hline \hline
\end{tabular}

*Erro-padrão entre parênteses

Observamos portanto resultados bastante significativos para a despesa total. Destaque-se que tal significância permanece variando bandwidtths até $14 \%$.

\footnotetext{
${ }^{4}$ Apresentamos apenas aquelas funções da despesa que apresentaram mais resultados significativos.A estatística descritiva das funções está no apêndice B.

${ }^{5}$ Confirmamos que os comandos clássicos de regressão descontínua do Stata (rd) e do R (rdestimante) geram os mesmos resultados
} 


\subsubsection{Robustez}

Com intuito de analisar a robustez desse resultado, a primeira análise que fizemos foi incluir covariáveis como escolaridade média, coeficiente de Gini, IDH, mortalidade infantil, taxa de urbanização, taxa de analfabetismo, indicador de pobreza e indicador de se o prefeito é da situação ou oposição ao governo federal (tabela 2.3). Variamos também o tipo de kernel e de polinômios utilizados na estimação (tabela 2.4). Como teste final de robustez, utilizamos a metodologia utilizada por Litschig and Morrison (2013), descrita no apêndice D. Observamos alteração em termos de signifiância quando aumentamos o grau do polinômio, apesar de o efeito se manter predominantemente positivo, e quando utilizamos a metodologia de Litschig and Morrison (2013) 6 ,

Tabela 2.3: Impacto do Tamanho do Legislativo - Com covariáveis*

\begin{tabular}{c|c|c|c|c|c|c|c|c}
\hline \hline despesa & $\mathbf{3 \%}$ & $\mathbf{4 \%}$ & $\mathbf{5 \%}$ & $\mathbf{6 \%}$ & $\mathbf{7 \%}$ & $\mathbf{8 \%}$ & $\mathbf{9 \%}$ & $\mathbf{1 0 \%}$ \\
\hline total & 106.4 & 267.9 & $326.7^{* *}$ & $360.9^{* *}$ & $390.9^{* * *}$ & $319.6^{* * *}$ & $219.7^{*}$ & $195.1^{*}$ \\
& $(198.1)$ & $(184.2)$ & $(154.2)$ & $(145.3)$ & $(134.9)$ & $(123.6)$ & $(115.1)$ & $(109.3)$ \\
\hline adm. & 45.76 & 80.75 & $66.49^{*}$ & $66.33^{*}$ & $71.51^{* *}$ & $64.53^{*}$ & 44.70 & 42.92 \\
& $(45.78)$ & $(54.60)$ & $(39.71)$ & $(36.35)$ & $(35.07)$ & $(33.50)$ & $(32.18)$ & $(31.26)$ \\
\hline assistência & $13.16^{*}$ & $14.11^{* *}$ & $16.50^{* * *}$ & $16.99^{* * *}$ & $17.07^{* * *}$ & $14.49^{* * *}$ & $10.13^{* *}$ & $9.718^{* *}$ \\
social & $(7.46)$ & $(6.28)$ & $(5.75)$ & $(5.45)$ & $(5.04)$ & $(4.71)$ & $(4.46)$ & $(4.26)$ \\
\hline educação & 25.77 & 60.77 & $79.16^{*}$ & $82.46^{*}$ & $71.45^{*}$ & $63.78^{*}$ & 40.06 & 37.02 \\
& $(58.27)$ & $(50.43)$ & $(44.44)$ & $(42.86)$ & $(38.56)$ & $(35.33)$ & $(32.58)$ & $(30.69)$ \\
\hline urbanismo & 18.29 & 28.94 & 37.61 & $39.43^{*}$ & $42.34^{* *}$ & 31.16 & 26.61 & 21.48 \\
& $(35.38)$ & $(30.93)$ & $(25.33)$ & $(23.04)$ & $(20.81)$ & $(19.38)$ & $(17.78)$ & $(16.89)$ \\
\hline desporto & 0.237 & 4.717 & $5.839^{* *}$ & $6.441^{* *}$ & $6.908^{* * *}$ & $4.663^{*}$ & 2.658 & 2.463 \\
& $(2.84)$ & $(3.39)$ & $(2.81)$ & $(2.58)$ & $(2.44)$ & $(2.59)$ & $(2.42)$ & $(2.37)$ \\
\hline n obs & 127 & 167 & 213 & 247 & 296 & 341 & 387 & 430 \\
\hline \hline
\end{tabular}

*Erro-padrão entre parênteses

\footnotetext{
${ }^{6}$ Os resultados para categorias de despesa utilizando a metodologia de Litschig estão no apêndice C
} 
Tabela 2.4: Impacto do Tamanho do Legislativo - Despesa Total

\begin{tabular}{c|c|c|c|c|c|c|c|c}
\hline \hline kernel & $\mathbf{3 \%}$ & $\mathbf{4 \%}$ & $\mathbf{5 \%}$ & $\mathbf{6 \%}$ & $\mathbf{7 \%}$ & $\mathbf{8 \%}$ & $\mathbf{9 \%}$ & $\mathbf{1 0 \%}$ \\
\hline triangular & 265.98 & $338.51^{*}$ & $375.32^{* *}$ & $393.11^{* *}$ & $420.65^{* *}$ & $418.8^{* *}$ & $396.14^{* * *}$ & $367.45^{* * *}$ \\
& $(225.15)$ & $(205.72)$ & $(190.73)$ & $(177.14)$ & $(166.5)$ & $(156.14)$ & $(148.15)$ & $(141.28)$ \\
\hline \multirow{2}{*}{ epane- } & 292.74 & $369.48^{*}$ & $397.88^{* *}$ & $408.63^{* *}$ & $438.19^{* * *}$ & $426.92^{* * *}$ & $391.9^{* * *}$ & $353.5^{* *}$ \\
chnikov & $(219.95)$ & $(204.74)$ & $(189.62)$ & $(174.5)$ & $(163.37)$ & $(152.35)$ & $(144.14)$ & $(137.15)$ \\
\hline \hline polinômio & $\mathbf{3 \%}$ & $\mathbf{4 \%}$ & $\mathbf{5 \%}$ & $\mathbf{6 \%}$ & $\mathbf{7 \%}$ & $\mathbf{8 \%}$ & $\mathbf{9 \%}$ & $\mathbf{1 0 \%}$ \\
\hline quadrático & 161.02 & 172.46 & 324.53 & 370.5 & 349.29 & $468.97^{* *}$ & $542.6^{* * *}$ & $492.32^{* * *}$ \\
& $(315.44)$ & $(288.13)$ & $(243.28)$ & $(234.03)$ & $(215.77)$ & $(206.26)$ & $(193.76)$ & $(186.76)$ \\
\hline \multirow{2}{*}{ cúbico } & -19.055 & 101.68 & 99.64 & 166.3 & 234.68 & 200.01 & 248.14 & 384.43 \\
& $(437.66)$ & $(391.81)$ & $(327.11)$ & $(288)$ & $(268.37)$ & $(258.52)$ & $(245.39)$ & $(237.49)$ \\
\hline \hline Litschig & $\mathbf{3 \%}$ & $\mathbf{4 \%}$ & $\mathbf{5 \%}$ & $\mathbf{6 \%}$ & $\mathbf{7 \%}$ & $\mathbf{8 \%}$ & $\mathbf{9 \%}$ & $\mathbf{1 0 \%}$ \\
\hline \multirow{2}{*}{ cov-não } & 66.15 & 289.2 & 236.9 & 213.6 & $311.9^{*}$ & 237.6 & 159.7 & 152.5 \\
& $(292.1)$ & $(246.1)$ & $(214.2)$ & $(198.1)$ & $(177.2)$ & $(165.0)$ & $(155.1)$ & $(148.0)$ \\
\hline \multirow{2}{*}{ cov-sim } & -25.76 & 129.1 & 112.5 & 100.5 & 190.1 & 122.8 & 39.27 & 40.43 \\
& $(272.2)$ & $(229.4)$ & $(199.6)$ & $(184.6)$ & $(165.1)$ & $(153.8)$ & $(144.5)$ & $(137.9)$ \\
\hline \hline
\end{tabular}


Com isso, observamos que há também para o Brasil indícios da veracidade da "Lei $1 / n$ ". Consideramos indícios pois ao variar bandwidths e polinômios perdemos a significância em alguns casos. Isto ocorre também na metodologia citada anteriormente. Destaque-se, porém, que observamos predominantemente uma relação positiva.

Passamos agora a considerar alguns efeitos presentes no caso brasileiro que podem tornar os resultados não tão evidentes como observado em Egger and Koethenbuerger (2010), por exemplo.

\subsubsection{Receitas Próprias}

O primeiro ponto refere-se à significativa dependência dos municípios brasileiros às receitas decorrentes das transferências dos outros entes federados, em especial, da União (tabela 2.5). As receitas próprias dos municípios presentes neste estudo representam, na média, cerca de 10\% do total de receitas.

Tabela 2.5: Receitas Próprias / Receita Total (\%)

\begin{tabular}{c|c|c|c|c|c|c}
\hline \hline mínimo & $1^{\circ}$ quartil & média & mediana & $3^{\circ}$ quartil & máximo & desvio padrão \\
\hline 0 & 4,4 & 10,6 & 7,8 & 14,0 & 100,0 & 9,0 \\
\hline \hline
\end{tabular}

Ao comparar com outros países, Arvate et al. (2010) destaca esta característica do federalismo fiscal do Brasil. Segundo ele, países com grandes territórios e uma diversidade social e econômica como Rússia, Canadá, Austrália e Estados Unidos possuem governos locais com menor dependência fiscal. Os vizinhos latino-americanos Colômbia, Chile e México também apresentam menores níveis de transferências. Segundo Baqir (2002), para um bom ajuste entre teoria e dados, a maior parte das receitas deveriam ser locais para evitar que atores externos tenham poder de decisão sobre a alocação dos recursos orçamentários. 
Aplicamos então o nosso modelo apenas para os municípios com maior ${ }^{7}$ parcela de recursos locais ${ }^{8}$ e para a base remanescente. Os resultados que obtivemos (tabela 2.6) parecem confirmar essa premissa:

Tabela 2.6: Impacto do Tamanho do Legislativo - Despesa Total*

\begin{tabular}{c|c|c|c|c|c|c|c|c}
\hline \hline rec. locais & $\mathbf{3 \%}$ & $\mathbf{4 \%}$ & $\mathbf{5 \%}$ & $\mathbf{6 \%}$ & $\mathbf{7 \%}$ & $\mathbf{8 \%}$ & $\mathbf{9 \%}$ & $\mathbf{1 0 \%}$ \\
\hline alto & 288.96 & $612.15^{*}$ & $490.80^{* *}$ & $536.70^{* *}$ & $564.18^{* * *}$ & $482.24^{* *}$ & $361.38^{*}$ & $360.68^{* *}$ \\
& $(319.8)$ & $(335.6)$ & $(248.0)$ & $(228.8)$ & $(215.4)$ & $(199.0)$ & $(187.2)$ & $(179.8)$ \\
\hline baixo & 53.99 & 24.34 & 92.51 & -.06 & 99.01 & 29.15 & .36 & -8.37 \\
& $(221.2)$ & $(181.0)$ & $(159.1)$ & $(151.8)$ & $(134.6)$ & $(123.1)$ & $(114.7)$ & $(109.3)$ \\
\hline \hline
\end{tabular}

*Erro-padrão entre parênteses

\subsubsection{Poder Executivo}

O segundo ponto está relacionado ao poder do Executivo no processo orçamentário brasileiro. Segundo Baqir (2002), nos estados em que o Executivo concentra poderes há um enfraquecimento da "Lei 1/n". A literatura recente na área de instituições orçamentárias - o estudo de como regras do jogo subjacente ao processo orçamentário afeta os resultados fiscais - indica que instituições políticas que centralizam a autoridade decisória na figura, do presidente, por exemplo, podem reduzir o gasto extra 9 É o caso do Brasil onde os prefeitos têm a iniciativa na elaboração do orçamento e o poder do legislativo de emendar o projeto de lei orçamentária é limitado. Segundo a Lei de Responsabilidade Fiscal, tais emendas têm que indicar a fonte de recursos que, em geral, corresponde a cancelamento de outros projetos. Isto porque há também limites explicitos de endividamento do município. Como ressaltado por Persson and Tabellini (2005), no Brasil, os presidentes (e também os prefeitos) têm mais poderes legis-

\footnotetext{
${ }^{7}$ Acima do $3^{\circ}$ quartil

${ }^{8}$ Diferença entre receitas totais e transferências

${ }^{9}$ Para uma revisão da literatura empírica ver Alesina and Perotti (1999)
} 
lativos como o poder de veto item a item, restrições a emendas legislativas e a possibilidade de legislar por decreto (Medidas Provisórias). Também ressaltado por Pereira and Mueller (2000), em se tratando de leis orçamentárias, embora uma maioria no Congresso tenha o direito de propor emendas às propostas que foram introduzidas pelo presidente, esta maioria só pode fazer isto se essas emendas forem compatíveis com o plano de orçamento plurianual elaborado pelo Executivo, bem como com a Lei de Diretrizes Orçamentárias. Além disso, o Congresso não pode autorizar despesas que excedam as receitas orçamentárias. Na prática, estas regras permitem ao presidente preservar o status quo em questões orçamentárias simplesmente pela não introdução de uma proposta. Neste sentido, testamos então o nosso modelo para os municípios onde o prefeito parece possuir maior ${ }^{10}$ poder local. Utilizamos o percentual de votos obtidos na eleição do prefeito como proxy para medir o seu poder local (tabela 2.7).

Tabela 2.7: Votos Eleição (\%)

\begin{tabular}{c|c|c|c|c|c|c}
\hline \hline mínimo & $1^{\circ}$ quartil & média & mediana & $3^{\circ}$ quartil & máximo & desvio padrão \\
\hline 24,0 & 25,0 & 55,6 & 54,0 & 59,0 & 100,0 & 12,6 \\
\hline \hline
\end{tabular}

Os resultados não corroboram o esperado (tabela 2.8). Uma das questões aqui é se a variável proxy para o poder local realmente é adequada.

Tabela 2.8: Impacto do Tamanho do Legislativo - Despesa Total*

\begin{tabular}{c|c|c|c|c|c|c|c|c}
\hline \hline poder & $\mathbf{3 \%}$ & $\mathbf{4 \%}$ & $\mathbf{5 \%}$ & $\mathbf{6 \%}$ & $\mathbf{7 \%}$ & $\mathbf{8 \%}$ & $\mathbf{9 \%}$ & $\mathbf{1 0 \%}$ \\
\hline \multirow{2}{*}{ alto } & $906.8^{* *}$ & $1022.2^{* *}$ & $1176.6^{* * *}$ & $1128.3^{* * *}$ & $1205.4^{* * *}$ & $1178.1^{* * *}$ & $1118.2^{* * *}$ & $1205.5^{* *}$ \\
& $(436.2)$ & $(425.3)$ & $(418.3)$ & $(401.2)$ & $(384.3)$ & $(369.8)$ & $(354.0)$ & $(340.7)$ \\
\hline \multirow{2}{*}{ baixo } & 96.03 & 227.11 & 164.47 & 181.19 & $253.12^{*}$ & 169.28 & 83.79 & 49.77 \\
& $(228.8)$ & $(230.8)$ & $(172.4)$ & $(159.2)$ & $(146.4)$ & $(134.1)$ & $(126.3)$ & $(120.6)$ \\
\hline \hline
\end{tabular}

*Erro-padrão entre parênteses

${ }^{10}$ Acima do $3^{\circ}$ quartil 


\subsubsection{Eleitor Mediano e Sistema Eleitoral}

Por fim, ressaltamos a necessidade também de se avaliar se, no caso brasileiro, as despesas orçamentárias estariam melhor explicadas pelo modelo discutido aqui ou pelo modelo de competição eleitoral de Downs. Menezes et al. (2011) apresentou evidências deste modelo para os municípios brasileiros. A competição eleitoral que, segundo o modelo, conduz à satisfação do eleitor mediano poderia ser, no caso em tela, a causa de obtermos resultados bastante significativos para a despesa com Assistência Social. Na medida em que temos mais representantes em uma casa legislativa (maior competição), confirmamos que uma política de bem-estar social, que aproxima-se da preferência do eleitor mediano no Brasil, tem destaque no orçamento municipal.

Combinado com isto, temos na literatura resultados que confirmam que em países com sistemas de eleição proporcional tais despesas (bem-estar social) são proeminentes, pois haveria incentivos fortes em ofertar programas amplos que apresentem muitos beneficiários. Um dos canais que poderia explicar tal fenômeno, segundo Persson and Tabellini (2002), seriam os incentivos eleitorais decorrentes da competição eleitoral. Estima-se que a substituição de um sistema de eleição proporcional para um sistema majoritário reduziria o gasto com políticas de bem-estar social em cerca de 2 a 3\% do PIB.

\subsection{Discussão}

Encotramos uma relação positiva entre o tamanho das câmaras de vereadores e o gasto público per capita nos municípios brasileiros. Tal relação não se mostrou significativa em todos os testes de robustez, o que nos leva a concluir por indícios da Lei $1 / \mathrm{n}$, no caso brasileiro. A dependência municipal das 
receitas de transferências de outros entes federados poderiam justificar tal ausência de robustez, conforme ressaltado pela literatura.

Destaque-se a importância de tal resultado já que a discussão sobre a criação de municípios é recorrente no caso brasileiro. Por exemplo, em 2013 e 2014, dois projetos de lei determinando novas regras para a criação de municípios foram aprovados no Congresso Nacional (e vetados pelo Poder Executivo). Assim, avaliamos que os resultados em tela indicam que um número maior de casas legislativas municipais implicariam em mais gastos públicos, apenas considerando o efeito da chamada Lei $1 / n$. Obviamente, tal gasto também tende a crescer pelos canais óbvios da maior estrutura necessária para manutenção da máquina administrativa e política destes novos municípios.

Avaliamos que, no caso brasileiro, a Lei 1/n dê-se principalmente pelo canal das emendas parlamentares, que caracteriza-se por representar o recurso público mais territorializado. Como vimos, Samuels (2002) destaca a importância das emendas no caso do Brasil, não pelos motivos clientelistas normalmente ressaltados pela literatura, e sim por representarem um mecanismo de obter recursos de financiamento de campanha. Assim, vê-se que a combinação dos resultados obtidos por Samuels (2002) e pelo presente estudo reforçam a necessidade fiscal de redução das casas legislativas e do aprimoramento dos mecanismos de financiamento de campanha.

Os resultados da regressão descontínua para as categorias de despesa confirmaram que, em países com sistemas de eleição proporcional como o Brasil, onde os incentivos em ofertar programas que atinjam um amplo número de beneficiários são fortes, as despesas com políticas de bem-estar social são proeminentes. Por fim, ressaltamos a necessidade também de se avaliar se, no caso brasileiro, as despesas orçamentárias estariam melhor explicadas pela Lei 1/n aqui ou pelo 
modelo de competição eleitoral de Downs, conforme evidenciado por Menezes et al. (2011). A competição eleitoral que, segundo o modelo, conduz à satisfação do eleitor mediano poderia ser, no caso em tela, a causa de obtermos resultados bastante significativos para a despesa com Assistência Social. Na medida em que temos mais representantes em uma casa legislativa (maior competição), confirmamos que uma política de bem-estar social, que aproxima-se da preferência do eleitor mediano no Brasil, teria destaque no orçamento municipal. 


\section{REFERÊNCIAS BIBLIOGRÁFICAS}

Acemoglu, D. (2005). Constitutions, politics and economics: A review essay on persson and tabellini's"the economic effect of constitutions". Technical report, National Bureau of Economic Research.

Alesina, A. F. and R. Perotti (1999). Budget deficits and budget institutions. In Fiscal institutions and fiscal performance, pp. 13-36. University of Chicago Press.

Alston, L. J. and B. Mueller (2006). Pork for policy: executive and legislative exchange in brazil. Journal of Law, Economics, and Organization 22(1), 87-114.

Arvate, P. R., M. Mendes, and A. Rocha (2010). Are voters fiscal conservatives? evidence from brazilian municipal elections. Estudos Econômicos (São Paulo) 40(1), 67-101.

Baqir, R. (2002). Districting and government overspending. Journal of Political Economy 110(6), 1318-1354.

Besley, T. (2007). The new political economy. The Economic Journal 117(524), F570-F587.

Bradbury, J. C. and W. M. Crain (2001). Legislative organization and government spending: cross-country evidence. Journal of Public Economics 82(3), 309-325.

DelRossi, A. F. and R. P. Inman (1999). Changing the price of pork: the impact 
of local cost sharing on legislators' demands for distributive public goods. Journal of Public Economics 71(2), 247-273.

Egger, P. and M. Koethenbuerger (2010). Government spending and legislative organization: Quasi-experimental evidence from germany. American Economic Journal: Applied Economics, 200-212.

Litschig, S. and K. M. Morrison (2013). The impact of intergovernmental transfers on education outcomes and poverty reduction. American Economic Journal:Applied Economics 5(4), 206-240.

Magalhães, J. C. (2007). Emancipação político-administrativa de municípios no brasil. XAVIER YAWATA, Alexandre; ALBUQUERQUE, Carlos Wagner; MOTA, José Aroudo.

McCrary, J. (2008). Manipulation of the running variable in the regression discontinuity design: A density test. Journal of Econometrics 142(2), 698-714.

Menezes, R. T. d., C. C. S. Saiani, and A. C. P. Zoghbi (2011). Demanda mediana por serviços públicos e desempenho eleitoral: evidências do modelo do eleitor mediano para os municípios brasileiros. Estudos Econômicos (São Paulo) 41(1), 25-57.

Monasterio, L. (2013). O fpm ea estranha distribuição da população dos pequenos municípios brasileiros.

Pereira, C. and B. Mueller (2000). Uma teoria da preponderância do poder executivo: O sistema de comissões no legislativo brasileiro. Revista Brasileira de Ciências Sociais 15(43), 45-67.

Pereira, C. and B. Mueller (2002). Comportamento estratégico em presidencialismo de coalizão: as relações entre executivo e legislativo na elaboração do orçamento brasileiro. Dados 45(2), 265-301. 
Persson, T. and G. E. Tabellini (2002). Political economics: explaining economic policy. MIT press.

Persson, T. and G. E. Tabellini (2005). The economic effects of constitutions. MIT press.

Pettersson-Lidbom, P. (2008). Does the size of the legislature affect the size of government? evidence from two natural experiments. Unpublished manuscript, Stockholm University.

Primo, D. M. and J. M. Snyder Jr (2005). Public goods and the law of $1 / n$. In Annual Meeting of the Midwest Political Science Association, Chicago, IL.

Samuels, D. J. (2002). Pork barreling is not credit claiming or advertising: Campaign finance and the sources of the personal vote in brazil. The journal of Politics 64(03), 845-863.

Santana, V. L. (2011). Atraindo o pork: que fatores emplicam a execução das emendas orçamentárias no brasil?

Schaltegger, C. A. and L. P. Feld (2004). Do large cabinets favor large governments?: Evidence from swiss sub-federal jurisdictions. Technical report, Marburger volkswirtschaftliche Beiträge.

Weingast, B. R., K. A. Shepsle, and C. Johnsen (1981). The political economy of benefits and costs: A neoclassical approach to distributive politics. The Journal of Political Economy 89(4), 642. 


\section{APÊNDICE A}

\section{REGRA $N^{\circ}$ DE VEREADORES}

\section{Tabela A.1: População $x N^{o}$ de Vereadores}

\begin{tabular}{c|c||c|c}
\hline \hline população municipal & $\mathrm{n}^{\mathrm{o}}$ de vereadores & população municipal & $\mathrm{n}^{\mathrm{o}}$ de vereadores \\
\hline até 47.619 & 09 & de 1.609 .757 até 1.731 .707 & 38 \\
\hline de 47.620 até 95.238 & 10 & de 1.731 .708 até 1.853 .658 & 39 \\
\hline de 95.239 até 142.857 & 11 & de 1.853 .659 até 1.975 .609 & 40 \\
\hline de 142.858 até 190.476 & 12 & de 1.975 .610 até 4.999 .999 & 41 \\
\hline de 190.477 até 238.095 & 13 & de 5.000 .000 até 5.119 .047 & 42 \\
\hline de 238.096 até 285.714 & 14 & de 5.119 .048 até 5.238 .094 & 43 \\
\hline de 285.715 até 333.333 & 15 & de 5.238 .095 até 5.357 .141 & 44 \\
\hline de 333.334 até 380.952 & 16 & de 5.357 .142 até 5.476 .188 & 45 \\
\hline de 380.953 até 428.571 & 17 & de 5.476 .189 até 5.595 .235 & 46 \\
\hline de 428.572 até 476.190 & 18 & de 5.595 .236 até 5.714 .282 & 47 \\
\hline de 476.191 até 523.809 & 19 & de 5.714 .283 até 5.833 .329 & 48 \\
\hline de 523.810 até 571.428 & 20 & de 5.833 .330 até 5.952 .376 & 49 \\
\hline de 571.429 até 1.000 .000 & 21 & de 5.952 .377 até 6.071 .423 & 50 \\
\hline de 1.000 .001 até 1.121 .952 & 33 & de 6.071 .424 até 6.190 .470 & 51 \\
\hline de 1.121 .953 até 1.243 .903 & 34 & de 6.190 .471 até 6.309 .517 & 52 \\
\hline de 1.243 .904 até 1.365 .854 & 35 & de 6.309 .518 até 6.428 .564 & 53 \\
\hline de 1.365 .855 até 1.487 .805 & 36 & de 6.428 .565 até 6.547 .611 & 54 \\
\hline de 1.487 .806 até 1.609 .756 & 37 & Acima de 6.547 .612 & 55 \\
\hline \hline
\end{tabular}




\section{APÊNDICE B}

\section{ESTATÍSTICA DESCRITIVA}

Tabela B.1: Estatística Descritiva - Funções da Despesa (em milhares)

\begin{tabular}{c|c|c|c}
\hline \hline função da despesa & média & desvio-padrão & máximo \\
\hline Legislativa & 659.33 & $1,462.17$ & $99,100.00$ \\
\hline Judiciária & 40.82 & 198.20 & $6,095.39$ \\
\hline Essencial à justiça & 17.00 & 214.28 & $14,600.00$ \\
\hline Administração & $3,369.62$ & $6,300.73$ & $204,000.00$ \\
\hline Defesa Nacional & 1.83 & 26.53 & $2,114.73$ \\
\hline Segurança Pública & 82.04 & 520.29 & $24,300.00$ \\
\hline Relações Exteriores & 0.22 & 10.62 & $1,004.71$ \\
\hline Assistência Social & 715.72 & $1,121.37$ & $26,200.00$ \\
\hline Previdência Social & 455.35 & $1,761.29$ & $91,600.00$ \\
\hline Saúde & $4,495.11$ & $7,296.24$ & $149,000.00$ \\
\hline Trabalho & 36.29 & 312.38 & $14,100.00$ \\
\hline Educação & $5,944.82$ & $8,588.92$ & $196,000.00$ \\
\hline Cultura & 230.98 & 541.95 & $20,200.00$ \\
\hline Direitos da Cidadania & 10.56 & 132.53 & $6,209.21$ \\
\hline Urbanismo & $1,862.98$ & $4,578.51$ & $173,000.00$ \\
\hline Habitação & 99.30 & 688.23 & $49,100.00$ \\
\hline Saneamento & 419.45 & $1,939.44$ & $62,700.00$ \\
\hline Gestão Ambiental & 108.06 & 696.92 & $43,700.00$ \\
\hline Ciência e Tecnologia & 2.59 & 52.48 & $3,279.41$ \\
\hline Agricultura & 264.07 & 452.03 & $19,700.00$ \\
\hline Organização Agrária & 1.15 & 30.20 & $2,236.74$ \\
\hline Indústria & 32.08 & 169.23 & $7,925.45$ \\
\hline Comércio e Serviços & 86.47 & 442.38 & $26,600.00$ \\
\hline Comunicações & 10.73 & 69.84 & $2,777.15$ \\
\hline Energia & 113.08 & $2,749.30$ & $255,000.00$ \\
\hline Transporte & 627.00 & $1,444.67$ & $73,500.00$ \\
\hline Desporto e Lazer & 186.02 & 504.49 & $17,400.00$ \\
\hline Encargos Especiais & 483.62 & $1,505.11$ & $69,900.00$ \\
\hline \hline & & &
\end{tabular}


APÊNDICE C

LITSCHIG - CATEGORIAS DE DESPESAS 
Tabela C.1: Impacto do Tamanho do Legislativo - Categorias de Despesa*

\begin{tabular}{|c|c|c|c|c|c|c|c|c|c|c|}
\hline Funções & $1 \%$ & $2 \%$ & $3 \%$ & $4 \%$ & $5 \%$ & $6 \%$ & $7 \%$ & $8 \%$ & $9 \%$ & $10 \%$ \\
\hline Legislativa & $\begin{array}{c}8.343 \\
(38.82)\end{array}$ & $\begin{array}{r}-0.364 \\
(24.05)\end{array}$ & $\begin{array}{c}-3.757 \\
(18.84)\end{array}$ & $\begin{array}{c}4.944 \\
(15.88)\end{array}$ & $\begin{array}{c}4.190 \\
(13.81)\end{array}$ & $\begin{array}{c}5.795 \\
(12.78)\end{array}$ & $\begin{array}{l}23.00^{* *} \\
(11.42)\end{array}$ & $\begin{array}{c}11.84 \\
(10.65)\end{array}$ & $\begin{array}{c}4.422 \\
(10.01)\end{array}$ & $\begin{array}{c}1.854 \\
(9.558)\end{array}$ \\
\hline Judiciária & $\begin{array}{c}6.024 \\
(5.828)\end{array}$ & $\begin{array}{c}-2.152 \\
(3.615)\end{array}$ & $\begin{array}{l}-4.740^{*} \\
(2.833)\end{array}$ & $\begin{array}{l}-3.983^{*} \\
(2.388)\end{array}$ & $\begin{array}{l}-2.683 \\
(2.079)\end{array}$ & $\begin{array}{l}-2.373 \\
(1.923)\end{array}$ & $\begin{array}{c}-2.753 \\
(1.721)\end{array}$ & $\begin{array}{l}-2.236 \\
(1.603)\end{array}$ & $\begin{array}{l}-1.427 \\
(1.508)\end{array}$ & $\begin{array}{l}-1.161 \\
(1.439)\end{array}$ \\
\hline Administração & $\begin{array}{c}107.2 \\
(148.8)\end{array}$ & $\begin{array}{c}52.27 \\
(92.18)\end{array}$ & $\begin{array}{c}25.33 \\
(72.20)\end{array}$ & $\begin{array}{c}51.73 \\
(60.86)\end{array}$ & $\begin{array}{c}38.26 \\
(52.96)\end{array}$ & $\begin{array}{c}28.45 \\
(48.98)\end{array}$ & $\begin{array}{l}55.70 \\
(43.82)\end{array}$ & $\begin{array}{c}51.32 \\
(40.81)\end{array}$ & $\begin{array}{c}37.46 \\
(38.36)\end{array}$ & $\begin{array}{c}37.78 \\
(36.61)\end{array}$ \\
\hline Defesa Nacional & $\begin{array}{r}-0.0979 \\
(0.869)\end{array}$ & $\begin{array}{c}-0.0231 \\
(0.538)\end{array}$ & $\begin{array}{c}-0.0356 \\
(0.422)\end{array}$ & $\begin{array}{r}-0.0653 \\
(0.356)\end{array}$ & $\begin{array}{r}-0.0989 \\
(0.310)\end{array}$ & $\begin{array}{c}-0.0992 \\
(0.286)\end{array}$ & $\begin{array}{c}-0.0951 \\
(0.256)\end{array}$ & $\begin{array}{c}-0.0672 \\
(0.239)\end{array}$ & $\begin{array}{c}-0.0677 \\
(0.225)\end{array}$ & $\begin{array}{l}-0.0539 \\
(0.214)\end{array}$ \\
\hline Segurança Pública & $\begin{array}{l}-1.458 \\
(7.994)\end{array}$ & $\begin{array}{l}-8.311^{*} \\
(4.959)\end{array}$ & $\begin{array}{c}-9.677^{* *} \\
(3.887)\end{array}$ & $\begin{array}{l}-2.749 \\
(3.275)\end{array}$ & $\begin{array}{l}-4.770^{*} \\
(2.850)\end{array}$ & $\begin{array}{l}-3.927 \\
(2.635)\end{array}$ & $\begin{array}{l}-3.495 \\
(2.358)\end{array}$ & $\begin{array}{l}-2.930 \\
(2.195)\end{array}$ & $\begin{array}{c}-4.289^{* *} \\
(2.060)\end{array}$ & $\begin{array}{c}-2.741 \\
(1.967)\end{array}$ \\
\hline Assistência Social & $\begin{array}{c}33.81 \\
(38.42)\end{array}$ & $\begin{array}{c}20.92 \\
(23.80)\end{array}$ & $\begin{array}{c}19.79 \\
(18.65)\end{array}$ & $\begin{array}{c}19.38 \\
(15.71)\end{array}$ & $\begin{array}{c}18.80 \\
(13.67)\end{array}$ & $\begin{array}{c}17.25 \\
(12.65)\end{array}$ & $\begin{array}{c}18.40 \\
(11.31)\end{array}$ & $\begin{array}{c}15.65 \\
(10.53)\end{array}$ & $\begin{array}{c}12.22 \\
(9.905)\end{array}$ & $\begin{array}{c}11.14 \\
(9.453)\end{array}$ \\
\hline Previdência Social & $\begin{array}{l}66.83^{*} \\
(35.51)\end{array}$ & $\begin{array}{l}36.91^{*} \\
(22.01)\end{array}$ & $\begin{array}{c}19.16 \\
(17.24)\end{array}$ & $\begin{array}{l}16.90 \\
(14.54)\end{array}$ & $\begin{array}{c}9.593 \\
(12.66)\end{array}$ & $\begin{array}{c}8.859 \\
(11.71)\end{array}$ & $\begin{array}{c}10.25 \\
(10.48)\end{array}$ & $\begin{array}{c}7.071 \\
(9.760)\end{array}$ & $\begin{array}{c}5.855 \\
(9.178)\end{array}$ & $\begin{array}{c}6.636 \\
(8.760)\end{array}$ \\
\hline Saúde & $\begin{array}{l}-17.90 \\
(129.5)\end{array}$ & $\begin{array}{l}-56.97 \\
(80.23)\end{array}$ & $\begin{array}{l}-53.89 \\
(62.84)\end{array}$ & $\begin{array}{l}-2.049 \\
(52.94)\end{array}$ & $\begin{array}{c}4.244 \\
(46.08)\end{array}$ & $\begin{array}{c}1.226 \\
(42.62)\end{array}$ & $\begin{array}{c}33.40 \\
(38.12)\end{array}$ & $\begin{array}{c}26.32 \\
(35.51)\end{array}$ & $\begin{array}{c}15.76 \\
(33.38)\end{array}$ & $\begin{array}{c}21.40 \\
(31.86)\end{array}$ \\
\hline Trabalho & $\begin{array}{c}5.227 \\
(9.078)\end{array}$ & $\begin{array}{c}0.812 \\
(5.634)\end{array}$ & $\begin{array}{l}-2.456 \\
(4.415)\end{array}$ & $\begin{array}{c}0.839 \\
(3.722)\end{array}$ & $\begin{array}{c}0.854 \\
(3.240)\end{array}$ & $\begin{array}{c}1.294 \\
(2.998)\end{array}$ & $\begin{array}{c}1.440 \\
(2.682)\end{array}$ & $\begin{array}{c}3.019 \\
(2.499)\end{array}$ & $\begin{array}{c}2.535 \\
(2.350)\end{array}$ & $\begin{array}{c}2.515 \\
(2.243)\end{array}$ \\
\hline Educação & $\begin{array}{c}179.0 \\
(143.7)\end{array}$ & $\begin{array}{c}29.99 \\
(89.00)\end{array}$ & $\begin{array}{c}17.42 \\
(69.74)\end{array}$ & $\begin{array}{c}79.98 \\
(58.77)\end{array}$ & $\begin{array}{c}67.64 \\
(51.14)\end{array}$ & $\begin{array}{c}56.10 \\
(47.30)\end{array}$ & $\begin{array}{c}57.78 \\
(42.30)\end{array}$ & $\begin{array}{c}44.72 \\
(39.40)\end{array}$ & $\begin{array}{c}23.88 \\
(37.04)\end{array}$ & $\begin{array}{c}19.96 \\
(35.34)\end{array}$ \\
\hline Cultura & $\begin{array}{c}4.759 \\
(17.93)\end{array}$ & $\begin{array}{c}3.539 \\
(11.11)\end{array}$ & $\begin{array}{c}3.291 \\
(8.705)\end{array}$ & $\begin{array}{c}8.889 \\
(7.337)\end{array}$ & $\begin{array}{c}3.986 \\
(6.389)\end{array}$ & $\begin{array}{c}1.390 \\
(5.910)\end{array}$ & $\begin{array}{l}1.526 \\
(5.288)\end{array}$ & $\begin{array}{l}-0.269 \\
(4.927)\end{array}$ & $\begin{array}{l}-0.717 \\
(4.633)\end{array}$ & $\begin{array}{c}0.249 \\
(4.422)\end{array}$ \\
\hline Urbanismo & $\begin{array}{c}64.93 \\
(96.22)\end{array}$ & $\begin{array}{c}40.23 \\
(59.61)\end{array}$ & $\begin{array}{c}34.79 \\
(46.74)\end{array}$ & $\begin{array}{c}48.46 \\
(39.37)\end{array}$ & $\begin{array}{c}36.94 \\
(34.29)\end{array}$ & $\begin{array}{c}30.38 \\
(31.72)\end{array}$ & $\begin{array}{c}34.19 \\
(28.38)\end{array}$ & $\begin{array}{c}19.60 \\
(26.44)\end{array}$ & $\begin{array}{c}17.94 \\
(24.87)\end{array}$ & $\begin{array}{c}18.29 \\
(23.73)\end{array}$ \\
\hline Habitação & $\begin{array}{l}-11.50 \\
(18.75)\end{array}$ & $\begin{array}{l}-5.147 \\
(11.62)\end{array}$ & $\begin{array}{c}0.773 \\
(9.104)\end{array}$ & $\begin{array}{c}2.144 \\
(7.674)\end{array}$ & $\begin{array}{c}2.844 \\
(6.681)\end{array}$ & $\begin{array}{c}1.914 \\
(6.180)\end{array}$ & $\begin{array}{c}2.919 \\
(5.530)\end{array}$ & $\begin{array}{c}0.859 \\
(5.152)\end{array}$ & $\begin{array}{c}1.367 \\
(4.845)\end{array}$ & $\begin{array}{c}2.402 \\
(4.625)\end{array}$ \\
\hline Saneamento & $\begin{array}{c}55.42 \\
(39.79)\end{array}$ & $\begin{array}{c}11.23 \\
(24.66)\end{array}$ & $\begin{array}{c}10.51 \\
(19.35)\end{array}$ & $\begin{array}{c}21.45 \\
(16.31)\end{array}$ & $\begin{array}{c}18.49 \\
(14.20)\end{array}$ & $\begin{array}{l}21.74^{*} \\
(13.13)\end{array}$ & $\begin{array}{l}19.35^{*} \\
(11.75)\end{array}$ & $\begin{array}{c}16.01 \\
(10.95)\end{array}$ & $\begin{array}{c}8.103 \\
(10.29)\end{array}$ & $\begin{array}{c}7.034 \\
(9.827)\end{array}$ \\
\hline Gestão Ambiental & $\begin{array}{c}3.751 \\
(13.89)\end{array}$ & $\begin{array}{c}3.459 \\
(8.606)\end{array}$ & $\begin{array}{c}4.652 \\
(6.744)\end{array}$ & $\begin{array}{c}7.593 \\
(5.684)\end{array}$ & $\begin{array}{c}5.160 \\
(4.948)\end{array}$ & $\begin{array}{c}4.481 \\
(4.577)\end{array}$ & $\begin{array}{c}4.916 \\
(4.096)\end{array}$ & $\begin{array}{c}3.458 \\
(3.816)\end{array}$ & $\begin{array}{c}3.220 \\
(3.588)\end{array}$ & $\begin{array}{c}1.796 \\
(3.425)\end{array}$ \\
\hline Ciência e Tecnologia & $\begin{array}{c}-0 \\
(1.542)\end{array}$ & $\begin{array}{c}0.222 \\
(0.956)\end{array}$ & $\begin{array}{l}0.0898 \\
(0.750)\end{array}$ & $\begin{array}{c}0.283 \\
(0.632)\end{array}$ & $\begin{array}{c}0.227 \\
(0.551)\end{array}$ & $\begin{array}{c}0.189 \\
(0.509)\end{array}$ & $\begin{array}{c}0.202 \\
(0.456)\end{array}$ & $\begin{array}{c}0.211 \\
(0.425)\end{array}$ & $\begin{array}{c}0.270 \\
(0.399)\end{array}$ & $\begin{array}{c}0.239 \\
(0.381)\end{array}$ \\
\hline Agricultura & $\begin{array}{c}16.84 \\
(41.53)\end{array}$ & $\begin{array}{c}6.390 \\
(25.73)\end{array}$ & $\begin{array}{c}4.393 \\
(20.15)\end{array}$ & $\begin{array}{c}1.771 \\
(16.98)\end{array}$ & $\begin{array}{c}1.049 \\
(14.78)\end{array}$ & $\begin{array}{c}0.850 \\
(13.66)\end{array}$ & $\begin{array}{c}2.106 \\
(12.22)\end{array}$ & $\begin{array}{c}1.066 \\
(11.38)\end{array}$ & $\begin{array}{c}1.022 \\
(10.70)\end{array}$ & $\begin{array}{l}0.0808 \\
(10.21)\end{array}$ \\
\hline Comunicações & $\begin{array}{l}-4.621 \\
(3.595)\end{array}$ & $\begin{array}{c}0.388 \\
(2.229)\end{array}$ & $\begin{array}{c}-0.0242 \\
(1.746)\end{array}$ & $\begin{array}{c}-0.0228 \\
(1.472)\end{array}$ & $\begin{array}{c}0.232 \\
(1.282)\end{array}$ & $\begin{array}{c}0.211 \\
(1.185)\end{array}$ & $\begin{array}{c}0.138 \\
(1.061)\end{array}$ & $\begin{array}{l}0.0789 \\
(0.988)\end{array}$ & $\begin{array}{l}0.0963 \\
(0.929)\end{array}$ & $\begin{array}{c}0.115 \\
(0.887)\end{array}$ \\
\hline Energia & $\begin{array}{l}-14.00 \\
(19.42)\end{array}$ & $\begin{array}{l}-10.51 \\
(11.52)\end{array}$ & $\begin{array}{l}-6.947 \\
(9.145)\end{array}$ & $\begin{array}{l}13.21^{*} \\
(7.736)\end{array}$ & $\begin{array}{l}13.82^{* *} \\
(6.741)\end{array}$ & $\begin{array}{l}12.68^{* *} \\
(6.238)\end{array}$ & $\begin{array}{c}17.15^{* * *} \\
(5.596)\end{array}$ & $\begin{array}{c}18.58^{* * *} \\
(5.221)\end{array}$ & $\begin{array}{c}19.18^{* * *} \\
(4.912)\end{array}$ & $\begin{array}{c}19.93^{* * * *} \\
(4.698)\end{array}$ \\
\hline Transporte & $\begin{array}{c}47.12 \\
(89.69)\end{array}$ & $\begin{array}{c}14.73 \\
(55.57)\end{array}$ & $\begin{array}{c}10.43 \\
(43.52)\end{array}$ & $\begin{array}{c}12.43 \\
(36.67)\end{array}$ & $\begin{array}{c}13.19 \\
(31.90)\end{array}$ & $\begin{array}{c}19.58 \\
(29.50)\end{array}$ & $\begin{array}{c}21.24 \\
(26.39)\end{array}$ & $\begin{array}{c}15.78 \\
(24.57)\end{array}$ & $\begin{array}{c}10.67 \\
(23.10)\end{array}$ & $\begin{array}{c}3.095 \\
(22.04)\end{array}$ \\
\hline Desporto e Lazer & $\begin{array}{l}-3.844 \\
(18.18)\end{array}$ & $\begin{array}{l}-2.817 \\
(11.27)\end{array}$ & $\begin{array}{l}-0.194 \\
(8.828)\end{array}$ & $\begin{array}{c}5.375 \\
(7.438)\end{array}$ & $\begin{array}{c}4.022 \\
(6.477)\end{array}$ & $\begin{array}{c}5.280 \\
(5.990)\end{array}$ & $\begin{array}{c}5.805 \\
(5.361)\end{array}$ & $\begin{array}{c}3.031 \\
(4.995)\end{array}$ & $\begin{array}{c}1.562 \\
(4.696)\end{array}$ & $\begin{array}{c}1.275 \\
(4.483)\end{array}$ \\
\hline Encargos Especiais & $\begin{array}{c}-7.418 \\
(30.28)\end{array}$ & $\begin{array}{c}-9.629 \\
(18.76)\end{array}$ & $\begin{array}{l}-4.069 \\
(14.70)\end{array}$ & $\begin{array}{c}2.971 \\
(12.39)\end{array}$ & $\begin{array}{c}0.817 \\
(10.79)\end{array}$ & $\begin{array}{c}0.966 \\
(9.980)\end{array}$ & $\begin{array}{c}6.391 \\
(8.929)\end{array}$ & $\begin{array}{c}2.876 \\
(8.318)\end{array}$ & $\begin{array}{c}-0.442 \\
(7.822)\end{array}$ & $\begin{array}{r}-0.00922 \\
(7.466)\end{array}$ \\
\hline
\end{tabular}

*Erro-padrão entre parênteses 


\section{APÊNDICE D}

\section{METODOLOGIA LITSCHIG}

Fazemos as observações comparáveis em termos das distâncias aos respectivos limiares, reescalonando a população:

$$
\begin{aligned}
& X_{m s}=\text { pop }_{m s}-c_{1} \text { se } \quad s e g_{0}<\text { pop }_{m s}<s e g_{1} \\
& =\operatorname{pop}_{m s}-c_{2} \text { se } \operatorname{seg}_{1}<\text { pop }_{m s}<\operatorname{seg}_{2} \\
& =\operatorname{pop}_{m s}-c_{3} \text { se } \operatorname{seg}_{2}<\text { pop }_{m s}<\operatorname{seg}_{3}
\end{aligned}
$$

A especificação estimada então é

$$
\begin{aligned}
Y_{m s} & =\tau 1\left[X_{m s}>0\right] 1_{p}+\left[\alpha_{10} X_{m s}+\alpha_{11} X_{m s} 1\left[X_{m s}>0\right]\right] 1_{1 p}+ \\
& +\left[\alpha_{20} X_{m s}+\alpha_{21} X_{m s} 1\left[X_{m s}>0\right]\right] 1_{2 p}+ \\
& +\left[\alpha_{30} X_{m s}+\alpha_{31} X_{m s} 1\left[X_{m s}>0\right]\right] 1_{3 p}+ \\
& +\sum_{j=1}^{3} \beta_{j} 1\left[\operatorname{seg}_{j-1}<\operatorname{pop}_{m s} \leq \operatorname{seg}_{j}\right] 1_{j p}+\gamma z_{m s}+u_{m s}
\end{aligned}
$$

onde $Y_{m s}$ é a despesa per capita, $z_{m s}$ é o vetor de covariáveis e para um bandwidth $p$ temos: $1_{j p}=1\left[c_{j}(1-p)<p o p_{m s}<c_{j}(1+p)\right], \quad j=1,2,3 ; \quad p=$ $1 \%, 2 \%, 3 \%$, etc. e $1_{p}=1_{1 p}+1_{2 p}+1_{3 p}$. O efeito tratamento então é dado por $\tau$. 
CAPÍTULO 3

\section{EQUIDADE DE RENDA NA EDUCAÇÃO SUPERIOR PÚBLICA}


SUMÁRIO

3 Equidade de Renda na Educação Superior Pública 113 3.1 Introdução . . . . . . . . . . . . . . . . . . . . . 116

3.2 Literatura . . . . . . . . . . . . . . . . . . . . . . . . . . . . . . 119

3.3 Metodologia e Dados . . . . . . . . . . . . . . . . . . . 123

3.4 Resultados . . . . . . . . . . . . . . . . . . . . . . 137

3.5 Discussão . . . . . . . . . . . . . . . . . . . . . . . 143 
LISTA DE TABELAS

3.1 Gastos da União . . . . . . . . . . . . . . . . . . . . . . . . . 124

3.2 Contratos Formalizados . . . . . . . . . . . . . . . . 126

3.3 Bolsas e Renúncia $\ldots \ldots \ldots$. . . . . . . . . . . . . . . . . . 131

3.4 Custo Bolsa Mensal - 2006 . . . . . . . . . . . . . . . . . . 132

3.5 Gasto PNAES . . . . . . . . . . . . . . . . . . . . . . . . . . 134

3.6 Gasto no Ensino Superior Público - 2012 . . . . . . . . . . . . . 135

3.7 Carga tributária total sobre a renda familiar per capita . . . . 136

3.8 Decis de Renda $\ldots \ldots \ldots$. . . . . . . . . . . . . . . . . 137

3.9 Estudantes do Ensino Superior por Decil de Renda Familiar per capita . . . . . . . . . . . . . . . . . 138

3.10 Benefícios Orçamentário e Específico . . . . . . . . . . . . . 139

3.11 Renda e Carga Tributária . . . . . . . . . . . . . . . . . . . . 140

3.12 Contribuição . . . . . . . . . . . . . . . . . 141

3.13 Benefício Líquido . . . . . . . . . . . . . . . . . . 142

3.14 Benefício Líquido sem FIES e PROUNI . . . . . . . . . . . . . 143 


\subsection{Introdução}

Ao observarmos a recente expansão do ensino superior no Brasil, uma questão natural é como tal oferta tem evoluído em termos de equidade. As metas presentes no novo Plano Nacional de Educação para as taxas de escolarização, neste nível de ensino, são expressivas. Assim, torna-se também importante a discussão acerca da alocação do volume significativo dos novos recursos públicos a serem aplicados.

A recente expansão do ensino superior no Brasil implicou em uma taxa de crescimento anual média de matrículas de 5\% de 2009 a 2012. Com 45\% das novas matrículas, a rede pública apresentou um esforço bastante superior ao da rede privada. Isto porque esta possuía, em 2012, mais do que o dobro das matrículas realizadas pela rede pública. Com este esforço , a média de matrículas de 2009 a 2012 permaneceu em torno de 3\% da população. Em 2006, países como Coréia do Sul, Rússia e Estados Unidos apresentavam taxas próximas a 6\% enquanto Japão, Alemanha e México posicionavam-se próximos ao Brasil.

Considerando que a composição da população é fundamental para avaliar tal indicador e fazer comparações internacionais, faz-se necessário realizar esta análise também em relação à faixa etária em idade universitária. A educação superior no Brasil atendeu a 14,6\% da população de 18 a 24 anos (taxa de escolarização líquida), em 2011. Mesmo se considerarmos todas as matrículas em relação a população desta faixa etária, a taxa bruta de escolarização do ensino superior alcançou apenas 27,8\%. O Plano Nacional de Educação prevê que, em 10 anos, a taxa líquida chege a 33\% e a bruta a 50\%. Em 2006, a média dos países da OCDE era de 61,9\%. 
Segundo Santiago et al. (2008), equidade em educação possui duas dimensões. A primeira é a justiça, que implica em garantir que circunstâncias sociais e pessoais - por exemplo gênero, situação socioeconômica ou raça - não sejam obstáculos para o desenvolvimento do seu potencial educacional. A segunda é a inclusão, que implica em garantir um padrão mínimo de educação para todos, ou seja, que qualquer um seja capaz de ler, escrever e dominar a aritmética simples. As duas dimensões são fortemente relacionadas: o ataque às deficiências escolares colabora para a transposição das privações sociais que, por sua vez, também implicam no fracasso escolar.

Mais especificamente, sistemas de ensino superior com equidade são aqueles para os quais se assegura que o acesso, a participação e os resultados estejam baseados apenas na habilidade inata do indivíduo e no seu esforço como estudante. Ele garante que a aquisição de educação em nível superior não seja resultado de circunstâncias sociais e pessoais, incluindo fatores como situação socioeconômica, gênero, origem ética, status de imigrante, local de residência, idade ou doença.

Neste contexto é que surgem as recentes políticas de cotas na educação superior pública brasileira. A Lei $\mathrm{n}^{\mathrm{O}} 12.711 / 2012$ garante a reserva de 50\% das matrículas por curso e turno nas instituições públicas de nível superior a alunos oriundos integralmente do ensino médio público, em cursos regulares ou da educação de jovens e adultos. As vagas reservadas às cotas (50\% do total de vagas da instituição) serão subdivididas - metade para estudantes de escolas públicas com renda familiar bruta igual ou inferior a um salário mínimo e meio per capita e metade para estudantes de escolas públicas com renda familiar superior a um salário mínimo e meio. Em ambos os casos, também será levado em conta percentual mínimo correspondente ao da soma de pretos, pardos e indígenas no Estado, de acordo com o último censo demográfico do Instituto Brasileiro de 
Geografia e Estatística (IBGE). A aplicação destes percentuais ocorrerá de modo gradual.

O presente trabalho aborda uma das facetas da equidade: a renda. Como que a oferta de educação superior pública no Brasil está distribuída pelas diversas classes de renda. Assim como em outros países, a percepção usual é de que as universidades públicas brasileiras são bens públicos usufruídos principalmente pelas classes de maior rendimento e portanto os mais pobres estariam financiando os mais ricos. E no caso específico do Brasil, esta discussão se impõe com mais veemência dada a distância entre o gasto por aluno da educação básica e o da educação superior. Segundo o INEP, o gasto por aluno da educação superior era 4,8 vezes o gasto por aluno da educação básica, em 2011. Tal indicador mostra-se bastante superior ao observado internacionalmente. Os gastos em educação superior no Brasil também são significativos na comparação com outros tipos de despesa.

Na linha de Barbaro (2005), ao incluir os principais bens públicos relacionados à educação superior e os respectivos custos tributários, estimamos um benefício líquido por classe de renda. Este indicador nos permite avaliar quais classes de renda são mais beneficiadas.

A seguir a literatura relacionada é apresentada e com base nela discutimos, na sequência, a metodologia que constrói o benefício líquido e as proxies utilizadas no caso brasileiro. A dependência dos resultados do perfil da carga tributária brasileira, da distribuição dos estudantes é debatida também, nesta seção. Por fim, os resultados são evidenciados e, a partir deles, é possível avaliar o comportamento da transferência líquida entre as diversas classes de renda. 


\subsection{Literatura}

Friedman (2009) afirmou que a educação superior pública produz uma distribuição de renda perversa. A intuição relaciona-se com o processo de seleção e alocação dos estudantes, dado que os filhos de famílias com maior renda são selecionados com maior probabilidade relativamente àqueles de menor renda. No seu livro Free to Choose, Milton e Rose Friedman expressam sua opinião da seguinte forma:

We know of no government program that seems to us so inequitable in its effects, so clear an example of Director's Law, as the financing of higher education. In this area those of us who are in the middle-and upper-income classes have conned the poor into subsidizing us on the grand scale-yet we not only have no decent shame, we boast to tue treetops of our selflessness and public-spiritedness. Friedman and Friedman (1990)

O primeiro trabalho empírico sobre o impacto distributivo da educação superior pública foi realizado por Hansen and Weisbrod (1969). Neste artigo, eles mostram que as famílias mais pobres na Califórnia ganham menos subsídios da educação superior do que as famílias mais ricas, mesmo considerando o fato que eles contribuem menos em termos de tributos que mantêm universidades públicas.

Pechman (1970) foi o primeiro a se opor a esta tese. Ele argumentou que em nenhum ponto Hansen e Weisbrod comparou os benefícios e custos da educação superior pública em diferentes níveis, como eles sugerem. Sua comparação foi realizada entre benefícios e tributos pagos na média de famílias com e sem filhos matriculados no sistema da Califórnia. Além disso, demonstrou que os dados de Hansen e Weisbrod poderiam ser retrabalhados de modo que os 
resultados levariam a um resultado progressivo. A partir daí tal discussão ficou conhecida como Hansen-Weisbrod-Pechman debate.

Um procedimento similar, baseado nos mesmos dados, foi realizado por McGuire (1976). Ele argumentou que o chefe do grupo familiar utilizado na base de dados deveria ter de 36 a 60 anos para melhor comparação em termos de renda e que o auxílios financeiros ao estudante deveria ser considerado entre os benefícios. Com isso, ele concluiu que os estudantes de famílias com menor renda seriam mais beneficiados do que aqueles de maior renda.

Machlis (1973) para Nova Iorque, Fields (1975) para o Quênia, Crean (1975) para o Canadá, Merz (1982) para a Suícia, James (1987) para o Japão são exemplos de resultados empíricos mais antigos. Todos eles usam um cálculo de transferência líquida. Exceto Fields, Lemelin e Merz, todos os autores concluem por incidência proporcional. Fields apresenta os grupos de renda média como os principais beneficiados, Lemelin encontrou um impacto regressivo quando a educação dos pais é usada para definir a posição social das famílias.

Khan (1991) mostrou que a incidência tributária e os subsídios à educação superior existentes no Paquistão geram uma redistribuição das classes média e superior de renda para os grupos de baixa renda.

A hipótese de regressividade não é rejeitada por Lemelin (1992) no financiamento público da educação superior no Quebec no ano de 1984. Neste estudo, é constatado também que, naquele contexto, as famílias cujos chefes possuem maior escolaridade realizam mais ganhos.

As classes baixa e média são as mais favorecidas no sistema público de educação superior em Illinois em 1989, segundo Soo Lee et al. (1999). Comparam também as diferenças observadas entre universidades e faculdades comunitárias, destacando que, nestas, os principais beneficiários pertencem à classe de renda 
média. A transferência líquida é maior na classe alta e o ganho líquido é menor na classe baixa quando se compara as faculdades às universidades.

Gonzalez Rozada and Menendez (2002) estudou questões de eficiência e equidade na educação superior da Argentina. O público atendido pertence principalmente aos decis superiores da distribuição da renda e às famílias com maior grau de escolaridade. Cerca de 90\% dos estudantes das universidades públicas têm renda per capita superior à mediana recebida pelas famílias argentinas.

Utilizando a base de dados de desigualdade de renda obtidos nos Indicadores de Desenvolvimento do Banco Mundial, Bergh and Fink (2008) infere que gasto público em educação superior não tem nenhum efeito sobre número de matrículas e que crescimento destas é principalmente explicado por maiores níveis de PIB per capita. Não encontrou também relação robusta entre gasto em educação superior e baixa desgualdade de renda.

Caner and Okten (2013), utilizando um modelo de três estágios e dados da Turquia, estima o subsídio recebido por estudante das universidades públicas e conclui que este é positivamente relacionado com a renda e nível educacional da família. Obtém também que filhos de famílias com renda e educação superiores têm mais sucesso no exame de acesso à educação superior pública.

Os trabalhos empíricos, que, em sua maioria, são análises de corte transversal, mostram-se inconclusivos. Tais estudos, que representam uma foto do impacto distributivo em um ponto particular do tempo, são também criticados por ignorar a dimensão longitudinal da questão. Na abordagem longitudinal, a análise de benefícios e custos se estenderia por toda a vida dos indivíduos educados e não educados.

Grüske (1994) e Barbaro (2005), que aplicaram a metodologia do benefício 
líquido para a Alemanha, são as duas principais referências do nosso estudo. Em Grüske (1994), as famílias são classificadas através da renda familiar bruta anual. São considerados todos os benefícios recebidos pelos estudantes, tais como taxas, anuidades e outros. Os estudantes são associados à sua família de origem, que são classificadas em quatro grupos de renda (baixo, médio, elevado e alto). A contribuição para financiar o gasto público da educação superior e a respectiva parcela sobre os pagamentos recebidos são determinados para cada parcela. No fim, seria possível determinar para cada grupo de renda se ele é um beneficiário líquido ou um contribuinte líquido do financiamento público da educação superior. Gruske encontrou um efeito distributivo das famílias sem estudantes para aqueles com estudantes. Além disso, a distribuição entre as famílias com estudantes ocorre dos dois grupos de renda superior para os dois inferiores. Assim, aqueles benefícios que os dois grupos de renda superiores não recebem têm um impacto especial, por exemplo, benefícios como o Bafog. Gruske distingue entre incidência líquida relativa e absoluta, que descrevem a diferença entre benefícios recebidos e a carga tributária. Para as faixas de renda mais baixas, os benefícios recebidos excedem a carga mais que cinco vezes. Se os efeitos líquidos absolutos são aplicados à renda bruta, a incidência é mais balanceada.

Barbaro (2005) aprimora o trabalho de Grüske (1994) ao utilizar escalas de equivalência, ponderando assim as famílias de acordo com seu tamanho e ao determinar com maior precisão os benefícios tributários relacionados ao ensino. Os resultados apontaram para uma incidência claramente a favor dos decis de menor renda. Com isso, o presente estudo busca aplicar esta metodologia do benefício líquido para o caso brasileiro na linha destes últimos dois trabalhos. 


\subsection{Metodologia e Dados}

A metodologia usada nesse artigo consiste em calcular uma transferência líquida entre classes de renda. A idéia é classificar as famílias segundo sua renda e avaliar se cada grupo ganha mais ou menos benefícios do que paga em termos de tributos que mantêm o ensino superior público. O padrão de tais transferências líquidas depende da distribuição dos benefícios e da carga tributária. A distribuição dos benefícios, por sua vez, depende fundamentalmente da representação dos estudantes em cada classe. Para sua implementação utilizamos dados da Pesquisa Nacional por Amostra de Domicílios do ano de 2012 (PNAD), além de outras fontes que passamos a destacar.

\subsubsection{Benefícios}

\section{Despesa Federal}

A despesa empenhada pela União na subfunção Ensino Superior foi a base para definição dos benefícios ofertados em nível federal. Tais informações foram obtidas no Sistema Integrado de Administração Federal (SIAFI). Considerouse apenas as despesas relacionadas à graduação. Portanto foram excluídas despesas com os hospitais universitários e a concessão de bolsas, que são principalmente para a pós-graduação. As despesas com FIES e com o PNAES foram consideradas separadamente, como veremos a seguir. Assim, o volume total de recursos assinalados como despesa federal correspondeu, em valores de 2012, a R $\$ 21,3$ bilhões.

Conforme vemos na tabela 3.1, são principalmente gastos com pessoal (70\%). No gasto com o custeio ordinário e com os investimentos, duas ações orçamen- 
tárias correspondem a quase 90\% desses grupos de despesa: "Funcionamento das Universidades Federais"e "Reestruturação e Expansão das Universidades Federais (REUNI)".

Tabela 3.1: Gastos da União

\begin{tabular}{c|c|c}
\hline \hline Grupos de Despesa & R\$ bilhão & Part. $\%$ \\
\hline pessoal & 14,9 & 70 \\
\hline custeio & 3,9 & 18 \\
\hline investimento & 2,4 & 11 \\
\hline inversão & 0,03 & 0,1 \\
\hline total & $\mathbf{2 1 , 3}$ & $\mathbf{1 0 0}$ \\
\hline \hline Fonte: SIAFI
\end{tabular}

Considerando o total de 985.202 matrículas na rede federal, informado pelo Censo da Educação Superior de 2012, chegamos a um benefício médio anual, nesta rede, da ordem de $\mathrm{R} \$ 21.698,67$.

\section{Despesas Estadual e Municipal}

Segundo os dados divulgados pela Secretaria do Tesouro Nacional, as despesas dos estados e municípios em 2012 na subfunção "Ensino Superior"foram iguais a $\mathrm{R}$ \$ 7,5 bilhões e $\mathrm{R}$ \$ 0,8 bilhão, respectivamente. A indisponibilidade da desagregação destas despesas em ações orçamentárias de uma forma computacionalmente tratável nos fez considerar toda ela como benefícios ofertados pelos entes subnacionais.

Considerando o total de 560.505 matrículas na rede estadual e de 170.045 na rede municipal, informados pelo Censo da Educação Superior de 2012, chegamos a um beneficio médio nos estados de $\mathrm{R} \$ 13.428,57$ e de $\mathrm{R} \$ 4.749,57$, nos municípios. 
Desta forma, associaremos a cada família com aluno da rede pública de ensino superior um benefício $b g=17.317,19$, que corresponde à média ponderada dos valores por aluno na União, nos Estados e nos Municípios.

\section{FIES}

O Fundo de Financiamento Estudantil - FIES - é destinado à concessão de financiamento a estudantes regularmente matriculados em cursos superiores não gratuitos e com avaliação positiva no Ministério da Educação - MEC. Desde 1999, quando o FIES foi criado, o MEC vem promovendo alterações no programa, sendo a mais recente a promovida pela lei 12.202 de 2010. É uma das ações que tem como objetivo ampliar o acesso e a permanência de estudantes no ensino superior, contribuindo para o cumprimento da meta do Plano Nacional de Educação, citada anteriormente, relacionada às taxas de matrícula neste nível de ensino.

É um programa focalizado nas classes de menor renda, pois possui taxa bastante subsidiada (a taxa foi reduzida de $6,5 \%$ para 3,4\% ao ano) e percentual máximo de financiamento, inversamente proporcional à renda familiar, que é limitada em 20 salários mínimos. Por exemplo, para os estudantes cuja renda familiar mensal bruta é de até 10 salários mínimos, é possível financiar 100\% dos encargos, se estes forem superiores a $60 \%$ da renda familiar per capita. Os estudantes com renda familiar per capita de até 1,5 salário mínimo, por exemplo, contam com acesso direto a um fundo garantidor de crédito que os avalizam junto à instituição financeira. Segundo o MEC, 78\% dos estudantes com FIES têm renda de até 1,5 salário mínimo per capita.

O financiamento possui três fases: utilização, carência e amortização. A fase de utilização corresponde ao período do curso, quando ele paga trimestralmente, 
no máximo, $\mathrm{R}$ \$ 50,00 a título de juros. A carência é de 18 meses após a conclusão do curso para que ele recomponha seu orçamento. Neste período continua pagando apenas a trimestralidade de $\mathrm{R} \$ 50,00$. A quitação do financiamento, que se dá na fase de amortização, também foi alongada na nova legislação de 2010. Agora o estudante tem o prazo de três vezes o período financiado acrescido de 12 meses.

Existe ainda um benefício extra para professores e médicos que financiam seus cursos de graduação pelo FIES. Esses profissionais podem solicitar abatimento de $1 \%$ do saldo devedor por mês de efetivo exercício nas redes públicas de ensino e saúde, respectivamente. No caso dos docentes, o benefício vale para professores da educação básica pública com jornada de trabalho de, no mínimo, 20 horas semanais. Para os médicos, apenas aqueles que integrem equipes de saúde da família ou equipes que realizem atenção básica a quilombolas, indígenas, populações de assentamentos ou de regiões ribeirinhas em áreas definidas como prioritárias pelo Ministério da Saúde podem pedir o abatimento. Em ambos os casos, para solicitar o benefício é preciso comprovar o mínimo de um ano de trabalho ininterrupto.

Segundo dados do Relatório de Gestão do FIES/MEC de 2012, a demanda por financiamento (tabela 3.2) tem crescido significativamente:

Tabela 3.2: Contratos Formalizados

\begin{tabular}{c|c|c}
\hline \hline ano & $\mathbf{n}^{\mathbf{o}}$ de contratos & cresc. $\%$ \\
\hline 2009 & 32.669 & - \\
\hline 2010 & 75.932 & $132 \%$ \\
\hline 2011 & 153.570 & $102 \%$ \\
\hline 2012 & 368.841 & $140 \%$ \\
\hline \hline
\end{tabular}

Fonte: Relatório de Gestão FIES/MEC (2012)

Em 2012, um total de 623.241 estudantes foram financiados a um custo de $\mathrm{R} \$ 5,18$ 
bilhões de reais. Aqui são considerados os financiados em fase de utilização, ou seja, apenas os contratos daqueles que estão em sala de aula. Em uma análise de longo prazo, deveríamos considerar todos os contratos gerenciados, onde estariam inclusos também aqueles cujos estudantes já estariam formados, chegamos a um total de 918.137 financiamentos. Além disso, em uma análise de longo prazo, poderíamos considerar também o retorno que o fundo tem quando o estudante amortiza a sua dívida. Considerando o escopo do presente estudo, onde nos restringimos ao período de um ano, consideramos como benefício exatamente o valor que o FIES transfere para a Instituição de Ensino Superior durante o período de utilização, que corresponde exatamente ao valor da mensalidade do curso. Desta forma, consideramos como benefício por estudante a razão $\mathrm{R} \$ 5,18$ bilhões / 623.241 estudantes, que corresponde a uma anuidade de $\mathrm{R} \$ 8.312,86$ e a uma mensalidade de $\mathrm{R} \$ 692,74$. Denominaremos tal anuidade de benef - fies - rede - priv:

$$
\text { benef }- \text { fies }- \text { rede }- \text { priv }=8.312,86
$$

Considerando que, em 2012, havia 4.208.086 matrículas no ensino superior privado, como informa o Censo da Educação Superior, concluímos que 14,81\% destes possuíam FIES. Denominaremos tal percentual de parc - priv - comfies:

$$
\text { parc }- \text { priv }- \text { com }- \text { fies }=0.1481
$$

O MEC informa que $82 \%$ dos beneficiários do FIES possuem renda familiar até cinco salários mínimos. Denominaremos tal percentual de parc - fies - ate $5 s m$. 


$$
\text { parc }- \text { fies }- \text { ate }-5 s m=0,82
$$

Dados amostrais da PNAD indicam que 44,87\% dos alunos do ensino superior privado possuíam renda familiar mensal de até 5 salários mínimos. Denominaremos tal percentual de

$$
\text { parc }- \text { rede }- \text { priv }- \text { ate }-5 s m=0,4487
$$

Com essas informações atribuiremos a cada estudante do ensino superior privado, presente na PNAD, um benefício devido ao FIES. Como não temos a informação na PNAD se ele é beneficiário do FIES, dividiremos o gasto total do programa igualmente a todos os estudantes do ensino superior privado, fazendo apenas a distinção se a renda familiar é inferior ou superior a 5 salários-mínimos. O benefício portanto será calculado da seguinte forma: 


$$
\begin{aligned}
& \text { benef }- \text { ate }-5 \mathrm{sm}= \\
& =\frac{\text { gasto }- \text { ate }-5 s m}{n-e s t-\text { rede }- \text { priv }- \text { ate }-5 s m} \\
& =\frac{\text { gasto }- \text { ate }-5 s m}{\text { gasto }- \text { total }} \times \frac{\text { gasto }- \text { total }}{n-e s t-\text { fies }} \quad x \quad \frac{n-e s t-\text { fies }}{\text { est }- \text { rede }- \text { priv }- \text { ate }-5 \mathrm{sm}} \\
& =\text { parc }- \text { fies }- \text { ate }-5 s m \quad x \text { benef }- \text { fies }- \text { rede }- \text { priv } x \\
& x \frac{n-e s t-\text { fies }}{n-e s t-r e d e-\text { priv }} \quad x \quad \frac{n-e s t-\text { rede }- \text { priv }}{n-e s t-\text { rede }- \text { priv }- \text { ate }-5 s m}= \\
& =\text { parc }- \text { fies }- \text { ate }-5 s m \quad x \text { benef }- \text { fies }- \text { rede }- \text { priv } x \\
& x \quad \text { parc-priv-com-fies } \quad x \quad \frac{1}{\text { parc-rede-priv-ate }-5 \mathrm{sm}}
\end{aligned}
$$

benef-ate-5sm $=0,82 \quad x \quad 8.312,86 \quad x \quad 0,1481 \quad x \quad 2,22=2.249,90$

De modo similar, calculamos um benefício para os estudantes pertencentes às famílias com renda entre 5 e 20 salários mínimos e chegamos a um valor de $\mathrm{R} \$$ 453,90 . 


\section{PROUNI}

O Programa Universidade para Todos - Prouni é destinado à concessão de bolsas de estudos integrais ou parciais (50\%) para estudantes de cursos de graduação em instituições privadas de ensino superior com ou sem fins lucrativos. As instituições que aderem ao programa cumprindo uma proporção de bolsas prevista em lei fazem jus a isenção de tributos federais. O Prouni, por não implicar gastos diretos para o Tesouro, constitui-se em uma ação extraorçamentária.

O programa é dirigido aos estudantes egressos do ensino médio da rede pública ou da rede particular na condição de bolsistas integrais, com renda familiar per capita máxima de três salários mínimos. Os candidatos são selecionados pelas notas obtidas no Exame Nacional do Ensino Médio - Enem e já atendeu, desde sua criação até o processo seletivo do segundo semestre de 2013, mais de 1,2 milhão de estudantes, sendo $69 \%$ com bolsas integrais. Os beneficiários do Prouni que possuem bolsa parcial desde 2005, têm prioridade na concessão de financiamento do montante não coberto pelo Programa por meio do Fies. Esse benefício, que era de até $50 \%$ do valor da mensalidade não coberto pela bolsa, foi ampliado com a possibilidade de financiamento de até $100 \%$.

Segundo o Relatório de Gestão da Secretaria de Educação Superior do MEC SESU/MEC, em 2012, havia mais de 327 mil bolsas ativas e o valor de renúncia fiscal, naquele ano, foi superior a $\mathrm{R} \$ 680$ milhões (tabela 3.3). 
Tabela 3.3: Bolsas e Renúncia

\begin{tabular}{c|c|c}
\hline \hline ano & bolsas ativas & renúncia fiscal (R\$) \\
\hline 2010 & 275.577 & 578.115 .899 \\
\hline 2011 & 298.173 & 633.329 .017 \\
\hline 2012 & 327.033 & 680.430 .774 \\
\hline \hline
\end{tabular}

Fonte: Relatório de Gestão SESU/MEC (2012)

Considerando esses números, poderíamos inferir que o valor de renúncia médio por bolsa em 2012 seria de $\mathrm{R} \$ 2.080,62$. Isso corresponderia a uma mensalidade de $\mathrm{R} \$ 173,38$, que é um valor bastante distante do valor médio de mensalidades cobrado pela rede privada de ensino superior. Segundo dados da consultoria Hoper Educação, que estão no documento "Análise Setorial do Ensino Superior Privado", a mensalidade média em 2012 seria de R\$ 518,15.

O referido relatório de gestão da SESU/MEC, informa que:

... a renúncia fiscal decorrente do Prouni afeta somente as instituições com fins lucrativos, tendo em vista que as instituições sem fins lucrativos não beneficentes e beneficentes de assistência social possuem tratamento tributário próprio, razão pela qual a renúncia fiscal das entidades sem fins lucrativos não se aloca ao Programa.

Em 2009, em um relatório de auditoria operacional, o Tribunal de Contas da União - TCU apresentou exatamente a dificuldade de estimar tal indicador, dada as diferenças existentes no tratamento tributário das entidades com e sem fins lucrativos. Neste sentido, o TCU solicitou à Secretaria da Receita Federal - SRF que elaborasse uma estimativa mais apurada, considerando as especificidades de cada instituição. Com isso, a SRF informou que o custo médio mensal de cada bolsa Prouni, no ano de 2006, foi de $\mathrm{R} \$ 786,00$. 
Tabela 3.4: Custo Bolsa Mensal - 2006

\begin{tabular}{c|c}
\hline \hline Tipo de Instituição & Custo \\
\hline com fins lucrativos & 495,00 \\
\hline sem fins lucrativos não beneficentes & 916,00 \\
\hline sem fins lucrativos beneficentes & $1.043,00$ \\
\hline total & 786,00 \\
\hline \hline
\end{tabular}

Fonte: TCU

Segundo o relatório elaborado pela consultoria Hoper, o tíquete médio, razão entre o faturamento e o número de matrículas, das instituições privadas de ensino superior, era de $\mathrm{R} \$ 550$, em 2009, e R \$ 518,50, em 2012. Utilizando tal indicador para o valor de mercado das mensalidades, elaboramos uma proxy para o valor da renúncia fiscal do Prouni por bolsa.

Observamos que, em 2009, o valor da renúncia era $43 \%$ superior ao valor da mensalidade média. Aplicando este mesmo percentual ao valor da mensalidade média de 2012 ( $R$ \$ 518,5), chegamos a um valor de $R$ \$ 743, que em termos anuais correspondem a $\mathrm{R} \$ 8.916$

Novamente, como não temos a informação na PNAD se o estudante do ensino superior privado é beneficiário do PROUNI, dividiremos o gasto total do programa igualmente a todos focalizando nas famílias com renda per capita inferior a 1,5 salário mínimo. O benefício portanto será calculado da seguinte forma: 


$$
\begin{aligned}
& \text { benef }- \text { ate }-1,5 \mathrm{sm}= \\
& =\frac{\text { gasto }- \text { total }}{n-e s t-\text { rede }- \text { priv }- \text { ate }-1,5 \mathrm{sm}} \\
& =\frac{\text { gasto }- \text { total }}{n-\text { est }- \text { prouni }} \quad x \quad \frac{n-\text { est }- \text { prouni }}{n-e s t-\text { rede }- \text { priv }- \text { ate }-1,5 \mathrm{sm}} \\
& =\text { benef-prouni } \quad x \frac{n-e s t-\text { prouni }}{n-e s t-\text { rede }- \text { priv }} \quad x \frac{n-e s t-\text { rede }- \text { priv }}{n-e s t-\text { rede }- \text { priv }- \text { ate }-1,5 \mathrm{sm}}= \\
& =\text { benef-prouni } \quad x \quad \text { parc-priv-com-prouni } x \frac{1}{\text { parc-rede-priv-ate-1,5sm }} \\
& \text { benef }- \text { ate }-1,5 \mathrm{sm}=8.916 \quad x \quad 0,078 \quad x \quad 2,26=1.571,64
\end{aligned}
$$

\section{PNAES}

O Plano Nacional de Assistência Estudantil (PNAES) é um programa direcionado à permanência de estudantes de baixa renda matriculados em cursos de graduação presencial das instituições federais de ensino supeior. O PNAES atua na assistência à moradia estudantil, à alimentação, ao transporte, entre outras áreas. Os critérios de seleção dos estudantes levam em conta o perfil socioeconômico dos alunos, sendo que, por força do decreto 7.234 de 19 de Julho de 2010, devem ser atendidos prioritariamente estudantes oriundos da rede pública de educação básica ou com renda familiar per capita de até um salário mínimo e meio. 
Em 2012, 59 Universidades Federais receberam o montante de $\mathrm{R} \$ 503.843 .628,00$ cuja finalidade foi a de oferecer condições de permanência aos estudantes em vulnerabilidade socioeconômica, conforme vemos na tabela 3.5 .

Tabela 3.5: Gasto PNAES

\begin{tabular}{c|c}
\hline \hline ano & R\$ milhões \\
\hline 2008 & 101,19 \\
\hline 2009 & 197,03 \\
\hline 2010 & 305,65 \\
\hline 2011 & 395,18 \\
\hline 2012 & 503,84 \\
\hline \hline
\end{tabular}

Fonte: MEC

Assim como nos casos anteriores, considerando o total de matrículas da rede pública e a proporção de alunos com renda per capita inferior a 1,5 salários mínimos, estimamos um valor de $\mathrm{R} \$ 1.022,42$ como benefício por aluno nas universidades públicas.

\subsubsection{Contribuições}

Estimaremos a parcela que cada família arca para o custeio dos bens públicos relacionados à educação superior. Isto considerando a parcela que o gasto público relacionado ao ensino superior representa da carga tributária suportada pelas famílias.

\section{Orçamento do Ensino Superior}

Ao olhar para os orçamentos públicos, citados anteriormente, temos que as despesas relacionadas ao ensino superior público ultrapassam R $\$ 36$ bilhões (tabela 3.6): 
Tabela 3.6: Gasto no Ensino Superior Público - 2012

\begin{tabular}{c|c}
\hline \hline Gasto & R\$ milhões \\
\hline União & $21.377,58$ \\
\hline Estados & $7.526,78$ \\
\hline Municípios & 807,64 \\
\hline FIES & $5.180,92$ \\
\hline PROUNI & 680,43 \\
\hline PNAES & 536,56 \\
\hline Total & $36.109,91$ \\
\hline \hline Fonte: Elaboração do autor
\end{tabular}

Quando aplicamos as proxies definidas anteriormente como benefícios individuais aos estudantes presentes na PNAD, onde excluímos também observações com problemas nos dados de renda, chegamos a um total de $\mathrm{R} \$ 34,9$ bi.

\section{Carga Tributária}

Neste estudo, utilizamos a carga tributária estimada em Pintos-Payeras (2010) para auferir as transferências de cada indivíduo para o financiamento da educação superior. Nela, o autor verifica que o sistema tributário brasileiro é regressivo quando tomamos como base a renda. Isso se deve em grande parte aos impostos indiretos, mais especificamente ao Imposto sobre Circulação de Mercadorias e Serviços (ICMS), ao Programa de Integração Social (PIS) e à Contribuição para Financiamento da Seguridade Social (Cofins). Tal estudo dá um passo significativo pois apura as alíquotas de ICMS de cada estado, bem como os tratamentos diferenciados, tais como a redução da base de cálculo e a isenção dadas aos produtos constantes da Pesquisa de Orçamento Familiar (POF) de 2002-2003. Quando nenhum tratamento é dado às isenções e reduções na base de cálculo tende-se a superestimar a carga tributária indireta. No caso do ISS, devido a impossibilidade de levantar as alíquotas de todos os municípios do 
Brasil, foram escolhidas as capitais de cada unidade da federação. Na tabela 3.7 . a seguir, apresentamos os percentuais obtidos naquele estudo e sua incidência sobre a renda apurada na PNAD.

Tabela 3.7: Carga tributária total sobre a renda familiar per capita

\begin{tabular}{c|c|c|c}
\hline $\begin{array}{c}\text { Classes de Renda } \\
\text { per capita (s.m.) }\end{array}$ & $\begin{array}{c}\text { Alíquotas Carga } \\
\text { Tributária (\%) }\end{array}$ & $\begin{array}{c}\text { Renda Total } \\
\text { da Classe (R\$ bi) }\end{array}$ & $\begin{array}{c}\text { Carga Tributária } \\
\text { Total da Classe (R\$ bi) }\end{array}$ \\
\hline $0-0.5$ & 22,90 & 122 & 28,0 \\
\hline $0.5-1$ & 20,37 & 317 & 64,5 \\
\hline $1-1.5$ & 19,55 & 276 & 54,0 \\
\hline $1.5-2$ & 19,50 & 212 & 41,3 \\
\hline $2-2.5$ & 19,32 & 157 & 30,4 \\
\hline $2.5-3$ & 19,79 & 104 & 20,6 \\
\hline $3-4$ & 20,12 & 146 & 23,9 \\
\hline $4-5$ & 20,37 & 118 & 14,7 \\
\hline $5-6$ & 19,75 & 74,3 & 22,2 \\
\hline $6-8$ & 21,41 & 104 & 21,8 \\
\hline $8-11$ & 20,53 & 106 & 14,9 \\
\hline $11-16$ & 20,25 & 73,6 & 22,7 \\
\hline acima de 16 & 17,29 & 131 & 388,0 \\
\hline total & 19,79 & 1.940 & \\
\hline \hline
\end{tabular}

Fonte: alíquotas extraídas de Pintos-Payeras (2010) e Renda da PNAD 2012

Com isso, se considerarmos que toda a despesa pública com ensino superior seja financiada pelas famílias, temos que o seu orçamento corresponde a $9 \%$ de sua carga tributária.

\section{Contribuição por família}

Cada família $i$ será classificada segundo sua renda familiar per capita, $y_{i}$, em uma das 13 classes possíveis, digamos a classe $j$, e a sua contribuição para o 
financiamento da educação superior pública, $p_{i}$ será definida como:

$$
p_{i}=0,09 t_{j} y_{i} n_{i}
$$

onde $t_{j}$ é a carga tributária da classe $j, n_{i}$ é o tamanho da família $i$ e 0,09 corresponde a parcela do total de tributos pagos pela família destinada ao ensino superior público.

\subsection{Resultados}

Apresentamos agora as distribuições das principais variáveis que nos permitem avaliar como se dá transferência de benefícios entre as diversas classes renda, que é o nosso objetivo final. Antes, evidenciamos, na tabela 3.8, os valores de renda per capita familiar que caracterizam os limites de cada decil de renda, segundo PNAD 2012, para qualificar a análise.

Tabela 3.8: Decis de Renda

\begin{tabular}{c|c}
\hline \hline Decil & Renda per capita (R\$) \\
\hline 1 & 181 \\
\hline 2 & 287 \\
\hline 3 & 383 \\
\hline 4 & 500 \\
\hline 5 & 622 \\
\hline 6 & 725 \\
\hline 7 & 933 \\
\hline 8 & 1.248 \\
\hline 9 & 2.000 \\
\hline 10 & - \\
\hline \hline
\end{tabular}




\subsubsection{Distribuição dos Alunos}

De fato, observamos que cerca de $50 \%$ dos alunos das redes pública e privada estão nos últimos três decis de renda e que nos três primeiros não há sequer $10 \%$ deles (tabela 3.9). Isto confirma que realmente os alunos do ensino superior no Brasil são majoritariamente das classes média e alta.

Tabela 3.9: Estudantes do Ensino Superior por Decil de Renda Familiar per capita

\begin{tabular}{c|c|c|c|c|c|c|c}
\hline \hline Decis & $\begin{array}{c}\text { Estudantes } \\
\text { Rede Pública }\end{array}$ & Part. \% & $\begin{array}{c}\text { Estudantes } \\
\text { Rede Privada }\end{array}$ & Part. \% & Total & Part. \% & $\%$ acum. \\
\hline 1 & 55.828 & 3,8 & 91.704 & 2,0 & 147.532 & 2,5 & 2,5 \\
\hline 2 & 73.720 & 5,0 & 103.536 & 2,3 & 177.256 & 3,0 & 5,4 \\
\hline 3 & 84.030 & 5,7 & 174.579 & 3,9 & 258.609 & 4,3 & 9,7 \\
\hline 4 & 131.342 & 9,0 & 309.133 & 6,8 & 440.475 & 7,3 & 17,1 \\
\hline 5 & 152.928 & 10,4 & 363.543 & 8,0 & 516.471 & 8,6 & 25,7 \\
\hline 6 & 108.558 & 7,4 & 325.123 & 7,2 & 433.681 & 7,2 & 32,9 \\
\hline 7 & 187.672 & 12,8 & 641.969 & 14,2 & 829.641 & 13,8 & 46,8 \\
\hline 8 & 190.540 & 13,0 & 723.170 & 16,0 & 913.710 & 15,2 & 62,0 \\
\hline 9 & 255.087 & 17,4 & 983.335 & 21,7 & 1.238 .422 & 20,7 & 82,7 \\
\hline 10 & 226.477 & 15,4 & 813.824 & 18,0 & 1.040 .301 & 17,3 & 100,0 \\
\hline Total & 1.466 .182 & 100,0 & 4.529 .916 & 100,0 & 5.996 .099 & 100,0 & - \\
\hline \hline
\end{tabular}

Fonte: PNAD 2012

\subsubsection{Benefícios}

O benefício público geral obtido a partir dos orçamentos públicos federal, estadual e municipal tem distribuição idêntica àquela apresentada pelos estudantes da rede pública. Os dados da PNAD 2012 informam que 45\% dos alunos estão nos três últimos decis. Portanto, quase metade desse benefício público geral $(45 \%)$, que retrata principalmente as universidades públicas, está sendo usufruído pelos $30 \%$ mais ricos. 
Os benefícios considerados específicos, por serem programas focalizados em termos de renda, naturalmente concentram-se nas primeiras classes. Com isso, somando os benefícios gerais e específicos, encontramos 38\% deles concentrados nesta parcela da população com mais renda, conforme vemos nos decis 8,9 e 10 da tabela 3.10 .

Tabela 3.10: Benefícios Orçamentário e Específico

\begin{tabular}{c|c|c|c|c}
\hline \hline Decil & Orçamentário (R\$ bi) & Específico (R\$ bi) & Total (R\$ bi) & Part. $\%$ \\
\hline 1 & 0,96 & 0,40 & 1,37 & 3,9 \\
\hline 2 & 1,28 & 0,47 & 1,75 & 5,0 \\
\hline 3 & 1,46 & 0,75 & 2,21 & 6,3 \\
\hline 4 & 2,27 & 1,29 & 3,57 & 10,2 \\
\hline 5 & 2,65 & 1,48 & 4,13 & 11,8 \\
\hline 6 & 1,88 & 1,20 & 3,08 & 8,8 \\
\hline 7 & 3,25 & 2,15 & 5,40 & 15,5 \\
\hline 8 & 3,30 & 0,76 & 4,07 & 11,6 \\
\hline 9 & 4,42 & 0,73 & 5,15 & 14,7 \\
\hline 10 & 3,92 & 0,30 & 4,22 & 12,1 \\
\hline Total & 25,4 & 9,56 & 34,9 & 100,0 \\
\hline \hline
\end{tabular}

Fonte: Elaboração do autor

\subsubsection{Contribuição}

A estimativa feita para o pagamento de tributos que financiariam a educação superior pública no Brasil é decorrente de dois fatores: a distribuição da carga tributária e a distribuição da renda. Como a carga tributária sobre a renda estimada por Pintos-Payeras (2010) resulta em uma distribuição apenas ligeiramente regressiva, a distribuição do total de tributos pago por faixa de renda é muito próxima da distribuição da renda, conforme destacado na tabela 3.11. 
Tabela 3.11: Renda e Carga Tributária

\begin{tabular}{|c|c|c|c|c|}
\hline Decil & Renda Total (R\$ bi) & part. $(\%)$ & Carga Tributária (R\$ bi) & part. (\%) \\
\hline 1 & 30,2 & 1,6 & 6,9 & 1,8 \\
\hline 2 & 65,3 & 3,4 & 15,0 & 3,9 \\
\hline 3 & 82,0 & 4,2 & 17,4 & 4,5 \\
\hline 4 & 118,0 & 6,1 & 23,9 & 6,1 \\
\hline 5 & 144,0 & 7,4 & 29,3 & 7,5 \\
\hline 6 & 99,0 & 5,1 & 19,4 & 5,0 \\
\hline 7 & 177,0 & 9,1 & 34,6 & 8,9 \\
\hline 8 & 213,0 & 11,0 & 41,5 & 10,7 \\
\hline 9 & 314,0 & 16,2 & 61,6 & 15,9 \\
\hline 10 & 698 & 36,0 & 139,0 & 35,7 \\
\hline total & 1.940 & 100 & 388,0 & 100 \\
\hline
\end{tabular}

Por sua vez, como a contribuição é apenas uma fração constante da carga tributária que cada família suporta, observamos que a distribuição dos pagamentos relativos à educação superior seria idêntica à da carga tributária, que por sua vez é similar à da renda. Assim, a significativa desigualdade de renda que caracteriza o caso brasileiro reflete-se na distribuição dos pagamentos. Observamos que mais de $50 \%$ destes estariam nos dois últimos decis de renda, conforme vemos nos decis 9 e 10 da tabela 3.12 . 
Tabela 3.12: Contribuição

\begin{tabular}{c|c|c}
\hline \hline Decis & contribuição (R\$ bi) & part. $\%$ \\
\hline 1 & 0,62 & 1,8 \\
\hline 2 & 1,35 & 3,9 \\
\hline 3 & 1,56 & 4,5 \\
\hline 4 & 2,16 & 6,2 \\
\hline 5 & 2,63 & 7,5 \\
\hline 6 & 1,74 & 5,0 \\
\hline 7 & 3,12 & 8,9 \\
\hline 8 & 3,74 & 10,7 \\
\hline 9 & 5,55 & 15,9 \\
\hline 10 & 12,5 & 35,7 \\
\hline Total & 34,9 & 100,0 \\
\hline \hline
\end{tabular}

Fonte: Elaboração do autor

\subsubsection{Benefício Líquido}

O resultado obtido, destacado na tabela 3.13 , indica transferência dos dois últimos decis de renda para os oito primeiros. Destaque-se que mais de $95 \%$ desta transferência ( $\mathrm{R} \$ 8,2$ bi) é realizada pelo último decil, que corresponde às famílias que possuem renda familiar per capita superior a $R \$ 2.000,00$ (3 s.m.) , em valores de 2012. Os principais beneficiários são as famílias que estão do $4^{\circ}$ ao $7^{\circ}$ decil, com destaque para este último, com $R \$ 2,2$ bi de benefício líquido.

Isto nos leva a concluir que os $10 \%$ mais ricos financiam o ensino superior público de todos os $90 \%$ restantes. Esse resultado contraria, em certa medida, o senso comum de que os bens públicos relacionados à educação superior seriam financiados principalmente pelos mais pobres e usufruídos pelos mais ricos. De fato, quando avaliamos a distribuição dos alunos do ensino superior no Brasil, segundo a PNAD, observamos que os três últimos decis de renda 
Tabela 3.13: Benefício Líquido

\begin{tabular}{c|l|l|l|l}
\hline \hline Decis & $\begin{array}{l}\text { Benefício Total } \\
\text { (R\$ bi) }\end{array}$ & $\begin{array}{l}\text { Contribuição } \\
\text { (R\$ bi) }\end{array}$ & $\begin{array}{l}\text { Benefício } \\
\text { Líquido (R\$ bi) }\end{array}$ & $\begin{array}{l}\text { Ben. Liq. / Total das } \\
\text { Contribuiçóes(\%) }\end{array}$ \\
\hline 1 & 1,3 & 0,6 & 0,7 & 2,2 \\
\hline 2 & 1,7 & 1,3 & 0,4 & 1,1 \\
\hline 3 & 2,2 & 1,5 & 0,6 & 1,8 \\
\hline 4 & 3,5 & 2,1 & 1,4 & 4,0 \\
\hline 5 & 4,1 & 2,6 & 1,5 & 4,3 \\
\hline 6 & 3,0 & 1,7 & 1,3 & 3,8 \\
\hline 7 & 5,4 & 3,1 & 2,2 & 6,5 \\
\hline 8 & 4,0 & 3,7 & 0,3 & 0,9 \\
\hline 9 & 5,1 & 5,5 & $-0,4$ & $-1,1$ \\
\hline 10 & 4,2 & 12,5 & $-8,2$ & $-23,6$ \\
\hline Total & 34,9 & 34,9 & 0,00 & 0,0 \\
\hline \hline
\end{tabular}

Fonte: Elaboração do autor

concentram mais de $50 \%$ dos estudantes. Portanto a classe média alta e a classe alta são as que têm maior participação na universidade brasileira. Porém, ao considerarmos os resultados obtidos para o benefício líquido, concluímos que apesar de serem majoritários, os mais ricos contribuem de modo a financiarem não só os seus custos como também os custos das classes de menor renda.

Avaliamos também o papel dos programas focalizados, como FIES e PROUNI, nas classes de menor renda. Eles se concentram do $4^{\circ}$ ao $7^{\circ}$ decis e cumprem um papel importante de inclusão. Ressalte-se que, mesmo se os desconsiderarmos no total de benefícios, ainda observamos transferência líquida do último decil para o restante da população, conforme observamos na tabela 3.14 a seguir: 
Tabela 3.14: Benefício Líquido sem FIES e PROUNI

\begin{tabular}{c|l|l|l|l}
\hline \hline Decis & $\begin{array}{l}\text { Benefício Total } \\
\text { (R\$ bi) }\end{array}$ & $\begin{array}{l}\text { Contribuição } \\
\text { (R\$ bi) }\end{array}$ & $\begin{array}{l}\text { Benefício } \\
\text { Líquido (R\$ bi) }\end{array}$ & $\begin{array}{l}\text { Ben. Liq. I Total das } \\
\text { Contribuições(\%) }\end{array}$ \\
\hline 1 & 1,0 & 0,5 & 0,5 & 2,0 \\
\hline 2 & 1,3 & 1,0 & 0,3 & 1,2 \\
\hline 3 & 1,5 & 1,1 & 0,3 & 1,3 \\
\hline 4 & 2,3 & 1,6 & 0,7 & 2,8 \\
\hline 5 & 2,7 & 1,9 & 0,7 & 2,9 \\
\hline 6 & 1,9 & 1,3 & 0,6 & 2,4 \\
\hline 7 & 3,3 & 2,3 & 1,0 & 3,9 \\
\hline 8 & 3,3 & 2,7 & 0,6 & 2,3 \\
\hline 9 & 4,4 & 4,0 & 0,4 & 1,5 \\
\hline 10 & 3,9 & 9,1 & $-5,1$ & $-20,2$ \\
\hline Total & 25,4 & 25,4 & 0,00 & 0,0 \\
\hline \hline
\end{tabular}

Fonte: Elaboração do autor

\subsection{Discussão}

Com o objetivo de avaliar equidade de renda no acesso ao ensino superior no Brasil, aplicamos a metodologia de Barbaro (2005), que calcula uma transferência líquida de benefícios relacionados ao ensino superior entre as diversas classes de renda brasileiras.

O benefício público geral obtido a partir dos orçamentos públicos federal, estaduais e municipais tem distribuição idêntica àquela apresentada pelos estudantes da rede pública. Os dados da PNAD 2012 informam que 45\% dos alunos estão nos três últimos decis. Portanto, aproximadamente metade desse benefício público geral, que retrata principalmente as universidades públicas, está sendo usufruída pelos 30\% mais ricos.

Os benefícios considerados específicos, por serem programas focalizados em termos de renda, naturalmente concentram-se nas primeiras classes. Apenas 
$18 \%$ deste total estão nos últimos três decis de renda. Com isso, somando os benefícios gerais e específicos, encontramos 38\% deles concentrados nesta parcela da população com mais renda.

A carga tributária estimada por Pintos-Payeras (2010) e utilizada neste estudo é apenas ligeiramente regressiva. Quando aplicada à renda apurada na PNAD, gera uma distribuição do total de tributos muito similar à distribuição de renda brasileira, que é extremamente desigual. Mais de $63 \%$ da renda está concentrada nos 30\% mais ricos. Como a contribuição de cada família é apenas uma fração constante do total de tributos, sua distribuição segue a distribuição da renda brasileira.

A combinação de mais contribuições e menos benefícios, proporcionalmente, faz com que os últimos dois decis de renda financiem os bens públicos relacionados à educação superior dos oito primeiros. Dito de outra forma, observamos no caso brasileiro uma transferência líquida destes bens dos $20 \%$ mais ricos para o restante da população.

Destaque-se ainda que a população que poderíamos caracterizar como classe média brasileira seria a principal beneficiária líquida. A parcela que vai do $4^{\mathrm{O}}$ ao $7^{\circ}$ decil agrega $75 \%$ do total de benefícios líquidos. Com isso, do ponto de vista de equidade de renda, uma das questões que se coloca é como promover uma priorização da política nos primeiros três decis de renda. Lembremos que estes domicílios mais pobres (e geralmente com menor qualificação) não têm sequer $10 \%$ dos alunos do ensino superior.

Naturalmente, além de uma questão de equidade, a focalização nos três primeiros decis também representaria uma política importante de qualificação profissional e com diversas externalidades positivas para a sociedade brasileira. A recente política de cotas estabelecida para as instituições federais de ensino 
superior reserva 50\% das vagas para alunos do ensino médio público. Com o objetivo de focalizar a política, a legislação estabelece um corte de renda de um salário-mínimo e meio. Como este limite é bastante superior ao terceiro decil de renda (0,61 salário-mínimo), avaliamos que, apesar de colaborar, não será tão efetivo no sentido de ampliar a participação nos três primeiros decis de renda. Obviamente que a ausência de representantes dessas faixas de renda relacionam-se com diversos aspectos, entre eles, com o insucesso na educação básica.

A concentração dos benefícios líquidos do $4^{\circ}$ ao $7^{\circ}$ decil devem-se em grande parte aos benefícios como FIES e PROUNI. Considerando a atual disparidade entre os gastos com aluno da educação superior e da educação básica no Brasil, a crítica existente sobre a qualidade dos cursos ofertados pela rede privada de educação superior (praticamente financiada pelo FIES e PROUNI) e a baixa qualidade dos resultados obtidos pelos alunos da educação básica, coloca-se a questão de se não seria mais adequado alocar tais recursos na educação básica ou técnica dos três primeiros decis de renda. Nesta alternativa, tornaríamos a educação superior mais equitativa, propiciaríamos às famílias de classe mais baixas a possibilidade de seus filhos alcançarem a educação superior e, em tese (considerando, por exemplo, os aspectos levantados no capítulo 1), promoveríamos uma educação básica de mais qualidade.

Por fim, destaque-se que, do ponto de vista, do benefício líquido, não há justificativa para exigir mais pagamentos pelo ensino superior público das famílias que têm renda familiar per capita superior a $\mathrm{R} \$ 2.000,00$, pois implicaria em uma distribuição menos equitativa ainda. 


\section{REFERÊNCIAS BIBLIOGRÁFICAS}

Barbaro, S. (2005). Equity and efficiency considerations of public higher education, Volume 557. Springer.

Bergh, A. and G. Fink (2008). Higher education policy, enrollment, and income inequality*. Social Science Quarterly 89(1), 217-235.

Caner, A. and C. Okten (2013). Higher education in turkey: Subsidizing the rich or the poor? Economics of Education Review 35, 75-92.

Crean, J. F. (1975). The income redistributive effects of public spending on higher education. Journal of human resources, 116-123.

Fields, G. S. (1975). Higher education and income distribution in a less developed country. Oxford Economic Papers 27(2), 245-259.

Friedman, M. (2009). Capitalism and freedom. University of Chicago press.

Friedman, M. and R. Friedman (1990). Free to choose: A personal statement. Houghton Mifflin Harcourt.

Gonzalez Rozada, M. and A. Menendez (2002). Public university in argentina: subsidizing the rich? Economics of Education Review 21(4), 341-351.

Grüske, K.-D. (1994). Verteilungseffekte der öffentlichen hochschulfinanzierung in der bundesrepublik deutschland-personale inzidenz im querschnitt und längsschnitt. Bildung, Bildungsfinanzierung und Einkommensverteilung 2, 71-147. 
Hansen, W. L. and B. A. Weisbrod (1969). Benefits, costs, and finance of public higher education. Markham Publishing Company Chicago.

James, Estelle e Benjamin, G. (1987). Educational distribution and income redistribution through education in japan. Journal of Human Resources, 469489.

Khan, S. R. (1991). The income redistributional impact of financing higher education in pakistan. World Development 19(9), 1241-1246.

Lemelin, C. (1992). Short-term redistributive effects of public financing of university education in quebec. Canadian Public Policy/Analyse de Politiques, 176-188.

Machlis, P. D. (1973). The distributional effects of public higher education in new york city. Public Finance Review 1(2), 35-57.

McGuire, J. W. (1976). The distribution of subsidy to students in california public higher education. Journal of Human Resources 11(3).

Merz, D. (1982). Umverteilungswirkungen der schweizerischen Hochschulpolitik. Ph. D. thesis.

Pechman, J. A. (1970). The distributional effects of public higher education in california: A review article.

Pintos-Payeras, J. A. (2010). Análise da progressividade da carga tributária sobre a população brasileira. Pesquisa e Planejamento Econômico 40(2), 153-186.

Santiago, P., K. Tremblay, E. Basri, and E. Arnal (2008). Tertiary Education for the Knowledge Society. Technical report, Organisation fo Economic Co-operation and Development. 
Soo Lee, S., R. Ram, and C. W. Smith (1999). Distributive effect of state subsidy to undergraduate education: the case of illinois. Economics of Education Review 18(2), 213-221. 


\section{Conclusão}

Este trabalho apresenta algumas propostas no sentido do aprimoramento do gasto público no Brasil. Abordam-se questões clássicas de eficiência e equidade. Tais direcionamentos podem contribuir para contornar um quadro que conjuga restrições fiscais com uma oferta de serviços públicos cuja qualidade é sempre questionada.

No âmbito da educação básica e mais especificamente no ensino fundamental público municipal, o estudo confirma que apenas a aplicação de mais recursos não nos conduzirá à proficiência dos nossos alunos. Faz-se necessário conjugar aprimoramento da gestão (eficiência), principalmente nos municípios com melhores indicadores socioeconômicos, com priorização na alocação de novos recursos nos municípios mais eficientes, que em geral apresentaram menor custo por aluno. Devemos levar em consideração também variáveis como alunos por turma e carga horária diária, buscando um equilíbrio de forma a aumentar a qualidade via educação integral com redução de custos. Avaliamos que a continuidade da pesquisa passa pelo estudo mais focalizado dos municípios com piores indicadores socioeconômicos e melhores escores de eficiência. Tentar caracterizá-los, por exemplo, com outras variáveis para além do custo.

Ainda na esfera educacional, concluímos que os principais beneficiários da educação superior pública do Brasil pertencem ao grupo que vai do $4^{\circ}$ ao $7^{\circ}$ decil de renda. Este grupo contém a grande massa beneficiária do FIES e do PROUNI, que também consideramos como benefício público. Do ponto de vista da equidade de renda, concluímos pela necessidade de focalizarmos a politica um pouco mais nos três primeiros decis de renda e que, do ponto de vista do benefício líquido (benefício e custo), não há razão de se cobrar, por 
exemplo, mensalidades dos alunos que pertencem ao $9^{\circ}$ e $10^{\circ}$ decis de renda, dada a sua significativa contribuição tributária. Uma das discussões levantadas e que nos motiva em estudos posteriores é avaliar como o FIES e PROUNI estão contribuindo para uma formação de nível superior de qualidade e que contribua para a produtividade do país. Quais são os cursos principais, como tem-se avaliado as instituições que aderem ao programa, qual é o produto que estão entregando são algumas das questões que gostaríamos de investigar. Isto porque talvez fosse mais eficiente, por exemplo, utilizar esses recursos para o melhor qualificar a educação básica dos alunos pertencentes aos três primeiros decis de renda.

No contexto mais geral das finanças municipais, concluímos que há indícios que nos permitem inferir que, no Brasil, quanto maior for a câmara de vereadores do município maior é o gasto municipal per capita. Tal resultado reforça a necessidade de restringir a ampliação do número de vereadores no Brasil, inclusive pela via da criação de municípios. Desta forma, como indica a literatura, uma menor necessidade de subdivisão do processo elaboração do orçamento implicaria em um Estado menor do ponto de vista fiscal.

Portanto, avaliamos que, nos três âmbitos abordados neste trabalho, concluímos que há espaço para qualificar melhor o gasto público. A presente tese confirma a necessidade de se realizar estudos similares em outros setores (saúde, segurança e outros) que nos permitam apontar algumas políticas, ineficiências e desigualdades na oferta. No mesmo sentido, as implicações econômicas das instituições políticas apresentam também espectro amplo onde podemos apontar caminhos para sustentabilidade fiscal no Brasil. 